\title{
AVALIAÇÃO DE FILMES RADIOGRÁFICOS PERIAPICAIS EM DIFERENTES CONDIÇÕES DE PROCESSAMENTO PELOS MÉTODOS SENSITOMÉTRICO, DIGITAL E MORFOMÉTRICO.
}

Mariela Siqueira Gião Dezotti

Tese apresentada à Faculdade de Odontologia de Bauru da Universidade de São Paulo, como parte dos requisitos para obtenção do título de Doutor em Odontologia, na área de Estomatologia.

(Edição Revisada)

Bauru

2003 


\section{AVALIAÇÃO DE FILMES RADIOGRÁFICOS PERIAPICAIS EM DIFERENTES CONDIÇÕES DE PROCESSAMENTO PELOS MÉTODOS SENSITOMÉTRICO, DIGITAL E MORFOMÉTRICO.}

Mariela Siqueira Gião Dezotti

Tese apresentada à Faculdade de Odontologia de Bauru da Universidade de São Paulo, como parte dos requisitos para obtenção do título de Doutor em Odontologia, na área de Estomatologia.

Orientador: Professor Dr. Orivaldo Tavano

(Edição Revisada)

BAURU

2003 


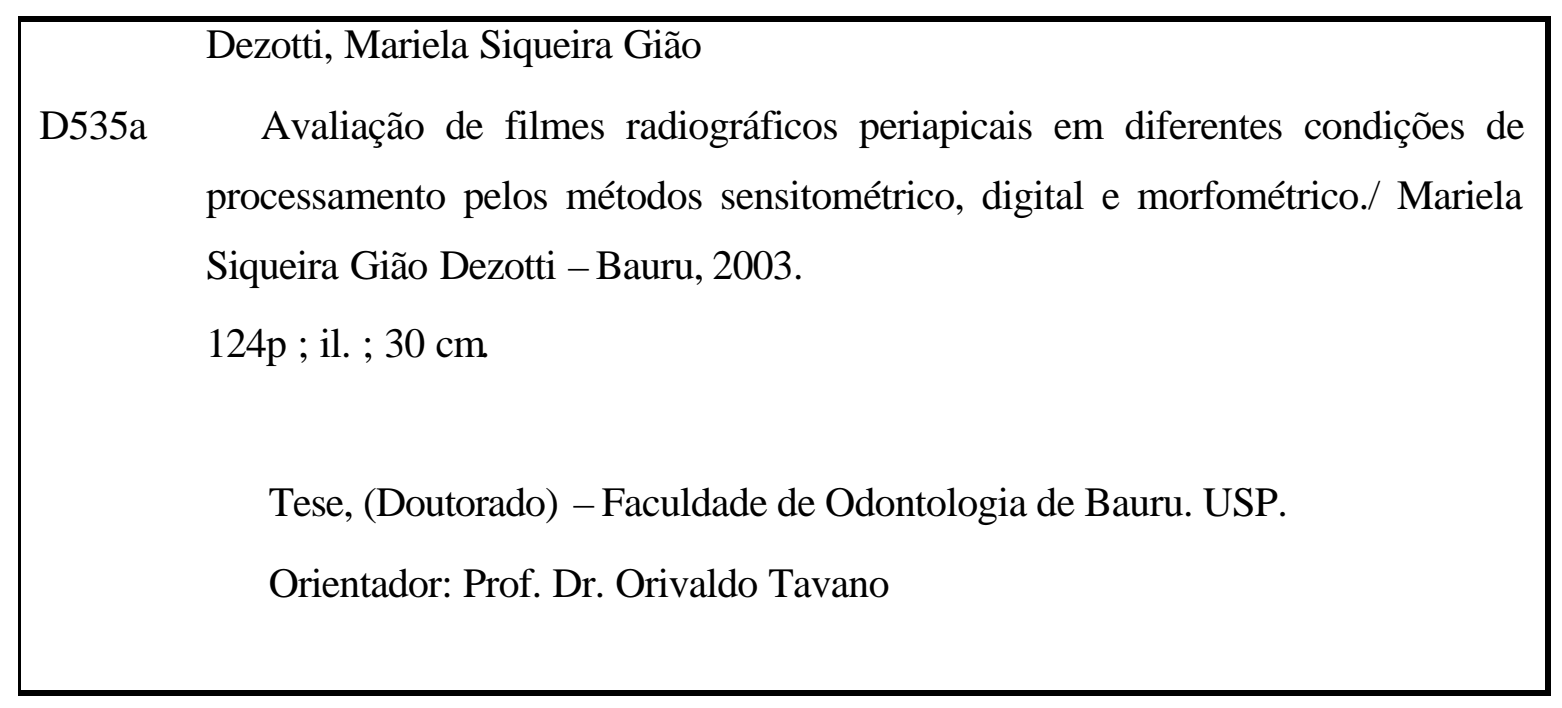

Autorizo, exclusivamente para fins acadêmicos e científicos, a reprodução total ou parcial desta dissertação/tese, por processos fotocopiadores elou meios eletrônicos.

Assinatura do autor:

Data: 


\section{DADOS CURRICULARES}

\section{MARIELA SIQUEIRA GIÃO DEZOTTI}

01 de outubro de 1971

Bauru - SP

1992- 1995

$1996-1997$

$1997-1998$

$1998-2000$
Nascimento

Curso de Odontologia -

Universidade do Sagrado Coração

- Bauru -SP.

Curso de Aperfeiçoamento em Endodontia - Hospital de Reabilitação de Anomalias Craniofaciais da USP.

Curso de Especialização em Endodontia - Hospital de Reabilitação de Anomalias Craniofaciais da USP.

Curso de Pós-Graduação em Diagnóstico Bucal em nível de Mestrado - Faculdade de Odontologia de Bauru - USP. 
$2000-2003$

Curso de Pós-Graduação em

Estomatologia em nível de

Doutorado - Faculdade de

Odontologia de Bauru - USP.

Associações

ABO - Associação Brasileira de

Odontologia.

ABRO - Associação Brasileira de Radiologia Odontológica.

APCD - Associação Paulista de Cirurgiões-Dentistas do Estado de São Paulo.

SOBE - Sociedade Brasileira de Estomatologia. 


\section{Dedico este trabalho,}

Aos meus pais Marco e Diléa, onde, com certeza, tudo começou. Sem o apoio dessas pessoas maravilhosas, que estão sempre ao meu lado, apoiando e compreendendo, eu não teria alcançado meus objetivos.

Aos meus irmãos João e Márcia, por serem as pessoas maravilhosas que são, pelo orgulho que vejo estampado em seus olhos. Obrigada por tanto apoio.

À Cátia, Thayana e Marco, companheiros de todas as horas. Obrigada pelo estímulo constante.

Aos tios queridos Jandyra e Lara (in memorian), pela admiração com que me tratam, pelo orgulho que, diariamente, vejo em suas palavras $e$ ações.

À Neida pela inestimável colaboração $e$ preocupação dispensadas em todos os momentos. 
À Elisa pelo carinho com que trata a mim e a minha família. Sem seu auxílio eu não teria vencido mais esta etapa da minha vida.

A toda a minha família, pelas maravilhosas pessoas que são, pelo agradável convívio, pela confiança e amor que acompanham todos os dias da minha vida.

Dedico este trabalho, especialmente ao Norberto e ao Cássio, pessoas maravilhosas, que Deus me deu o privilégio da convivência. Pessoas que me proporcionam uma vida alegre, cheia de aventuras, amor, paciência e muita compreensão. 
Ao Professor Dr. Orivaldo Tavano, agradeço sinceramente pela orientação e dedicação neste trabalho e em muitos outros desenvolvidos no decorrer deste Curso. Agradeço os grandes conhecimentos de Radiologia Odontológica transmitidos, com a certeza de que tem ainda muito a transmitir. Agradeço pela amizade e pelo aprendizado de vida que sempre me foi transmitido com confiança, preocupação $e$ dedicação. 


\section{AGRADECIMENTOS}

À Faculdade de Odontologia de Bauru da Universidade de São Paulo, na pessoa de sua Diretora, $D r^{a}$. Maria Fidela de Lima Navarro e do Coordenador da Pós - Graduação, Dr. José Carlos Pereira.

À Faculdade de Odontologia da Universidade do Sagrado Coração, onde tudo começou, pela excelente formação que tive $e$ por despertar em mim a vontade de seguir a carreira universitária.

Aos professores do Departamento de Estomatologia e Cirurgia da Faculdade de Odontologia de Bauru da Universidade de São Paulo, Dra ${ }^{a}$. Ana Lúcia Alvares Capelozza, Dr ${ }^{a}$. Izabel Regina Fisher Rubira de Bullen, Dr. José Humberto Damante, Dr. Luiz Eduardo Montenegro Chinellato, Dr. Eduardo Sant'Ana, Dr. Júlio Gurgel e Dr. Osny Ferreira Júnior, pela contribuição na minha formação profissional e incentivo constante.

Às amigas da Pós-Graduação, Flávia e Luciana, pessoas maravilhosas, com as quais pude contar durante este curso. 
Obrigada pela amizade e agradável convivência durante este período.

Aos colegas da Pós-Graduação (Mestrado), Cláudio, Fernando, Flávio, Josiane, Luís Fernando e Nicole, pela inestimável colaboração e pelos momentos agradáveis que passamos juntos.

Aos funcionários do Departamento de Estomatologia e Cirurgia da Faculdade de Odontologia de Bauru da Universidade de São Paulo, Camila, Cristina, Fernanda, José Messias, Josi e Walderez, pela competência nos serviços prestados e pela valiosa colaboração, sempre presentes.

Em especial às amigas Marilia Gião e Elizabeth Cariani, pessoas que nunca pouparam esforços no incentivo e auxílio em todas as etapas da minha vida.

Ao colega José Roberto pelo trabalho de confecção dos gráficos.

Ao amigo Eraldo pela paciência e cooperação em inúmeros trabalhos realizados durante o Curso de Pós-Graduação. 
À Tânia, profissional técnica do Departamento de Histologia da Faculdade de Odontologia de Bauru da Universidade de São Paulo, pela confecção das fotomicrografias.

Ao Prof. José Roberto Pereira Lauris, do Departamento de Odontologia Social da Faculdade de Odontologia de Bauru da Universidade de São Paulo, pela confecção da análise estatística deste trabalho.

À bibliotecária Valéria, da Biblioteca da Faculdade de Odontologia de Bauru da Universidade de São Paulo, pela revisão das Referências Bibliográficas.

Aos funcionários da Biblioteca da Faculdade de Odontologia de Bauru da Universidade de São Paulo que, em todos os momentos, auxiliaram na confecção de trabalhos científicos e levantamentos bibliográficos.

A todos os colegas, professores e funcionários da Faculdade de Odontologia de Bauru da Universidade de São Paulo que, de uma forma ou de outra, contribuíram para a confecção deste trabalho e para a minha formação profissional. 
À equipe de professores da Disciplina de Radiologia da Faculdade de Odontologia da Universidade do Sagrado Coração, $D r^{a}$. Flávia Noemy Gasparini Kiatake Fontão, $D r^{a}$. Izabel Maria Marchi de Carvalho, Dr. Luis Casati Alvares e Dr ${ }^{a}$. Márcia Ferreira Vasconcelos pela grande cooperação, compreensão e incentivo.

Em especial, aos professores $D r^{a}$. Ana Lúcia Alvares Capelozza, Dr ${ }^{a}$. Izabel Maria Marchi de Carvalho e Dr. Luis Casati Alvares, por despertarem em mim o interesse pela Radiologia Odontológica.

A todos os colegas, professores e funcionários da Faculdade de Odontologia da Universidade do Sagrado Coração pela amigável convivência.

À CAPES, meus agradecimentos pela oportunidade de poder freqüentar o Curso de Pós-Graduação. 


\section{SUMÁRIO}

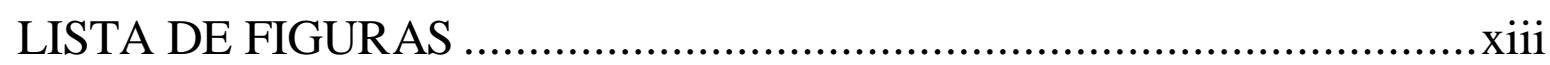

LISTA DE TABELAS................................................................ xvi

LISTA DE ABREVIATURAS E SÍMBOLOS ..................................... xix

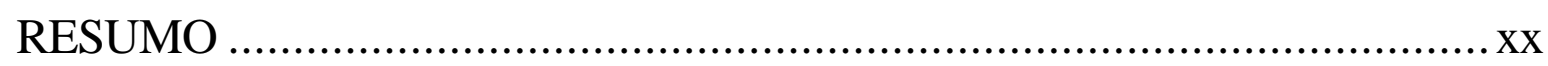

1. INTRODUÇÃ

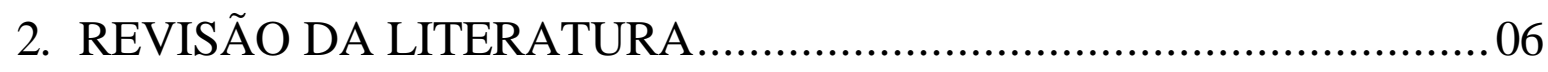

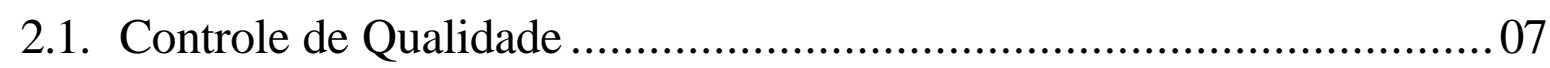

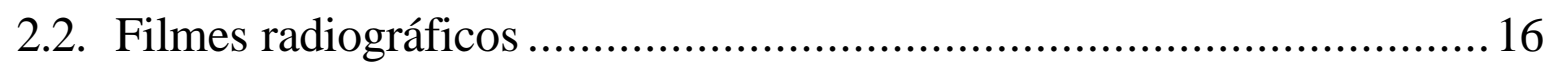

2.3. Soluções de processamento ...................................................... 25

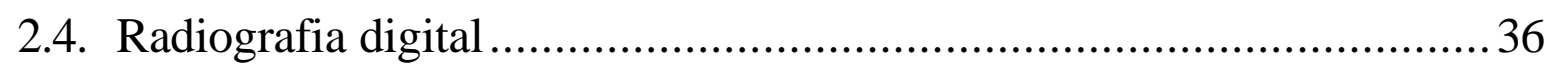

2.5. Análise morfométrica da prata................................................... 45

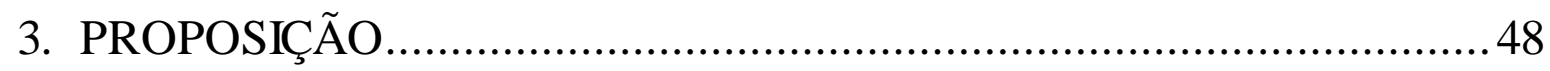

4. MATERIAL E MÉTODOS..........................................................50

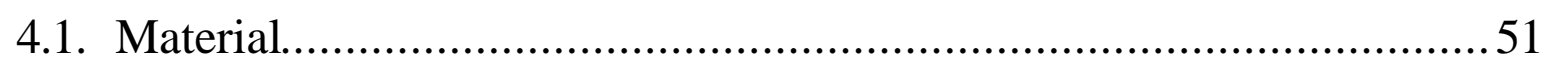

4.1.1. Filmes radiográficos, soluções processadoras e aparelho de raios X...51

4.1.2. Exposição aos raios $\mathrm{X}$ e processamento radiográfico........................52

4.1.3. Aparelho fotodensitômetro ....................................................53

4.1.4. Captura das imagens, microscopia e leituras computadorizadas .........54

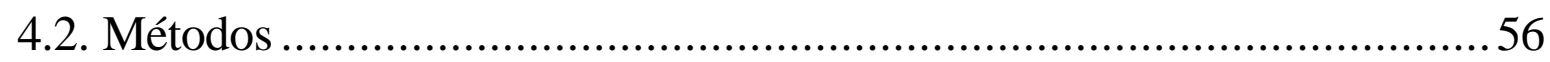

4.2.1. Exposição dos filmes aos raios $\mathrm{X}$, processamento radiográfico e leituras das Densidades Óticas.....................................................56

4.2.2. Construção das Curvas Características .............................................59

4.2.3. Digitalização e análise das imagens ..............................................60

4.2.4. Análise morfométrica da prata na emulsão dos filmes radiográficos...61

4.2.5. Análise estatística .....................................................................63

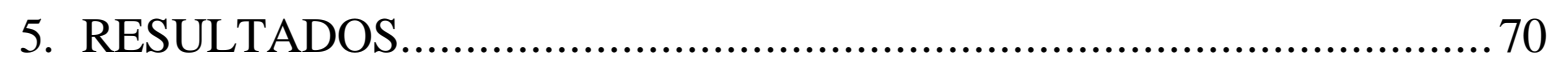




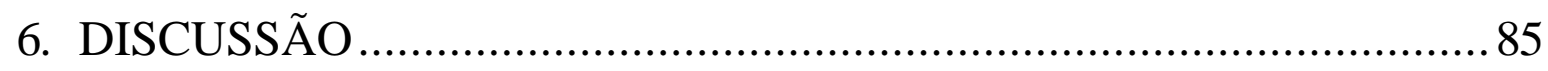

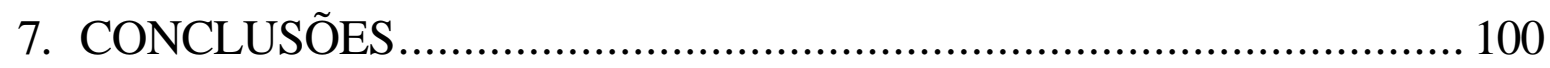

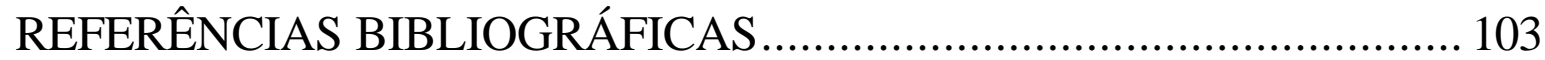

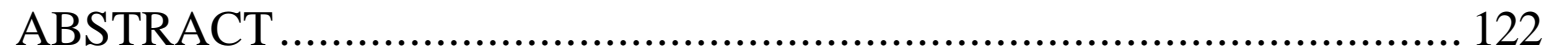

ANEXOS 


\section{LISTA DE FIGURAS}

FIGURA 1 - Caixas de filmes radiográficos intrabucais Ultra-speed DF-

58 e Insight IP-21 64

FIGURA 2 - Soluções para o processamento radiográfico manual marcas Kodak e Sillib

FIGURA 3 - Dispositivo de chumbo acoplado ao aparelho de raios $\mathrm{X}$ para manter fixa a distância foco-filme em $50 \mathrm{~cm}$. No detalhe observa-se como as radiografias foram fixadas na lâmina de chumbo, de maneira que apenas $1 / 5$ do filme fosse exposto de cada vez

FIGURA 4 - Aparelho fotodensitômetro MRA com uma radiografia em posição para realização da leitura da Densidade Ótica

FIGURA 5 - Radiografias obtidas com os filmes Ultra-speed (A) e Insight (B) após a exposição e processamento com as soluções Kodak e Sillib nas temperaturas de $20^{\circ} \mathrm{C}, 25^{\circ} \mathrm{C}$ e $30^{\circ} \mathrm{C}$ e respectivas exposições 66

FIGURA 6 - Demonstração da tela do monitor com uma radiografia no Programa Adobe Photoshop 5.5, que mostra a média da quantificação dos níveis de cinza da área, a mediana e o desvio padrão 67

FIGURA 7 - Fotomicrografias (100X) dos cristais de prata da emulsão dos filmes radiográficos Ultra-speed e Insight, processados 
nas soluções Kodak e Sillib, nas temperaturas de $20^{\circ}, 25^{\circ}$ e $30^{\circ} \mathrm{C}$, na faixa de 1 impulso de exposição, observadas no Programa Adobe Photoshop 5.5 ......................................... 68

FIGURA 8 - Demonstração da tela do monitor com imagens da microscopia dos cristais de prata na emulsão dos filmes radiográficos no programa Adobe Photoshop 5.5, mostrando como foi realizada a Densidade de Volume de prata. A) Obtendo a imagem no programa Adobe Photoshop, B) Aplicando o filtro Treshold, C) Quantificando a porcentagem de prata na emulsão do filme radiográfico.

FIGURA 9 - Curvas Características do filme Ultra-speed processado na solução Kodak a $20^{\circ} \mathrm{C} / 5 \mathrm{~min}$. (A), $25^{\circ} \mathrm{C} / 2,5 \mathrm{~min}$. (B), $30^{\circ} \mathrm{C} / 1,25 \mathrm{~min}$. (C) e superposição das três combinações (D) 74

FIGURA 10 - Curvas Características do filme Ultra-speed processado na solução Sillib a $20^{\circ} \mathrm{C} / 2 \mathrm{~min}$. (A), $25^{\circ} \mathrm{C} / 1 \mathrm{~min}$. (B), $30^{\circ} \mathrm{C} / 0,5 \mathrm{~min}$. (C) e superposição das três combinações (D) ... 75

FIGURA 11 - Curvas Características do filme Insight processado na solução Kodak $20^{\circ} \mathrm{C} / 5 \mathrm{~min}$. (A), $25^{\circ} \mathrm{C} / 2,5 \mathrm{~min}$. (B), $30^{\circ} \mathrm{C} / 1,25 \mathrm{~min}$. (C) e superposição das três combinações (D) 76

FIGURA 12 - Curvas Características do filme Insight processado na solução Sillib a $20^{\circ} \mathrm{C} / 2 \mathrm{~min}$. (A), $25^{\circ} \mathrm{C} / 1 \mathrm{~min}$. (B), $30^{\circ} \mathrm{C} / 0,5 \mathrm{~min}$. (C) e superposição das três combinações (D) ... 77 
FIGURA 13 - Fotomicroscopia (100X) da emulsão do filme radiográfico Ultra-speed processado nas soluções Kodak (K) a $20^{\circ}, 25^{\circ}$ e $30^{\circ} \mathrm{C}$ e Sillib (S) a $20^{\circ}, 25^{\circ}$ e $30^{\circ} \mathrm{C}$ e respectivas médias das porcentagens de prata depositada................................... 82

FIGURA 14 - Fotomicroscopia (100X) da emulsão do filme radiográfico Insight processado nas soluções Kodak $(\mathrm{K})$ a $20^{\circ}, 25^{\circ}$ e $30^{\circ} \mathrm{C}$ e Sillib (S) a $20^{\circ}, 25^{\circ}$ e $30^{\circ} \mathrm{C}$ e respectivas médias das porcentagens de prata depositada......................................... 83 


\section{LISTA DE TABELAS}

TABELA 1 - Média das Densidades Óticas das quatro radiografias (Ultra-speed), nas cinco faixas de exposição, processadas a $20^{\circ}, 25^{\circ}$ e $30^{\circ} \mathrm{C}$ na solução Kodak

TABELA 2 - Média das Densidades Óticas das quatro radiografias (Ultra-speed), nas cinco faixas de exposição, processadas a $20^{\circ}, 25^{\circ}$ e $30^{\circ} \mathrm{C}$ na solução Sillib

TABELA 3 - Média das Densidades Óticas das quatro radiografias (Insight), nas cinco faixas de exposição, processadas a $20^{\circ}$, $25^{\circ}$ e $30^{\circ} \mathrm{C}$ na solução Kodak

TABELA 4 - Média das Densidades Óticas das quatro radiografias (Insight), nas cinco faixas de exposição, processadas a $20^{\circ}$, $25^{\circ}$ e $30^{\circ} \mathrm{C}$ na solução Sillib

TABELA 5 - Comparativo das Densidades Máximas, propriedades sensitométricas (sensibilidade em mAs e $\mathrm{R}^{*}$ e contraste) e densidade base e velamento (DBV) dos filmes Ultra-speed e Insight, processados nas soluções Kodak e Sillib nas temperaturas de $20^{\circ}, 25^{\circ}$ e $30^{\circ} \mathrm{C}$

TABELA 6 - Média da quantificação dos níveis de cinza, em cada uma das cinco faixas de exposição, realizada no programa Adobe Photoshop 5.5, em filmes radiográficos Ultraspeed, processados na solução Kodak, nas temperaturas de $20^{\circ}, 25^{\circ}$ e $30^{\circ} \mathrm{C}$ 
TABELA 7 - Média da quantificação dos níveis de cinza, em cada uma das cinco faixas de exposição, realizada no programa Adobe Photoshop 5.5, em filmes radiográficos Ultraspeed, processados na solução Sillib, nas temperaturas de $20^{\circ}, 25^{\circ}$ e $30^{\circ} \mathrm{C}$

TABELA 8 - Média da quantificação dos níveis de cinza, em cada uma das cinco faixas de exposição, realizada no programa Adobe Photoshop 5.5, em filmes radiográficos Insight, processados na solução Kodak, nas temperaturas de $20^{\circ}$, $25^{\circ}$ e $30^{\circ} \mathrm{C}$ 79

TABELA 9 - Média da quantificação dos níveis de cinza, em cada uma das cinco faixas de exposição, realizada no programa Adobe Photoshop 5.5, em filmes radiográficos Insight, processados na solução Sillib, nas temperaturas de $20^{\circ}, 25^{\circ}$ e $30^{\circ} \mathrm{C}$

TABELA 10 - Comparativo entre Densidade Ótica (D.O.) e quantific ação dos níveis de cinza (N.C.), da média das quatro radiografias processadas em todas as combinações utilizadas, nas cinco faixas de exposição, com os filmes Ultra-speed e Insight 80

TABELA 11 - Coeficiente de Correlação de Pearson entre Densidade Ótica (D.O.) e quantificação dos níveis de cinza (N.C.) para todos os grupos conjuntamente e para as combinações Ultra-speed/Kodak, Ultra-speed/Sillib, Insight/Kodak, Insight/Sillib, em todas as temperaturas, separadamente, com nível de confiança de $95 \%$ 
TABELA 12 - Comparativo entre os valores de Densidade Ótica (D.O.), quantificação dos níveis de cinza (N.C.) e Densidade de Volume de prata (D.V.), na faixa de 1 impulso de exposição em uma radiografia de cada combinação................ 8

TABELA 13 - Coeficiente de Correlação de Pearson entre Densidade Ótica (D.O.) e Densidade de Volume de prata (D.V.) e quantificação dos níveis de cinza (N.C.) e Densidade de Volume de prata em todos os grupos conjuntamente, com nível de confiança de $95 \%$ 84 


\section{LISTA DE ABREVIATURAS E SÍMBOLOS}

CCD - Charge Coupled Device (Dispositivo Acoplado de Carga)

$\mathrm{CD}$ - compact disc

$\mathrm{cm}$ - centímetros

DBV - Densidade base e velamento

D.O. - Densidade Ótica

D.V. - Densidade de Volume de prata

GB - gigabytes (capacidade de armazenamento)

${ }^{\circ} \mathrm{C}$ - graus Celsius

$\mathrm{HD}$ - disco rígido

$\mathrm{kVp}$ - quilovoltagem pico

$\mathrm{mA}$ - miliamperagem

mAs - miliamperagem segundo

MB - megabytes (capacidade de armazenamento)

min. - minutos

$\mathrm{mm}$ - milímetro

N.C. - quantificação dos níveis de cinza

Pixel - picture element (elemento de figura)

RAM - Memória de acesso aleatório

$\mathrm{R} 1$ - radiografia 1

$\mathrm{R} 2$ - radiografia 2

$\mathrm{R} 3$ - radiografia 3

$\mathrm{R} 4$ - radiografia 4

$\mathrm{R}^{*}$ - Röntgen recíproco

r - correlação 
RESUMO 


\section{RESUMO}

Analisar o comportamento dos filmes radiográficos e a atividade das soluções de processamento é uma das etapas do Controle de Qualidade que deveria ser implementado em todas as Clínicas de Radiologia Odontológica. A moderna Radiologia Odontológica evolui continuamente no que diz respeito à fabricação de materiais e na atualização das técnicas que reduzam cada vez mais as doses de radiação emitidas ao paciente. Um exemplo concreto é a ampla aceitação dos sistemas de aquisição de imagens digitais e o lançamento de filmes radiográficos cada vez mais sensíveis. O objetivo do presente trabalho foi analisar as propriedades sensitométricas do novo filme lançado no mercado pela Kodak, o Insight (IP-21), processado em diferentes combinações de solução/temperatura/tempo e compará-las com as do filme Ultra-speed (DF-58). Utilizaram-se para esta comparação três diferentes métodos de análise do comportamento dos filmes e das soluções de processamento, com o objetivo de correlacioná-los. Foram utilizados os métodos: o convencional, quando obtemos as Densidades Óticas em um fotodensitômetro; o digital, que avalia, por meio de um programa de imagem, a quantificação dos níveis de cinza da imagem e o morfométrico, que avalia a forma, o tamanho e a porcentagem de cristais de prata depositados na emulsão do filme radiográfico após o seu processamento. Os filmes periapicais em estudo foram expostos padronizadamente e processados nas soluções Kodak a $20^{\circ} \mathrm{C}$ por 5 minutos, a $25^{\circ} \mathrm{C}$, por 2,5 minutos e a $30^{\circ} \mathrm{C} 1,25$ minuto e Sillib a $20^{\circ} \mathrm{C}$ por 2 minutos, a $25^{\circ} \mathrm{C}$ por 1 minuto e a $30^{\circ} \mathrm{C}$ por 0,5 minuto. Para a leitura da Densidade Ótica utilizouse um fotodensitômetro MRA. Para a quantificação dos níveis de cinza e morfometria dos cristais de prata utilizou-se o programa Adobe Photoshop 
5.5. Os resultados mostraram que o filme Insight apresentou sensibilidade do grupo $\mathrm{F}$ em todas as combinações analisadas, mesmo no processamento manual, sendo mais sensível na solução Kodak a $30^{\circ} \mathrm{C}$ e menos sensível na solução Sillib a $20^{\circ} \mathrm{C}$. O filme Ultra-speed apresentou sensibilidade dentro do grupo D, sendo mais sensível na solução Kodak a $30^{\circ} \mathrm{C}$ e menos sensível na solução Sillib a $20^{\circ} \mathrm{C}$. Assim como para o filme Insight, a solução Kodak ofereceu ao Ultra-speed maiores valores de sensibilidades do que a solução Sillib. O contraste radiográfico permaneceu dentro de uma faixa de variação aceitável para este fator, variando de 1,55 (Insight/Sillib a $\left.30^{\circ} \mathrm{C}\right)$ a 1,78 (Ultra-speed/Kodak a $30^{\circ} \mathrm{C}$ ). A análise estatística mostrou alta correlação entre os valores de Densidade Ótica e quantificação dos níveis de cinza nas cinco faixas de exposição em todas as radiografias testadas para cada combinação. Houve alta correlação estatística entre os valores de Densidade Ótica, quantificação dos níveis de cinza e Densidade de Volume de prata, na faixa de 1 impulso de exposição de uma radiografia de cada combinação analisada. Concluiu-se que o filme Insight é bastante promissor, pois mantém as propriedades sensitométricas adequadas para uso clínico na Odontologia. Os três métodos de análise de filmes radiográficos e atividade de soluções de processamento mostraram alta correlação estatística, provando que todos podem ser utilizados no Controle de Qualidade em Radiologia Odontológica. 
1. INTRODUÇÃO 


\section{INTRODUÇÃO}

O uso de radiografias como ferramenta para auxiliar no diagnóstico tornou-se uma rotina indispensável na Medicina e na Odontologia. A presença e extensão de muitas das condições patológicas ou anomalias somente podem ser avaliadas por meio deste exame. Em numerosas situações o uso de radiografias é também essencial durante a proservação do progresso do tratamento ${ }^{115}$.

A Radiologia é uma área da Odontologia que está sob constantes mudanças. Muito se estuda sobre seus efeitos, sobre os materiais utilizados para sua obtenção e, com ênfase, os meios para redução cada vez maior das doses de radiação emitidas durante um exame, pois, como é sabido, as radiações $\mathrm{X}$ podem produzir efeitos biológicos deletérios ao organismo. Fabricantes de materiais e pesquisadores buscam, incessantemente, métodos e materiais que minimizem cada vez mais a dose de radiação que o paciente recebe durante os exames radiográficos ${ }^{42,59,67}$. Uma prova disso é o lançamento de filmes cada vez mais sensíveis que, dependendo do método de processamento, necessitam de uma quantidade cada vez menor de exposição para produzir uma imagem radiográfica adequada para diagnóstico. A utilização de soluções de processamento enérgicas, o aumento da temperatura destas soluções e o uso de máquinas de processamento automáticas são outros recursos de grande importância dentro da Radiologia Odontológica, revolucionando esta ciência, reduzindo cada vez mais o tempo para obtenção de uma radiografia sem perda da qualidade.

Uma radiografia de qualidade deverá apresentar informações sutis, com ótimo detalhe, mínima distorção, densidade e contraste médios. Muitos fatores interferem na formação da imagem radiográfica e devem ser 
estudados e controlados de maneira a buscar, constantemente, uma rígida padronização. Estes fatores incluem: o equipamento de raios $\mathrm{X}$, o tipo de filme e a quantidade de radiação que ele requer, as soluções e os métodos de processamento ${ }^{58,60}$.

O filme radiográfico é o maior responsável pela redução da dose de radiação que o paciente recebe durante uma tomada radiográfica. Utilizando filmes mais sensíveis, o profissional conseqüentemente reduzirá o tempo de exposição e a quantidade de radiação produzida pelo aparelho, diminuindo, na mesma proporção, os efeitos biológicos nocivos ao paciente ou a si mesmo ${ }^{4,5,40}$.

Há aproximadamente 20 anos, a Kodak introduziu no mercado o filme Ektaspeed, de sensibilidade E, o qual promove uma redução de 40 a $50 \%$ na dose de radiação emitida ao paciente, em comparação ao Ultraspeed, do grupo D de sensibilidade. Apesar de muitos afirmarem que o Ektaspeed era similar ao Ultra-speed quanto à capacidade de diagnóstico, a maioria dos profissionais não o adotou. O Ektaspeed apresentava alta sensibilidade às variações de condições ideais de processamento, tais como flutuação de temperatura, concentração e exaustão da solução de processamento utilizada.

Em 1994, a Kodak introduziu no mercado o Ektaspeed Plus, que é um filme mais consistente em relação às variações de condições de processamento e, em 2000, lançou o filme Insight que, segundo as primeiras pesquisas realizadas, é um filme bastante promissor, reduzindo a dose de radiação de $20 \%$ a $50 \%$ sem perda na qualidade da imagem. Este filme se comporta na faixa do grupo $\mathrm{F}$ de sensibilidade, quando processado automaticamente e dentro do grupo E, quando processado manualmente. Em comparação ao filme Ultra-speed reduz em até $60 \%$ a dose de radiação e em comparação ao Ektaspeed pode reduzir até $20 \%$. Assim, tornam-se 
necessários estudos utilizando estes filmes sob condições variadas de processamento radiográfico ${ }^{66,101}$.

Além da preocupação com o tipo de filme a ser utilizado, existe ainda a preocupação com as soluções de processamento e com o tipo de processamento: manual ou automático. Um grande número de estudos avaliou as soluções de processamento ${ }^{1,14,16,22,38,50,51,54,63,65,68,69,72,74}$. Entre outros fatores, são avaliados o uso da elevação da temperatura dos banhos $^{32,33,71,103,107}$, a exaustão química das soluções processadoras ${ }^{8,86,105,111}$, sua degradação ${ }^{13,77,85}$, o uso de soluções enérgicas e a utilização de processadoras automáticas ${ }^{31,44,87,88,112}$, visando cada vez mais um rígido Controle de Qualidade.

A falta de cuidado no processamento é comum na prática diária, pois os profissionais não operam rotineiramente com um programa de Controle de Qualidade. Segundo pesquisas, as dificuldades verificadas na obtenção de uma radiografia de qualidade, podem chegar a 90\% na câmara escura, em virtude da falta de instalações adequadas, utilização do método visual de processamento, descuido com as etapas do processamento e, finalmente, desconhecimento da atividade e características das soluções processadoras depois de colocadas em uso ${ }^{13}$.

Para avaliarmos os filmes radiográficos e a atividade das soluções processadoras, utilizamos o método sensitométrico, que consiste na confecção de Curvas Características de onde se obtêm as propriedades sensitométricas dos filmes (contraste, latitude e sensibilidade). Estas curvas são construídas a partir da Densidade Ótica (D.O.) do filme radiográfico e dos tempos de exposição utilizados para sensibilizarmos os filmes. A Densidade Ótica é alcançada utilizando-se leituras a partir de um fotodensitômetro. Este é o método convencional, onde várias leituras são 
necessárias em cada faixa de exposição do filme radiográfico, obtendo-se uma média para posterior confecção das Curvas Características.

A Informática junto com seus programas de imagem mostraram ser possível avaliar o filme radiográfico em toda sua extensão, desde que seja reproduzido digitalmente, transformando a imagem original analógica em pequenos quadrados ou retângulos que denominamos pixel, e associar a cada um deles um número que represente sua cor, formando uma matriz que é avaliada e armazenada na memória de um computador ${ }^{24,52,80}$.

A utilização de um programa de imagem para quantificar os níveis de cinza (N.C.) de um filme radiográfico, vem contribuir na evolução da Radiologia Odontológica, no que se refere ao Controle de Qualidade. Este novo método traz agilidade, rapidez, facilidade e grande capacidade de armazenar dados para estudos comparativos das condições dos filmes radiográficos e soluções de processamento.

Quantificar a porcentagem de prata depositada na emulsão do filme radiográfico após a atuação das soluções de processamento (Densidade de Volume de prata) é um dos métodos de se analisar o comportamento dos filmes radiográficos e a atividade das soluções de processamento. Esta análise é microscópica e quando se analisa o tamanho, a forma e a quantidade de prata depositada, denominamos de método morfométrico ${ }^{17,70,75}$. Atualmente, com o advento da Informática, há a possibilidade de capturarmos uma imagem microscópica de uma faixa do filme radiográfico, exposto e processado padronizadamente, e quantificarmos, por meio de um programa de imagem, a porcentagem de prata depositada na emulsão. Este trabalho, entre outros objetivos, propôsse correlacionar este método aos métodos de análises convencional e digital, descritos previamente. 
2. REVISÃO DA LITERATURA 


\section{REVISÃO DA LITERATURA}

\subsection{Controle de Qualidade}

Toda a preocupação existente em torno das exposições radiográficas, processamento da imagem, proteção ao paciente, ganho de tempo, entre outros fatores aqui já mencionados, denomina-se Controle de Qualidade em Radiologia Odontológica. O Controle de Qualidade é justificado em qualquer parte da realização do exame radiográfico. O seu uso pode diminuir o tempo de atendimento aos pacientes $\mathrm{e}$ conseqüentemente os custos dos exames, pois além de evitar as repetições desnecessárias, pratica-se a proteção radiográfica ${ }^{14}$.

Os profissionais devem continuamente aferir a qualidade das imagens produzidas em seus consultórios para avaliar se os filmes radiográficos estão sendo expostos e processados corretamente. As condições de processamento otimizam a densidade e o contraste radiográficos e maximizam a qualidade da imagem. O monitoramento sensitométrico/densitométrico diário da qualidade da solução é recomendado. Um indicativo de que o revelador inicia o processo de exaustão e necessita ser substituído é a redução da densidade da imagem teste $^{125}$.

Em 2001, YAKOUMAKIS ${ }^{128}$ et al investigaram dois importantes aspectos na qualidade da imagem radiográfica: o tempo de exposição e o processamento do filme radiográfico. As imagens radiográficas foram obtidas de 108 consultórios odontológicos na Grécia. A qualidade da imagem e o processamento radiográfico foram avaliados subjetivamente e objetivamente comparando os filmes processados por cirurgiões-dentistas com filmes processados em condições ótimas. Os dados consistiram de 
medidas de densidade ótica, que foram usadas para se obter o contraste radiográfico e escores da qualidade da imagem e processamento do filme, baseados em critérios, por dois radiologistas independentemente. A dose de entrada foi também medida de acordo com cada técnica utilizada. Os resultados deste estudo indicaram grande variabilidade nos tempos de exposição usados pelos clínicos. O processamento do filme foi inadequado na maioria dos consultórios, o que resultou em qualidade deficiente da imagem e aumentou a dose de radiação ao paciente. Os autores concluíram que as técnicas intrabucais e o processamento radiográfico deveriam ser padronizados para melhorar a qualidade da imagem e reduzir a dose de radiação emitida ao paciente.

BRIDGMAN; CAMPBELL ${ }^{11}$, em 1995, recomendaram os procedimentos que devem ser seguidos para a obtenção de uma radiografia de ótima qualidade. Os erros na obtenção de uma radiografia podem ocorrer em qualquer etapa da produção radiográfica, porém um defeito em particular pode ser causado por diferentes fatores. O entendimento de cada uma das fases da produção de uma radiografia é necessário para obtermos radiografias de qualidade. Fatores como o equipamento utilizado para emissão dos raios X, a técnica radiográfica escolhida, estocagem do filme, processamento, acompanhamento dos procedimentos, resolução dos problemas encontrados, radiação ao paciente e infecção cruzada, foram discutidos neste trabalho.

O Controle de Qualidade em Radiologia Odontológica compreende, além de outras medidas, a correta observação dos equipamentos da câmara escura, a verificação do bom funcionamento dos aparelhos de raios $\mathrm{X}$ e avaliações sensitométricas dos filmes radiográficos. Qualquer negligência das regras de exposição e processamento 
radiográfico, mesmo que mais simples, poderá levar muitas vezes ao erro na obtenção de uma radiografia ${ }^{42}$.

De acordo com THOROGOOD; HORNER; SMITH ${ }^{111}$, em 1988, sensitometria é a resposta do filme à radiação eletromagnética (luz ou raios $\mathrm{X}$ ), verificada após o processamento radiográfico pela obtenção das densidades óticas. A tira sensitométrica, que é uma radiografia padronizada com diferentes faixas de densidades óticas em escala crescente, pode ser produzida utilizando-se dispositivos como penetrômetros de alumínio (para filmes sensíveis aos raios X) ou sensitômetros (para filmes sensíveis à luz). A avaliação das diferentes faixas da tira sensitométrica é realizada utilizando-se um fotodensitômetro, que tem a capacidade de medir a intensidade de luz transmitida pelo filme.

Vários autores dedicam-se aos estudos das propriedades sensitométricas dos filmes radiográficos e soluções processadoras. Eles utilizam penetrômetros, simuladores de mandíbula (fantoma), sensitômetros, fotodensitômetros, construção das curvas características e obtenção das propriedades sensitométricas, avaliando, desta forma, as possíveis variações sobre o contraste, a sensibilidade, a latitude e a densidade ótica dos filmes radiográficos ${ }^{1,8,43,61,62,82,89}$.

As propriedades sensitométricas de um filme podem ser estudadas a partir da construção da curva característica. Tal curva é uma representação gráfica criada em 1890 por HURTER; DRIFFIELD ${ }^{47}$, chamada curva H\&D ou sensitométrica. Esta metodologia era empregada para o estudo do comportamento de materiais sensíveis à luz, para verificar o resultado da exposição de papéis fotográficos. Atualmente com algumas modificações propostas pela AMERICAN STANDARDS ASSOCIATION $^{7}$, a curva mostra a relação entre a densidade ótica do filme e o logaritmo de exposição correspondente. 
Em um manual de sensitometria para filmes radiográficos, publicado em 1974 pela EASTMAN KODAK COMPANY ${ }^{27}$, foi descrita a padronização dos métodos para obtenção das curvas características e das propriedades sensitométricas. Neste manual, observou-se ainda que a curva característica tem sua confecção a partir da aplicação de uma série de exposições à luz ou raios $\mathrm{X}$ em um filme que, após o processamento, permitirá a obtenção das densidades óticas. Os valores das densidades óticas devem ser transferidos para um gráfico, no eixo das ordenadas (eixo Y), enquanto os valores de exposição devem ser transferidos para o eixo das abscissas (eixo X).

A curva característica determina as propriedades sensitométricas: contraste, latitude e sensibilidade. Contraste é a diferença entre os diversos graus de preto, branco e cinza do filme radiográfico e, quanto maior o número de tons intermediários de cinza, menor é o contraste. A forma da curva característica indica o contraste, quanto maior for sua inclinação, maior é o contraste ${ }^{110}$.

A latitude é a maior ou menor capacidade de um filme em ser subexposto ou superexposto, e ainda assim, produzir imagens de qualidade para o diagnóstico. Também é medida no eixo das exposições $(\mathrm{X})$.

A sensibilidade é a capacidade que um filme tem de gravar as imagens durante a exposição aos raios X. Esta eficácia pode ser também chamada de velocidade, uma vez que se refere à capacidade de produzir imagens com um maior ou menor tempo de exposição, ou maior ou menor quantidade de radiação ${ }^{41}$. Esta propriedade é determinada pelo posicionamento da curva característica sobre o eixo da abscissa (eixo X) e não pela sua forma. Pode ser definida como a recíproca de exposição em Röntgens requeridos para produzir a densidade 1,0 acima da densidade 
base e velamento sob condições padronizadas de exposição e processamento. Assim é expressa em Röntgen recíproco ( $\left.\mathrm{R}^{*}\right)$.

A densidade base e velamento (DBV) é a densidade intrínseca da própria base do filme e que pode ser resultante da qualidade da emulsão e sua interação com as soluções de processamento, radiação secundária e luz de segurança ${ }^{19}$.

Recomenda-se que o Controle de Qualidade se aplique também à análise das soluções processadoras, no que diz respeito às temperaturas e tempos ideais para a revelação e fixação da radiografia, a sua exaustão e degradação, e às condições de como estas soluções estão sendo armazenadas e preparadas, entre outros cuidados ${ }^{6}$.

Sabemos a importância de se conhecer a atividade da solução reveladora na qualidade das radiografias produzidas. A atividade do revelador concentrado inicia-se após a mistura de seus componentes. A partir deste momento, começam a ocorrer duas modificações distintas: a exaustão e a degradação. À medida que as soluções são gradualmente utilizadas, podem ser constatadas alterações na densidade da radiografia, tornando necessário o aumento do tempo de revelação. Quando estes detalhes são notados, o revelador está perdendo sua atividade química, sendo, portanto, recomendável a troca das soluções ${ }^{77}$.

Em 1981, TAVANO ${ }^{105}$ avaliou o comportamento de vários filmes radiográficos processados em diferentes soluções de processamento com a finalidade de verificar a atividade química das soluções, usando a quantidade de filmes processados como parâmetro, sem a interferência de fatores como oxidação, tempo de uso e luz de segurança, definindo o processo como exaustão química da solução, o que difere de degradação, que é decorrente além da oxidação, do tempo de uso da solução e da quantidade de filmes processados. 
SÁ; ALVARES; TAVANO ${ }^{90}$, em 1986, traçaram curvas características para estudar o comportamento de filmes radiográficos periapicais DF-58 quando processados na solução Kodak a $20^{\circ} \mathrm{C}$, sob diferentes condições de exposição e processamento. $\mathrm{O}$ intuito deste trabalho foi verificar até que ponto alterações nos tempos de exposição, compensando com os tempos de processamento, e vice-versa, alterariam a qualidade final das radiografias obtidas. Os resultados mostraram que os filmes radiográficos que receberam as quantidades de exposição recomendadas pelo fabricante responderam melhor às variáveis de revelação, pois o fator preponderante no grau de escurecimento do filme é a quantidade de radiação que ele recebe.

Para avaliar o comportamento de soluções processadoras desde a abertura dos galões até o seu término, 105 dias após, BRÜCKER; TAVANO; $\operatorname{COSTA}^{14}$, em 1992, utilizaram soluções RP X-Omat da Kodak para a revelação de filmes extrabucais, tipo "screen" da Kodak. Os filmes foram processados em processadora automática. Foram analisadas as propriedades sensitométricas dos filmes e de acordo com os resultados obtidos, concluíram que estas soluções, quando submetidas à armazenagem adequada, mantém um comportamento semelhante desde sua abertura até o final do uso.

Para RIBEIRO; TAVANO; PEREIRA ${ }^{85}$, em 1994, a obtenção de uma radiografia com requisitos necessários a uma boa interpretação, funcionando como eficiente meio auxiliar de diagnóstico tem seu êxito final baseado no processamento radiográfico. Nesta etapa é preciso avaliar não somente a qualidade, mas também o estado das soluções processadoras a serem empregadas, para que o resultado final do processamento radiográfico seja o melhor possível. Assim, muito se pesquisa sobre 
processamento radiográfico, visando a redução do tempo utilizado, sem o comprometimento final da radiografia.

YACOVENCO $^{126}$ et al, em 1995 e YACOVENCO $^{127}$ et al, em 1997, elaboraram um Programa de Garantia de Qualidade (PGC), com o objetivo de maximizar a obtenção de radiografias de boa qualidade para diagnóstico e com isto elevar o nível de desempenho. As metas fixadas para alcançar este objetivo foram: melhorar a qualificação dos profissionais, a atenção aos pacientes, a qualidade das radiografias, otimizar a dose por exame e reduzir os custos. O procedimento empregado na detecção de falhas no sistema baseou-se em uma análise dos filmes perdidos, procurando-se identificar se a causa foi devido ao aparelho, filme, paciente ou revelação. Os resultados obtidos mostraram uma redução de $70 \%$ na taxa de filmes perdidos com uma efetiva melhora na qualidade da imagem. Concluiu-se que a aplicação destes programas de qualidade radiográfica proporciona aos pacientes, serviços e produtos que atendam às expectativas, demonstrando uma efetiva melhoria na qualidade das imagens radiográficas.

SYRIOPOULOS ${ }^{100}$ et al, em 1999, examinaram os efeitos da exaustão em cinco soluções de processamento, analisando as propriedades sensitométricas de filmes radiográficos intrabucais Ektaspeed Plus, Ultraspeed e Agfa Dentus M2 "Comfort" antigo e o novo. Utilizaram as soluções para processamento manual, Agfa Dentus, Kodak e Demat e para processamento automático, Dürr XR e Periomat, sendo que todos os filmes foram processados manualmente. Os resultados mostraram que o Ektaspeed Plus foi mais sensível nas soluções para processamento manual. O Agfa Dentus M2 "Comfort" novo e o Ektaspeed Plus, apresentaram sensibilidade similar quando se utilizaram as soluções para processamento automático. A exaustão do revelador causou comparável decréscimo na sensibilidade do 
filme Ektaspeed Plus e nos dois filmes Agfa Dentus M2 "Comfort". A solução Agfa Dentus foi a solução de processamento manual mais duradoura, porém apresentou alta proporção de exaustão. A combinação do filme e solução processadora adequada é um importante fator para se alcançar as propriedades sensitométricas constantes. O Ektaspeed Plus e o recente Agfa Dentus M2 "Comfort" podem ser utilizados na prática odontológica e requerem menor quantidade de radiação. Estes filmes apresentam propriedades equivalentes ou superiores quando comparados com o filme Ultra-speed.

Em 1999, SULEIMAN ${ }^{98}$ et al publicaram um artigo onde divulgaram um levantamento realizado em Clínicas Odontológicas particulares, no ano de 1993, que utilizavam radiografias dentárias, e compararam com os resultados obtidos de um levantamento realizado em Faculdades de Odontologia entre 1995 e 1996. Uma amostra representativa de Clínicas Odontológicas particulares de cada estado participante foi estudada. Foram coletados dados como: exposição de radiação ao paciente, técnica radiográfica, qualidade da imagem radiográfica, qualidade do processamento radiográfico e velamento. Os autores descobriram que em Faculdades de Odontologia são utilizados filmes radiográficos do grupo E de sensibilidade com mais frequiência do que em clínicas particulares. $\mathrm{O}$ uso de filme $\mathrm{E}$ e melhores condições de processamento radiográfico nas Faculdades de Odontologia, resultam em baixas doses de radiação ao paciente sem perda de qualidade da imagem. Descobriram, também, que o velamento radiográfico ocorre mais nas Clínicas Odontológicas do que em Faculdades.

PRICE $^{84}$, em 2001 comparou um novo filme experimental da Kodak, de sensibilidade F, com os filmes Ultra-speed e Ektaspeed Plus. Analisou a densidade base e velamento, a sensibilidade, o contraste e a 
resolução dos filmes após condições ideais de exposição e processamento. $\mathrm{O}$ filme do grupo $\mathrm{F}$ apresentou grande redução na dose de radiação quando comparado aos filmes dos grupos $\mathrm{E}$ e $\mathrm{D}$, sendo quase duas vezes mais sensível que este último. O contraste foi comparável ao dos outros filmes. Os filmes dos grupos $\mathrm{E}$ e $\mathrm{F}$ de sensibilidade foram capazes de resolver 10 pares de linha por milímetro, porém ambas as emulsões foram inferiores a do filme Ultra-speed.

GEIST; KATZ ${ }^{39}$ em 2002 avaliaram Faculdades de Odontologia nos Estados Unidos e Canadá quanto aos procedimentos usados no Controle de Qualidade que reduzam a radiação aos pacientes. Enviaram questionários aos responsáveis pela Radiologia de 65 Faculdades de Odontologia, solicitando informações quanto à prática radiográfica intra e extrabucal e procedimentos de Controle de Qualidade. A taxa de resposta foi de $100 \%$. Os resultados mostraram que o filme do grupo $\mathrm{E}$ de sensibilidade é usado em $86 \%$ das instituições e a radiografia digital direta em 58\% para imagens intrabucais e $11 \%$ para as extrabucais. Outros meios de redução da dose foram: grande distância foco-filme (88\%), colimador retangular (47\%), avental de chumbo (95\% para filmes extrabucais e $85 \%$ para intrabucais) e ecrans intensificadores terras raras (100\%). Testes para velamento, sensibilidade e contraste dos filmes são realizados aproximadamente em $75 \%$ das escolas, enquanto cerca de $90 \%$ testam as luzes da câmara escura e o equipamento de raios X.

Estes fatores aqui discutidos, de fundamental importância dentro da Radiologia Odontológica, deixam claro a necessidade de se estudar as soluções de processamento e os filmes radiográficos processados sob diferentes condições. É desta maneira que buscamos constantemente um Controle de Qualidade indispensável aos profissionais que realizam radiografias rotineiramente como um método auxiliar de diagnóstico. 


\subsection{Filmes radiográficos}

Quando um feixe de raios X parte do aparelho, ele interage com o objeto e, desta maneira, terá reduzida sua intensidade, pois o feixe é atenuado pela sua absorção e espalhamento. Para que a informação relacionada com a estrutura e composição do objeto, que está sendo conduzida pelo feixe, seja aproveitada, necessitamos de um receptor de imagens, que no caso da Radiologia Convencional, é o filme radiográfico. Atualmente os filmes radiográficos apresentam uma padronização para a sua produção, possuem em ambos os lados de uma base de poliéster a emulsão, que se constitui de gelatina onde estão contidos os cristais de prata (brometo de prata e iodeto de prata). A emulsão tem por finalidade absorver radiação durante a exposição aos raios $\mathrm{X}$ e produzir imagem latente, a qual se transforma em imagem radiográfica visível após o uso das soluções para o processamento.

A partir da introdução no comércio de filmes radiográficos odontológicos, deu-se ênfase à redução da quantidade de radiação necessária para produzir radiografias, mantendo a qualidade para diagnóstico. Quando foram lançados os primeiros filmes radiográficos, eram necessários 4,5 segundos para a exposição da área de molares superiores. O primeiro filme radiográfico odontológico foi introduzido pela Kodak em 1913. Em 1919 foi lançado o primeiro filme odontológico "tipo moderno". A emulsão era feita para exposição direta aos raios X. A embalagem continha finas folhas de chumbo para reduzir a radiação por espalhamento. Em 1925 a Kodak anunciou um novo filme, com fina granulação, maior contraste e duas vezes mais rápido que o antecessor. $\mathrm{O}$ filme radiográfico periapical Ultra-speed foi introduzido em 1941 e era duas vezes mais rápido que o Radia-Tized, seu antecessor. Em 1955 a 
Kodak, relançou o filme Ultra-speed, cinco a seis vezes mais rápido que o novo Radia-Tized, lançado no mesmo ano. O Radia-Tized teve seu uso descontinuado a partir de $1974^{93}$ e em 1981, foi lançado no mercado o filme Ektaspeed, duas vezes mais sensível que qualquer outro do grupo D (Ultra-speed e Agfa Dentus M2) ${ }^{81}$. Por apresentar menor contraste, velamento acentuado, irregularidade na granulação e menor latitude, o filme Ektaspeed foi substituído pelo Ektaspeed Plus, lançado pela Kodak em 1994. O filme Ektaspeed Plus usa em sua emulsão, a tecnologia T-Mat, usada em filmes extrabucais, com grânulos tabulares, diferentes da emulsão anterior. Esta tecnologia além de melhorar a resolução da imagem, aumenta a sensibilidade do filme ${ }^{113}$. Em 1997, foi lançado no mercado, o Agfa Dentus M2 "Comfort", com características similares ao Ektaspeed Plus em condições de processamento ideal. Este filme apresenta sensibilidade E, diferindo do antigo que apresentava uma sensibilidade entre os grupos D/E. Em abril de 2000 a Eastman Kodak anunciou a introdução do filme Insight, classificado como um filme radiográfico intrabucal do grupo $\mathrm{E} / \mathrm{F}$ de sensibilidade. Este novo filme requer menor exposição que seus antecessores enquanto mantém a mesma qualidade de imagem para diagnóstico, de acordo com seu fabricante. Sua emulsão apresenta a tecnologia T-Mat, de grânulos tabulares, a mesma utilizada nos filmes Ektaspeed Plus ${ }^{66}$.

Os filmes mais sensíveis necessitam de menor quantidade de radiação para produzirem imagens com valor para diagnóstico e por isto representam o mais eficiente fator na redução da radiação ao paciente durante a tomada radiográfica. Este ganho na sensibilidade pode implicar em perda de nitidez. O tamanho dos cristais de prata contidos na emulsão dos filmes radiográficos é um dos fatores que determina uma maior ou menor sensibilidade dos mesmos, sendo assim, filmes mais sensíveis 
possuem cristais maiores e vice-versa. Desta maneira, quando estes cristais são maiores, aumenta-se também a área de sensibilização do filme, causando perda da nitidez do mesmo. Hoje em dia estão disponíveis no mercado filmes dos grupos D, E e F de sensibilidade. A sensibilidade dos filmes radiográficos é expressa em Röntgen recíproco $\left(\mathrm{R}^{*}\right)$, assim, filmes do grupo D necessitam de 14 a 28R*, filmes do grupo E, 28 a 56R* e do grupo F, 56 a 112R* de exposição para alcançar uma densidade específica $^{48,49}$. Quanto maior o $\mathrm{R}^{*}$, menor é a quantidade de radiação necessária para alcançar a Densidade Ótica de 1,0 acima da densidade base e velamento. Com o tempo foram surgindo inúmeros experimentos utilizando filmes radiográficos, realizados sob diferentes metodologias e que trouxeram grandes benefícios no que diz respeito ao avanço da Radiologia, redução da exposição aos raios X e melhoria na qualidade da imagem radiográfica.

KAFFE; LITTNER; KUSPET ${ }^{54}$, em 1984, realizaram um estudo comparando os filmes radiográficos Ultra-speed e Ektaspeed, dos grupos D e E de sensibilidade, respectivamente. Concluíram que não houve deterioração da imagem com 50\% de redução na exposição quando o filme Ektaspeed foi usado, sendo este recomendado para radiografias de rotina. A densidade base e velamento para os dois filmes foi similar e a resolução e o contraste foram idênticos para ambos.

ALVARES; ALVARES; TAVANO ${ }^{3}$, em 1986, realizaram um experimento no qual compararam os filmes radiográficos Agfa-Gevaert, Ultra-speed e Ektaspeed, processados na solução Kodak pronta para uso. Os filmes foram expostos em um fantoma e processados padronizadamente. Foi realizada uma análise subjetiva das imagens obtidas, por profissionais e técnicos especialistas, além da obtenção das propriedades sensitométricas. Concluíram que o filme mais sensível foi o 
Ektaspeed, seguido pelo Agfa-Gevaert, do grupo D e por último o Ultraspeed. O filme Agfa-Gevaert apresentou melhor qualidade de imagem, enquanto o filme Ektaspeed não deixa de ter suas vantagens, devido a sua maior sensibilidade.

CONOVER; HILDEBOLT; ANTHONY ${ }^{20}$, em 1995, compararam objetiva e subjetivamente filmes radiográficos intrabucais. Os filmes utilizados foram: Ektaspeed Plus, Agfa Dentus M2, Ideal MX58, Ultra-speed, Minimax TRX-S e Schein DX58. Foram realizadas medidas objetivas, tais como sensibilidade, contraste e densidade base e velamento. Avaliações subjetivas como facilidade de uso, granulação do filme e aparência geral, também foram realizadas. O filme Ektaspeed Plus foi o mais sensível, seguido pelo Agfa Dentus M2 e do Ultra-speed. O Agfa Dentus M2, Schein e Minimax apresentaram baixo contraste. O Ultra-speed e o Ideal MX58 mostraram alto contraste, seguido pelo Ektaspeed Plus.

CONOVER; HILDEBOLT; ANTHONY ${ }^{21}$, em 1995, compararam o filme Ektaspeed Plus com o Ektaspeed e o Ultra-speed. A comparação foi realizada utilizando medidas objetivas (sensibilidade, contraste e densidade base e velamento) e por uma avaliação subjetiva (granulação do filme e aparência). O Ektaspeed Plus apresentou maior contraste que o Ektaspeed e foi similar ao Ultra-speed e, além disso, o Ektaspeed Plus apresentou maior sensibilidade que o Ektaspeed. Os filmes foram estocados em vários locais e a densidade base e velamento foi determinada em diferentes dias. O Ektaspeed Plus e o Ultra-speed apresentaram estabilidade de resultados durante este teste e não houve diferença significante na formação da densidade base e velamento. $O$ Ektaspeed Plus apresentou a densidade base e velamento mais baixa e o Ektaspeed apresentou a mais alta. Imagens radiográficas foram realizadas da região de molares de um simulador e as radiografias avaliadas 
subjetivamente por três observadores. O filme Ektaspeed Plus apresentou a menor granulação. Com base nas avaliações realizadas, concluíram que o Ektaspeed Plus foi superior ao Ektaspeed e superior ou equivalente ao Ultra-speed.

Em 1995, WAKOH ${ }^{118}$ et al realizaram um estudo que comparou as propriedades sensitométricas e a quantidade de informações de quatro filmes radiográficos: Ultra-speed, Ektaspeed, Flow e o Agfa Dentus M2 "Comfort". Os resultados mostraram que o filme Agfa Dentus M2 "Comfort" apresentou melhor contraste, uma sensibilidade intermediária entre os grupos D/E e uma latitude de exposição maior que a do Ultraspeed e menor que a do Flow. O filme Agfa Dentus M2 "Comfort" e o Ektaspeed apresentaram nitidez superior aos filmes Ultra-speed e Flow.

Em 1995, LUDLOW; PLATIN; HILL ${ }^{65}$ compararam filmes radiográficos Ultra-speed, Ektaspeed e Ektaspeed Plus quanto à sensibilidade, latitude de exposição e resolução. Foram confeccionadas curvas características para cada tipo de filme sob condições padronizadas de processamento. O filme Ektaspeed Plus apresentou maior sensibilidade, sendo duas vezes mais rápido que o Ultra-speed. O Ektaspeed exibiu uma latitude de exposição relativamente grande, seguido do Ektaspeed Plus e Ultra-speed. Todos os filmes foram capazes de resolver mais que 16 pares de linhas por milímetro.

PRICE ${ }^{83}$, em 1995, comparou o filme Ektaspeed Plus com os filmes Ultra-speed e Ektaspeed, utilizando para isto a análise da curva característica. O Ektaspeed Plus foi duas vezes mais rápido do que o Ultraspeed. O contraste do filme Ektaspeed Plus foi similar ao Ultra-speed e maior que o do filme Ektaspeed. O Ektaspeed Plus mostrou boa resolução assim como o Ektaspeed, porém ambas as emulsões foram inferiores a do 
Ultra-speed. $\mathrm{O}$ autor concluiu que o Ektaspeed Plus pode ser uma alternativa aceitável ao filme Ultra-speed.

Para investigar o contraste radiográfico de três filmes radiográficos periapicais (Ultra-speed, Ektaspeed e Ektaspeed Plus), TAMBURÚS; LAVRADOR ${ }^{104}$, em 1997, radiografaram um penetrômetro de alumínio para avaliação objetiva e uma mandíbula humana seca, para avaliação subjetiva. Para avaliação objetiva, o contraste foi avaliado a partir das medidas de densidade ótica e os resultados analisados por meio de análise estatística. A avaliação subjetiva foi realizada por 12 cirurgiõesdentistas com ampla experiência clínica. Não houve diferença estatística significante no contraste obtido com o filme Ultra-speed e Ektaspeed Plus. Ambos apresentaram melhor contraste que o Ektaspeed. A avaliação subjetiva revelou que a maioria dos clínicos preferiu ou o Ultra-speed ou o Ektaspeed Plus em relação ao contraste.

SYRIOPOULOS ${ }^{101}$ et al, em 1999, avaliaram as propriedades sensitométricas dos filmes Ektaspeed Plus, Ultra-speed, Agfa Dentus M2 "Comfort" antigo e recente, utilizando cinco soluções para processamento. O filme Ektaspeed Plus apresentou a maior densidade base e velamento e o Ultra-speed, a mais baixa, independentemente da solução utilizada. O Ektaspeed Plus apresentou sensibilidade mais alta em quatro das cinco soluções utilizadas. O Agfa Dentus M2 "Comfort", lançado recentemente, foi mais sensível que o Ektaspeed Plus quando se utilizou a solução para processamento automático Dürr XR. Todos os filmes processados nas soluções para processamento automático foram mais sensíveis do que quando processados com as soluções para processamento manual. O filme Agfa Dentus M2 “Comfort" recente, é um filme de sensibilidade E e pode ser considerado uma alternativa ao Ektaspeed Plus. Ambos podem ser 
recomendados para uso na prática odontológica e contribuem para a redução da dose de radiação ao paciente.

WHITE; YOON ${ }^{124}$, em 2000, avaliaram os filmes radiográficos do grupo E de sensibilidade (Flow e Ektaspeed Plus) quanto às propriedades sensitométricas (sensibilidade e contraste) e capacidade em detectar cáries proximais. Os filmes foram expostos e processados de acordo com as especificações da ADA. Foram radiografados 80 prémolares e molares e as superfícies proximais avaliadas quanto à presença de cáries por 12 dentistas. A presença e profundidade das cáries foram determinadas por exame microscópico do dente após seu seccionamento. Quanto às propriedades sensitométricas, ambos os filmes excederam as especificações da ADA. A sensibilidade para o Ektaspeed Plus foi de 50,6 e para o Flow foi de 48,3. Os valores de densidade base e velamento foram 0,24 e 0,19 , respectivamente. O contraste do filme Flow foi de 1,88 e do Ektaspeed Plus de 1,70, valores bem acima do requerido pela ADA de 1,5. Não houve diferença significante na capacidade em detectar cáries proximais entre os dois tipos de filme. Ambos oferecem igual capacidade para detecção de cáries proximais.

Com o objetivo de comparar três filmes com diferentes grupos de sensibilidade para detecção de cáries proximais, LUDLOW; ABREU; $\mathrm{MOL}^{64}$, em 2001, radiografaram as superfícies proximais de 40 dentes posteriores extraídos utilizando os filmes Insight, Ektaspeed Plus e Ultraspeed. Seis observadores avaliaram as radiografias quanto à presença de cárie. O filme do grupo $\mathrm{F}$ de sensibilidade apresentou a mesma capacidade de detecção de cáries proximais que os filmes do grupo $\mathrm{E}$ e $\mathrm{D}$ de sensibilidade. Os autores concluíram que o filme Insight é bastante útil na redução da dose de radiação emitida ao paciente enquanto mantém qualidade para um diagnóstico radiográfico. 
Em 2001, NAIR; NAIR ${ }^{79}$ compararam a eficácia dos filmes Ektaspeed Plus, Insight e de um sensor digital, em relação à detecção de cáries em 92 superfícies proximais de 46 dentes extraídos e não restaurados. 51 superfícies apresentavam evidência microscópica de cárie. Oito observadores avaliaram as imagens. Para o filme Ektaspeed Plus utilizou-se um tempo de exposição de 0,42 segundos, para o Insight, 0,33 segundos e para o sensor digital, 0,16 segundos. As exposições foram padronizadas e a distância foco-filme foi de $40 \mathrm{~cm}$. Os filmes foram processados em uma processadora automática AT-2000, em química Readymatic da Kodak. Os resultados mostraram que a capacidade de diagnóstico foi de 0,760 para o Ektaspeed Plus, 0,778 para o Insight e 0,732 para o sensor digital, quando comparados com o diagnóstico microscópico, resultados estes, não significantes estatisticamente. Nenhuma das modalidades de imagens avaliadas neste estudo diferiu na capacidade de diagnóstico de cárie proximal. O filme Insight foi usado com $20 \%$ menos de radiação em relação ao Ektaspeed Plus e foi tão capaz quanto os dois outros sensores na detecção de cáries proximais.

Para comparar as propriedades sensitométricas do filme Insight com as do filme Ektaspeed Plus, SYRIOPOULOS ${ }^{102}$ et al, em 2001, construíram curvas características para o processamento manual e automático de ambos os filmes. Sete cirurgiões-dentistas compararam a extensão de uma lima endodôntica colocada no canal radicular para determinar a capacidade de diagnóstico dos dois filmes. Para comparar a qualidade de imagem, 100 pares de radiografias interproximais do lado esquerdo (Ektaspeed Plus) e do lado direito (Insight) do mesmo paciente foram feitas. Quatro cirurgiões-dentistas analisaram as radiografias e os dados foram analisados pelo Coeficiente de Concordância de Kendall. A densidade base e velamento do filme Insight foi 0,24 para o processamento 
manual e 0,25 para o processamento automático e para o filme Ektaspeed Plus foi 0,23 e 0,26, respectivamente. O filme Insight foi mais sensível que o Ektaspeed Plus e classificado dentro do grupo E de sensibilidade quando processado manualmente e no grupo $\mathrm{F}$, quando processado automaticamente. O contraste de ambos os filmes foi comparável, independentemente do processamento utilizado. Nenhuma diferença significante foi descoberta na capacidade de diagnóstico usando os dois filmes. Dois observadores mostraram uma preferência significante para o filme Ektaspeed Plus.

Para analisar os filmes radiográficos intrabucais dos grupos $\mathrm{D}, \mathrm{E}$ e F de sensibilidades, SHEAFFER ${ }^{92}$ et al, em 2002, realizaram um estudo no qual cinco cirurgiões-dentistas avaliaram as medidas endodônticas de molares superiores com quatro canais, radiografados com os referidos filmes. A distância da ponta de uma lima $\mathrm{n}^{\circ} 10$, colocada no interior dos canais até o ápice radiográfico, foi medida e comparada com a extensão conhecida para determinação do erro. Após análise estatística não foi observada diferença significante entre os três tipos de filmes para as medidas endodônticas, sendo assim, os filmes mais sensíveis são preferidos com o objetivo de minimizar a dose de radiação emitida ao paciente.

Desta forma a análise de novos materiais introduzidos no mercado, faz-se necessária, pois eles comportam-se diferentemente de acordo com as condições de exposição e processamento a que são submetidos. 


\subsection{Soluções de processamento}

Existe uma busca constante por parte da indústria e de pesquisadores pelo desenvolvimento de novos materiais e novas técnicas que reduzam ainda mais o tempo de processamento de filmes radiográficos utilizados em Odontologia. Isso é decorrente da urgência na obtenção de radiografias em tempo relativamente curto para procedimentos em Endodontia e Cirurgia, dispensando assim, pequenos detalhes de diagnóstico que na maioria das vezes podem ser desprezados por estas Especialidades.

Os fabricantes de filmes e soluções processadoras sugerem tempos de exposição e revelação, com os quais, admite-se, possa o profissional obter os melhores resultados. Porém não raro, encontram-se profissionais ou alunos que alteram alguns destes fatores com a inaceitável justificativa de ganho de tempo ${ }^{90}$.

Durante o processamento radiográfico, agentes redutores agem quimic amente sobre o sal de prata sensibilizado e provocam a precipitação do metal sob a forma de grãos emulsionados em gelatina. A temperatura utilizada para que esta reação ocorra afeta o processo, acelerando-o ou retardando-o, à medida que a mesma aumenta ou diminui, respectivamente ${ }^{34}$.

O processamento de um filme radiográfico envolve um tempo não produtivo em termos de aproveitamento no tratamento dentário do paciente $^{1}$. Quando existem boas razões para reduzir o tempo de revelação, métodos de processamento rápido ou o uso de processadoras automáticas devem ser considerados. Outras medidas para reduzir o tempo de revelação, compreendem o aumento da temperatura da solução reveladora, o uso de soluções concentradas e solução monobanho. É inadmissível o uso 
de exposições maiores que as recomendadas, pois se aumenta a dose de radiação para o paciente e profissional e não há redução significativa do tempo de processamento. Busca-se outras formas para se alcançar os resultados desejados no que diz respeito ao tempo de processamento.

TAVANO; ALVARES ${ }^{106}$, em 1978 compararam os resultados alcançados por soluções reveladoras rápidas com os obtidos com o revelador convencional (Kodak). Para isto utilizaram o filme DF-57 e analisaram suas propriedades sensitométricas. Concluíram que as soluções reveladoras testadas apresentaram praticamente as mesmas respostas quando as curvas características foram analisadas no que diz respeito ao contraste, latitude e sensibilidade. Os reveladores rápidos mostraram valores de densidade base e velamento ligeiramente maiores do que o revelador padrão.

SPOSTO; TAVANO; LOPES $^{97}$, em 1983, avaliaram as soluções de processamento Kodak e Sillib para o processamento de filmes radiográficos periapicais, utilizando a curva característica. Foram utilizados filmes Ultra-speed. O revelador Kodak (padrão) foi utilizado na combinação de $20^{\circ} \mathrm{C} / 5$ minutos e o Sillib, a $20^{\circ} \mathrm{C} / 2$ minutos, $22^{\circ} \mathrm{C} / 1,5$ minuto e $25^{\circ} \mathrm{C} / 1$ minuto. As propriedades sensitométricas dos filmes processados no revelador Sillib a $25^{\circ} \mathrm{C} / 1$ minuto, forneceram resultados semelhantes àqueles obtidos pelo uso do revelador Kodak a $20^{\circ} \mathrm{C} / 5$ minutos, considerado padrão.

KAFFE; LITTNER; TAMSE ${ }^{55}$, em 1984, estudaram os filmes radiográficos Ultra-speed, Agfa Dentus M2, e Rinn Auto 58 processados nas soluções Adefo, Agfa Gevaert, Kerr, Kodak e Durr Periomat em condições padronizadas, com o intuito de verificar qual a melhor combinação solução/filme em relação à densidade ótica, contraste, densidade base e velamento e sensibilidade. Os resultados mostraram que a 
combinação Ultra-speed/Adefo produziu densidade base e velamento e contraste aceitáveis aliados à alta sensibilidade. O filme Rinn, em todas as soluções de processamento, apresentou bom contraste e alta sensibilidade, porém, mostrou uma densidade base e velamento in aceitável, resultando em deterioração da qualidade de imagem.

Para verificar os efeitos de variáveis de processamento, tais como processamento manual e automático e variação na temperatura das soluções de processamento, $\mathrm{KOGON}^{57}$ et al, em 1985, utilizaram filmes Ultra-speed e Ektaspeed. A solução GBX da Kodak foi utilizada para processamento manual, e a RP X-Omat da Kodak para o processamento automático. O tempo de processamento manual foi mantido em quatro minutos, quando a temperatura da solução variava. Quando o tempo variava, a temperatura era mantida em $22^{\circ} \mathrm{C}$. Durante o processamento automático, quando a temperatura variava, o tempo era mantido em 4,5 minutos e quando o tempo variava, a temperatura era de $28,3^{\circ} \mathrm{C}$. Seis temperaturas (de $18,3^{\circ} \mathrm{C}$ a $26,7^{\circ} \mathrm{C}$ ) e seis tempos (variando de 2,5 - 6,0 minutos) foram utilizados para o processamento manual. Para o processamento automático utilizaram-se sete níveis de temperatura (variando de $23,3^{\circ} \mathrm{C}$ a $32,2^{\circ} \mathrm{C}$ ) e sete variações de tempo (de 1,2 a 6,0 minutos). Concluíram que quando se utilizou a solução GBX da Kodak durante o processamento manual, o filme Ektaspeed mostrou grande perda de contraste nas temperaturas acima de $22,2^{\circ} \mathrm{C}$. O filme $\mathrm{D}$ não foi afetado por altas temperaturas. No processamento automático, as temperaturas acima do recomendável, $28,3^{\circ} \mathrm{C}$, mostraram pouco efeito no contraste de ambos os filmes. Durante o processamento manual, quando a temperatura foi constante, não houve diferença significativa no contraste dos filmes. No tempo abaixo de três minutos para o processamento automático, ambos os filmes foram incompletamente revelados. 
FLETCHER $^{31}$, em 1987, comparou a qualidade dos filmes Ultraspeed (D) e Ektaspeed (E) de sensibilidade processados com duas técnicas de processamento manual e duas de processamento automático. A qualidade dos filmes foi determinada por avaliação sensitométrica para estudar o contraste, a resolução, observação através de lentes de magnificação de 3,5 vezes para determinar a granulação do filme e uma comparação para observar os efeitos do processamento manual e automático. Os resultados mostraram que o filme do grupo $\mathrm{E}$ apresentou alto contraste no processamento manual e grande variação da densidade ótica quando processado automaticamente. A redução na granulação ocorreu quando o filme $\mathrm{E}$ foi processado manualmente. A resolução foi idêntica para os filmes D e E processados tanto manualmente como automaticamente. $\mathrm{O}$ filme Ektaspeed processado manualmente ou automaticamente produziu radiografias de qualidade aceitável para diagnóstico.

Com o intuito de analisar os efeitos das variações da temperatura de uma solução reveladora sobre a densidade ótica e o contraste radiográfico, TAMBURÚS ${ }^{103}$, em 1987, utilizou o filme radiográfico Ektaspeed. A solução utilizada neste experimento foi a Sillib pronta para uso nas temperaturas de $20^{\circ} \mathrm{C}, 22^{\circ} \mathrm{C}, 24^{\circ} \mathrm{C}$ e $26^{\circ} \mathrm{C}$. O tempo de revelação foi de dois minutos. Utilizou-se um penetrômetro de alumínio puro, escalonado em oito degraus, com espessuras variando de 0 (exposição direta aos raios X) a $16 \mathrm{~mm}$. As alterações de temperatura do revelador foram obtidas com o emprego de gelo e/ou água aquecida, colocado no tanque de água em relação direta com os tanques das soluções reveladora e fixadora. Os resultados mostraram que as densidades óticas, nas espessuras 0 e $2 \mathrm{~mm}$, foram significativamente diferentes nas temperaturas de $20^{\circ} \mathrm{C}$, $22^{\circ} \mathrm{C}$ e $26^{\circ} \mathrm{C}$ e nas espessuras 4,6 e $8 \mathrm{~mm}$, nas temperaturas de $20^{\circ} \mathrm{C}$ e $26^{\circ} \mathrm{C}$. 
Nas espessuras de 4, 6 e 8mm, as densidades óticas não foram significativamente diferentes nas temperaturas de $22^{\circ} \mathrm{C}$ e $24^{\circ} \mathrm{C}$. Nas espessuras de 10, 12, 14 e 16mm, as densidades óticas não diferiram significativamente nas temperaturas de $20^{\circ} \mathrm{C}, 22^{\circ} \mathrm{C}$ e $24^{\circ} \mathrm{C}$. Para uma mesma temperatura, as densidades óticas diferiram significativamente para todas as espessuras utilizadas. O contraste radiográfico nas quatro temperaturas do revelador e nas diferentes espessuras do penetrômetro foi de boa qualidade.

Em 1989, SWART; SEELIGER ${ }^{99}$ determinaram o efeito de sete soluções de processamento na qualidade da imagem radiográfica de três filmes radiográficos do grupo $\mathrm{D}$ de sensibilidade. Utilizou-se um penetrômetro de alumínio e os filmes foram expostos padronizadamente. Os filmes processados foram avaliados subseqüentemente por uma avaliação sensitométrica, onde os dados referentes à densidade base e velamento, contraste e sensibilidade dos filmes radiográficos para cada combinação foram tabulados. A combinação filme Flow e solução Kolchem apresentou o maior contraste, mínima densidade base e velamento e a mais alta sensibilidade.

Para determinar quais os efeitos do aumento da temperatura em seis diferentes soluções para processamento manual e identificar qual a combinação de filme, solução e temperatura produziria melhores resultados em termos de contraste radiográfico e sensibilidade do filme, MATTHEE; BECKER; SEELIGER ${ }^{71}$, em 1990, realizaram um experimento utilizando os filmes Agfa Dentus M2, Flow e Ultra-speed. As soluções usadas foram: Agfa, Dürr, EBX, Kolchem, MEMS e Pro-tech. Os filmes foram expostos em um penetrômetro de alumínio em condições padronizadas. O processamento foi realizado em uma processadora automática com temperaturas que variavam de $25^{\circ} \mathrm{C}$ a $35^{\circ} \mathrm{C}$. Concluíram que, quando a 
temperatura da solução de processamento aumentava de $25^{\circ} \mathrm{C}$ para $35^{\circ} \mathrm{C}$, tanto o contraste radiográfico como a sensibilidade dos filmes também aumentavam. O maior contraste radiográfico foi obtido quando se utilizou o filme Agfa na solução Kolchem a $35^{\circ} \mathrm{C}$, enquanto o filme Ultra-speed na solução MEMS a $35^{\circ} \mathrm{C}$ apresentou a maior sensibilidade. Uma densidade base e velamento aceitável de 0,25 foi alcançada utilizando-se o filme Agfa em combinação com as soluções Agfa, Dürr, e Pro-tech e com o filme Flow na solução Dürr. Todas as outras combinações produziram uma densidade base e velamento maior que 0,25 .

Em 1991, MATTHEE; SEELIGER ${ }^{73}$ avaliaram quatro soluções rápidas de processamento para identificar qual a combinação de filme, solução e temperatura produziria os melhores resultados em termos de contraste radiográfico e sensibilidade do filme. Os filmes utilizados foram Agfa Dentus M2, Flow e Ultra-speed e as soluções foram Kolchem Rapid Dev 1, Kolchem Rapid Dev 2, MEMS Ultra-Neg e Siemens Insta-Neg. O processamento foi realizado manualmente nas temperaturas de $18^{\circ}, 20^{\circ}$, $22^{\circ}, 25^{\circ}, 27^{\circ}, 29^{\circ}$ e $32^{\circ} \mathrm{C}$. O contraste radiográfico e a sensibilidade foram calculados e os dados obtidos submetidos à análise estatística. Concluiu-se que o filme Agfa Dentus M2 processado com a solução Kolchem Rapid Dev 2 a $18^{\circ} \mathrm{C}$ apresentou o mais alto contraste e sensibilidade. Todos os valores de densidade base e velamento permaneceram dentro do limite aceitável de 0,25.

Em 1991, HASHIMOTO; THUNTHY; WEINBERG ${ }^{44}$ estudaram os efeitos das alterações na temperatura da solução processadora e no tempo de processamento automático utilizando filmes intrabucais Ultraspeed e Ektaspeed. Este estudo mostrou que quando se aumenta a temperatura da solução e o tempo de processamento automático, há um aumento da sensibilidade e do contraste tanto para o Ultra-speed como para 
o Ektaspeed. Alterações na temperatura da solução têm maior influência na sensibilidade e no contraste do que as alterações realizadas no tempo do processamento automático. As alterações ocorreram mais nos filmes Ektaspeed do que no Ultra-speed e, portanto, maiores cuidados devem ser tomados durante o processamento dos filmes Ektaspeed.

IUCIF; TAVANO ${ }^{51}$, em 1995, realizaram um estudo com o objetivo de conhecer as características da solução Agfa Dentus no processamento manual de filmes radiográficos Agfa Dentus M2 "Comfort". Após as exposições e processamentos padronizados, com quatro repetições, as radiografias foram analisadas quanto à densidade ótica e curvas características, de onde foram obtidas as propriedades sensitométricas. Os resultados mostraram que a solução é de excelente qualidade, promovendo no filme testado características de alto padrão para o diagnóstico radiográfico.

Em 1994, a Kodak substituiu o filme Ektaspeed pelo Ektaspeed Plus. Os fabricantes chamavam a atenção para o fato de que este filme não era fortemente afetado pela exaustão das soluções processadoras. Em 1995, THUNTHY; WEINBERG ${ }^{112}$ testaram filmes radiográficos periapicais Ektaspeed Plus, Ektaspeed e Ultra-speed, processados em processadora automática e com soluções Kodak. Concluíram que a solução apresentou suas melhores propriedades sensitométricas em um período de duas semanas e que, devido à exaustão, seus efeitos diminuíram na terceira semana. O filme Ektaspeed Plus foi o que apresentou maior estabilidade em relação a esta exaustão progressiva no que diz respeito a valores médios de contraste e latitude.

A fim de estudar as densidades óticas, curvas características e as variações das propriedades sensitométricas induzidas no filme periapical radiográfico Ultra-speed, TAVANO; CAPELOZZA; FONTÃO ${ }^{107}$, em 
1996, utilizaram tempos de revelação que variaram entre 60,30 e 15 segundos em soluções processadoras na temperatura de $35^{\circ} \mathrm{C}$. Utilizaram a solução Kodak Dental para Raios X, pronta para uso. Os resultados foram comparados com a combinação padrão a $20^{\circ} \mathrm{C} / 5$ minutos. $\mathrm{O}$ experimento foi repetido quatro vezes com o objetivo de buscar resultados mais exatos. Após as exposições e processamentos padronizados, as radiografias foram analisadas quanto à densidade ótica e curvas características, de onde se obtiveram as propriedades sensitométricas. Os resultados alcançados mostraram que a combinação temperatura/tempo de $35^{\circ} \mathrm{C} / 60$ segundos foi a que resultou em radiografias de melhor qualidade, sendo a que mais se aproximou do processamento padrão. $\mathrm{O}$ tempo de 30 segundos produziu radiografias com valores de sensibilidade e latitude próximos aos do processamento padrão. A combinação de $35^{\circ} \mathrm{C} / 15$ segundos produziu radiografias de qualidade precária e com propriedades sensitométricas inadequadas, não sendo indicada para diagnóstico radiográfico em Odontologia.

AKDENIZ; LOMÇALI' ${ }^{2}$, em 1998, avaliaram o contraste, a sensibilidade e a densidade base e velamento do filme Minimax, do grupo D de sensibilidade, processado automaticamente, em quatro soluções reveladoras, em três diferentes temperaturas: $25^{\circ} \mathrm{C}, 28^{\circ} \mathrm{C}$ e $30^{\circ} \mathrm{C}$. O tempo de revelação foi de 4,5 minutos para todas as combinações. Todas as soluções produziram valores aceitáveis de densidade base e velamento que não variaram significantemente com alterações da temperatura nas quatro soluções utilizadas. O contraste obtido com as soluções RP X-Omat e Fuji foi menor do que com as soluções Megasan e Hacettepe. A sensibilidade mais alta foi alcançada utilizando-se a solução Megasan.

SYRIOPOULOS ${ }^{101}$ et al, em 1999, avaliaram as soluções para processamento radiográfico manual, Agfa Dentus, Kodak (1:3) e Demat e 
para processamento automático, Dürr $\mathrm{XR}$ e Periomat Intra. O processamento manual foi realizado a $20^{\circ} \mathrm{C}$ por cinco minutos. A solução Dürr foi utilizada na temperatura de $28^{\circ} \mathrm{C}$ por um minuto e a Periomat a $25^{\circ} \mathrm{C}$ por um minuto. A densidade base e velamento e a sensibilidade foram mais altas quando se utilizaram as soluções para processamento automático. Das três soluções utilizadas para processamento manual, a Agfa Dentus produziu a maior sensibilidade. A solução Dürr XR a $28^{\circ} \mathrm{C}$ por um minuto produziu maior sensibilidade nos filmes do que a solução Periomat a $25^{\circ} \mathrm{C}$ por um minuto.

TAVANO; DEZOTTI ${ }^{108}$ em 2000 analisaram os filmes radiográficos Ektaspeed e Ultra-speed processados em reveladores Kodak em diferentes concentrações (pronto para uso, concentrado diluído em 1:1 e concentrado diluído em 1:3), por meio de curvas características e obtenção das propriedades sensitométricas. Concluíram que o filme radiográfico Ultra-speed apresentou menor sensibilidade e maior contraste em todas as combinações utilizadas. O Ektaspeed apresentou maior densidade base e velamento. O revelador Kodak nas três combinações utilizadas produziu nos filmes analisados, propriedades sensitométricas adequadas, sendo seu uso indicado para o processamento na clínic a diária.

DEZOTTI; TAVANO ${ }^{25}$ em 2000 avaliaram as propriedades sensitométricas do filme Agfa Dentus M2 "Comfort" quando processado na solução Sillib em diferentes combinações: $20^{\circ} \mathrm{C} / 2$ minutos, $25^{\circ} \mathrm{C} / 1$ minuto e $30^{\circ} \mathrm{C} / 0,5$ minuto. Os resultados mostraram que o filme Agfa Dentus M2 "Comfort" alcançou sensibilidade do grupo E em todas as combinações utilizadas. O contraste e a latitude permaneceram dentro de uma faixa de variação aceitável. Concluiu-se que a solução Sillib, nas diferentes combinações utilizadas, produziu propriedades sensitométricas adequadas no filme Agfa Dentus M2 “Comfort”. 
FARMAN; FARMAN ${ }^{29}$, em 2000, compararam as propriedades de um novo filme intrabucal de sensibilidade do grupo F com as obtidas por outros quatro filmes mais antigos dos grupos $\mathrm{D}$ e E, e avaliaram o uso de seis soluções de processamento. Utilizaram os filmes Flow, de sensibilidade do grupo F, o Ektaspeed Plus (E), o Agfa Dentus M2 "Comfort" (E) e o Ultra-speed (D). Foram calculados a densidade base e velamento, a densidade ótica, a sensibilidade, o contraste, a latitude e a resolução. Os resultados mostraram que a escolha da solução processadora pode afetar as propriedades do filme incluindo a sensibilidade. O novo filme do grupo F foi o mais sensível, o Agfa Dentus M2 "Comfort" pôde alcançar a sensibilidade do grupo F e o Ultra-speed, a sensibilidade do grupo E, quando se utilizou a solução Automat XR. O contraste dos filmes foi similar independente da solução utilizada. O novo filme F reduz pela metade a exposição de radiação ao paciente quando comparado com o filme E, sem detrimento da qualidade da imagem.

LUDLOW; PLATIN; MOL $^{66}$, em 2001, avaliaram a sensibilidade, o contraste, a latitude, a resolução e a resposta à química de processamento degradada do filme periapical Insight. Estas características foram comparadas com aquelas dos filmes Ultra-speed e Ektaspeed Plus. Quando o filme foi processado automaticamente em soluções novas, apresentou-se dentro do grupo F de sensibilidade. Nas soluções degradadas progressivamente o filme Insight manteve o contraste. Assim como o filme Ektaspeed Plus, o filme Insight foi capaz de resolver 20 pares de linha por milímetro.

De acordo com GEIST; BRAND ${ }^{37}$, em 2001, o filme Insight é um filme do grupo $\mathrm{F}$ de sensibilidade quando processado automaticamente. Neste estudo o filme Insight apresentou sensibilidade aproximadamente de $25 \%$ a $30 \%$ maior que o Ektaspeed Plus em soluções novas, com uma 
redução na dose de radiação de 20 a $24 \%$. A sensibilidade do filme foi de 66,1 quando processado em soluções novas. Além disso, este filme apresentou maior resistência que o Ektaspeed Plus na redução da sensibilidade quando processado em soluções usadas. $O$ contraste do Insight e do Ektaspeed Plus foi comparável.

CASANOVA $^{15}$, em 2002, avaliou as propriedades do filme Insight, relacionando o tipo de processamento e o efeito da degradação das soluções na qualidade da imagem radiográfica. As comparações foram feitas a partir de análises densitométrica, subjetiva e sensitométricas. Concluiu-se que o filme Insight apresentou redução de $20 \%$ na dose de radiação, quando comparado com o filme Ektaspeed Plus. O filme Insight foi menos susceptível à degradação dos líquidos de processamento, tanto no processamento manual como no automático, em relação ao filme Ektaspeed Plus. Não houve prejuízo da qualidade da imagem radiográfica obtida.

SILVEIRA $^{95}$ et al, em 2002, verificaram se filmes radiográficos de diferentes marcas, processados em diferentes soluções, sob variadas temperaturas, apresentam uma imagem final com mesmo nível de qualidade para diagnóstico. Foram analisados os filmes panorâmicos GB, G30 e TMG, sendo este último da Kodak e os dois primeiros da Fuji. As soluções utilizadas foram Fuji e Kodak e as temperaturas $28^{\circ}, 32^{\circ}$ e $35^{\circ} \mathrm{C}$. A análise estatística demonstrou que os três filmes analisados apresentaram maiores densidades quando processados no revelador Kodak, independentemente da temperatura da solução. O filme Kodak apresentou, na maioria das combinações, densidades maiores, enquanto o filme G30 sempre apresentou as menores densidades. Em relação às condições de temperatura, o processamento a $28^{\circ} \mathrm{C}$ proporcionou as menores densidades, independentemente do filme e solução utilizados. 


\subsection{Radiografia digital}

A imagem digital está sofrendo sensíveis alterações dentro da Odontologia. Novos dispositivos e sistemas de computadores têm sido introduzidos para registrar a imagem produzida pelos raios $\mathrm{X}$ e para sua manipulação, substituindo, desta forma, o filme radiográfico. Este desenvolvimento tem gerado interesse, expectativa, bem como pretensões de superioridade sobre o filme radiográfico ${ }^{26}$.

A tecnologia digital invadiu a vida das pessoas: máquinas de fax, escaneres, computadores, videocâmeras, entre outros; eles usam a mesma tecnologia agora descoberta nos sensores de sistemas digitais. Cirurgiõesdentistas norte-americanos lentamente estão adotando a radiografia digital. Os fabricantes estimam uma porcentagem de 4 a $5 \%$ de clínicos que aderiram ao sistema em 1999, cerca de 6000 a 7000 profissionais do país. Em uma pesquisa feita em 1998, 67\% dos cirurgiões-dentistas norteamericanos responderam que seu maior desejo de aquisição era um sistema de imagem digital ${ }^{76}$.

A Radiologia Convencional, na qual a imagem radiográfica forma-se a partir da ionização dos cristais de prata da emulsão do filme, tem o seu reconhecido valor e importância dentro da Odontologia, sendo um método extensamente utilizado para diagnóstico. O filme radiográfico, nosso receptor de imagens neste caso, nos oferece uma imagem de qualidade com um preço relativamente baixo. Além disso, a introdução no mercado de filmes radiográficos cada vez mais sensíveis e com qualidade de imagem, contribuem para a perpetuação deste método de aquisição de imagens. Porém, este método ainda apresenta algumas desvantagens como: ineficiência como fóton-receptor, pois absorve apenas pequeno percentual da totalidade de fótons que colidem sobre ele; fornece uma imagem estática 
e que não pode ser alterada; requer um processamento que deve ser realizado sob condições ideais, para que não haja perda de informações; utiliza-se de soluções químicas que podem provocar alergias e causar danos ao meio ambiente; requer uma dose de radiação relativamente alta e é muito sensível às variações nos tempos de exposições aos raios $\mathrm{X}^{10}$.

Digitalizar uma imagem, tornando-a uma matriz, significa transformá-la em dados numéricos e colocá-los na memória de um computador. Isto é feito por um processo chamado amostragem. A amostragem consiste em dividir a imagem original em pequenos quadrados e retângulos (amostras) e associar a cada um deles um número que representa a cor daquele pedaço da imagem. Isso faz com que se represente a imagem como um conjunto de números que pode ser armazenado na memória de um computador. A cada quadrado, que pode ser considerado um ponto da imagem devido ao seu tamanho reduzido, dá-se o nome de pixel. Uma imagem digital de boa qualidade é formada de centenas de milhares de pixels, cada um deles contendo um número com a informação da cor daquele ponto na imagem. Deste modo, o número de tons de cinza disponíveis no sistema digital determina a densidade da imagem e, em geral, o padrão para a radiografia intrabucal é a digitalização da imagem em 256 tons de cinza, onde o valor 0 (zero) representa o preto e o valor 255, representa o branco. Os demais tons de cinza estão entre os dois valores $^{115}$.

Hoje em dia, podemos obter imagens digitalizadas por meio de dois métodos, o indireto e o direto ${ }^{12,18,28,30,35,36,45,46,91,96,114,116,117,119,120,123}$.

Pelo método indireto, a imagem pode ser capturada de uma radiografia convencional por meio de escaneres de alta definição composto de um leitor de transparência que faz o papel de um negatoscópio, incidindo uma luz através da imagem permitindo assim a digitalização e, 
em seguida, esta imagem é enviada a um computador onde é visualizada em um monitor e analisada ou modificada por programas apropriados.

O método direto usa um sensor intrabucal para capturar a imagem, podendo-se utilizar dois métodos para esta finalidade. Um destes métodos é o Charge-Coupled-Device (CCD - dispositivo acoplado de carga), que por um cabo, envia o sinal elétrico produzido pelos raios $\mathrm{X}$ ao microcomputador. $\mathrm{O}$ sinal obtido do $\mathrm{CCD}$, após a exposição à radiação, é armazenado e convertido pixel por pixel em 256 níveis de cinza. A possibilidade de analisar, modificar, medir e quantificar a densidade da imagem radiográfica diretamente no monitor do microcomputador é possível pela tecnologia da radiografia digital. O sensor intrabucal, o hardware e o software associados substituem o filme e o processamento radiográfico $^{10,78}$.

O efeito de variar a resolução de profundidade da escala de cinza e filtragem da imagem de radiografias periapicais para detectar lesões ósseas foi discutido por WENZEL ${ }^{122}$, em 1987 e WENZEL ${ }^{121}$, em 1988. As radiografias foram digitalizadas por câmera CCD gerando uma matriz de 512x512 pixels e resolução da escala de cinza variável de 256 a 32 tons de cinza. Concluiu-se que quando se utilizou a resolução de 256 tons, o diagnóstico foi equivalente ou até melhor em algumas regiões do que o obtido com a radiografia convencional. Quando se utilizaram 128 e 64 tons de cinza o diagnóstico foi equivalente à radiografia original. Com 32 tons, o diagnóstico foi menos preciso do que com a radiografia original. Para testar o efeito de filtros utilizaram-se três tipos de tratamento: filtros, alteração de contraste e pseudocolorização. Os estudos deixaram evidente que a detecção de lesões ósseas na mandíbula pode ser melhorada pelo tratamento de imagem. 
A melhora da qualidade da imagem de radiografias panorâmicas, com o uso de um sistema de processamento digital indireto da imagem foi verificada por FUJITA ${ }^{35}$ et al, em 1987. A qualidade e a visibilidade de detalhes das radiografias digitalizadas foram melhores do que estes fatores nas radiografias originais. Os autores concluíram que o diagnóstico radiográfico pode ser melhorado com o uso deste sistema.

FUJITA $^{36}$ et al, em 1988, após estudarem radiografias periapicais, que foram escaneadas e transmitidas para a memória de um computador, concluíram que quando comparadas às imagens originais, as imagens digitalizadas apresentaram mais ruídos e artefatos, prejudicando muitas vezes a interpretação radiográfica. Uma melhora do contraste radiográfico foi obtida e, segundo estes autores, esta tecnologia pode ser empregada em casos de radiografias com baixo contraste.

BROOKS; MILES ${ }^{12}$, em 1993, discutiram as novas modalidades de captura de imagens utilizadas em Odontologia. A imagem radiográfica de um filme convencional pode ser convertida para um sinal digital, utilizando-se para isto, um escaner. Uma vez a imagem armazenada em um computador, um grande número de operações pode ser realizado, incluindo a subtração digital, que acompanha a progressão da doença durante o período de avaliação do tratamento periodontal e terapia endodôntica.

Segundo DUNN; KANTOR ${ }^{26}$, em 1993, o processamento da imagem radiográfica não aumenta o conteúdo da informação. A atual tecnologia limita o conteúdo das informações nos sensores digitais, que não são iguais aos filmes radiográficos convencionais. Os sensores podem capturar e mostrar uma imagem muito mais rápido que o filme e, num futuro próximo, poderão apresentar uma capacidade para diagnóstico equivalente ao filme radiográfico. A habilidade do observador para 
enxergar detalhes na imagem radiográfica é limitada pelas propriedades da imagem e pelo sistema visual do observador.

ZUBERY; DOVE; EBERSOLE ${ }^{130}$, em 1993, propuseram o sistema de avaliação radiográfica auxiliada por computador (CARE) que se baseia na variação logarítmica para detectar pequenas mudanças na densidade ótica. Os autores sugerem que os sistemas para análise quantitativa das mudanças de densidade sejam avaliados baseados em estudos clínicos, incluindo reprodutibilidade, validade e variação ótima da densidade ótica de cada sistema de trabalho individual.

Em 1996, KERBAUY; MORAES ${ }^{56}$ avaliaram se radiografias periapicais digitalizadas, tomadas com tempo de exposição reduzido, poderiam ser melhoradas com o auxílio de um programa de computador para tratamento digital da imagem. Utilizaram radiografias de áreas de molares e pré-molares inferiores, tomadas em série e padronizadas. 57 imagens com tempo de exposição reduzido (60\% a $80 \%$ do tempo considerado normal), foram digitalizadas, tratadas e submetidas à avaliação por sete examinadores que as compararam com as imagens não tratadas. Verificaram que cerca de $80 \%$ das imagens equivalentes às radiografias tomadas com redução de $60 \%$ da dose habitual foram consideradas de qualidade para elaboração de diagnóstico. Quanto às imagens radiográficas tomadas com $80 \%$ de redução do tempo de exposição, cerca de $50 \%$ foram consideradas adequadas para o mesmo propósito.

Para comparar a técnica periapical do paralelismo com os sistemas de imagens digitalizadas, de maneira que estes recursos sejam usados de forma segura e generalizada, ZENÓBIO; FERREIRA ${ }^{129}$, em 1997, obtiveram uma radiografia pela técnica do paralelismo, que foi submetida à digitalização, utilizando um escaner. Determinou-se a área de interesse para análise e a colorização para determinar as estruturas de maior 
radiolucidez e radiopacidade, utilizando o seguinte esquema de cores: vermelho - radiolúcido; amarelo - radiopacidade parcial e verde radiopaco. Concluíram que o processo de digitalização de imagens possibilita a identificação mais precisa da perda óssea, sendo o mesmo, uma boa opção para o diagnóstico. Apesar do desenvolvimento e aperfeiçoamento desta tecnologia, a aproximação da relação custo/benefício do uso deste sistema, sua viabilidade e praticidade comparados com o sistema convencional, ainda dificultam sua utilização na Clínica Odontológica.

CHEN; CHIANG ${ }^{18}$, em 1997, avaliaram o desempenho físico de um escaner tipo roller. Utilizaram o escaner VXR-12 para digitalizar imagens do filme Kodak T-Mat G. As radiografias foram submetidas a leituras com um fotodensitômetro. Em seguida foram escaneadas e também submetidas a leituras da densidade ótica no computador. Os valores de pixel da imagem foram avaliados. Os resultados mostraram que as imagens digitalizadas apresentaram valores de pixels distribuídos em uma variação dinâmica similar àquela do fotodensitômetro.

SILVA $^{94}$, em 1999, verificou uma possível substituição do método convencional, para avaliação de filmes radiográficos e atividade de soluções de processamento, pelo método digital, utilizando o programa de imagem Adobe Photoshop 4.0. Foram utilizadas tiras de filmes radiográficos extrabucais TMS-1, expostas no sensitômetro MRA por 0,5 segundo e processadas automaticamente, a $27^{\circ}, 29^{\circ}, 31^{\circ}$ e $34^{\circ} \mathrm{C}$. As soluções foram avaliadas quanto a sua atividade, degradação e uso em diferentes temperaturas. Os processamentos mais eficientes foram alcançados utilizando as temperaturas de $31^{\circ}$ e $34^{\circ} \mathrm{C}$. A análise estatística, obtida pela Correlação de Pearson, mostrou alta significância de resultados em todas as temperaturas avaliadas quanto à quantificação dos níveis de 
cinza das imagens após a digitalização dos filmes radiográficos e a densidade ótica obtida no fotodensitômetro. $\mathrm{O}$ autor concluiu ser possível a substituição de um método pelo outro quando se utiliza o programa de imagem Adobe Photoshop 4.0, com o objetivo de avaliar densidade ótica e quantificação dos níveis de cinza, sendo o método digital mais objetivo e rápido.

O programa Digora for Windows 1.51 como recurso de Controle de Qualidade, dada a sua aplicação prática para filmes odontológicos, foi analisado por $\mathrm{PAVAN}^{80}$, em 1999, quando realizou um estudo para verificar se o aumento de temperatura das soluções processadoras modificaria a qualidade da imagem. Concluiu que o uso de imagens digitalizadas pode substituir a avaliação das imagens radiográficas realizadas com um fotodensitômetro em filmes periapicais processados manualmente. As combinações $25^{\circ} \mathrm{C} / 3$ minutos e $35^{\circ} \mathrm{C} / 1$ minuto, utilizando a solução Kodak e filmes periapicais Ultra-speed, quando comparadas com a padrão (Kodak a $20^{\circ} \mathrm{C} / 5$ minutos) apresentaram maiores valores de densidade ótica, bem como de quantificação dos níveis de cinza em função de permanecerem tempo maior do que o necessário sob a ação dos agentes reveladores. As combinações $35^{\circ} \mathrm{C} / 15$ segundos, $40^{\circ} \mathrm{C} / 15$ segundos e $40^{\circ} \mathrm{C} / 10$ segundos apresentaram valores inferiores de densidade ótica e quantificação dos níveis de cinza e baixa qualidade de imagem, por permanecerem por menor tempo sob a ação da solução reveladora.

IWAKI $^{52}$, em 2000, comparou a densidade ótica obtida no fotodensitômetro com a quantificação dos níveis de cinza fornecidas pelo sistema Digora for Windows 2.0, a fim de verificar uma possível substituição do método convencional pelo método digital, para avaliar o comportamento de tiras sensitométricas obtidas com filmes radiográficos TMS-1 sensibilizadas pelo sensitômetro IDIM e processadas na solução RP 
X-Omat em uma processadora automática. Além disso, foi comparada a média da quantificação dos níveis de cinza obtida após medidas individualizadas em cada faixa produzida pelo sensitômetro IDIM na tira sensitométrica (19 faixas) com a média da medida total de todas as faixas tomadas conjuntamente. Após o estudo comparativo entre densidade ótica e quantificação dos níveis de cinza, os resultados mostraram, pela Correlação de Pearson, alta significância estatística, comprovando-se a validade e eficácia deste método de análise do comportamento de filmes radiográficos e atividade de soluções de processamento. A quantificação dos níveis de cinza assim como a densidade ótica detectou na mesma proporção a perda da atividade das soluções de processamento. Houve uma grande concordância dos valores quando a solução era nova e uma pequena oscilação quando a solução se apresentava exaurida e/ou degradada.

Esta metodologia foi também utilizada no trabalho de DEZOTTI $^{23}$, em 2000, quando avaliou as propriedades sensitométricas do filme Agfa Dentus M2 "Comfort" (sensibilidade, contraste e latitude) processado nas soluções de processamento Agfa Dentus, Kodak e Sillib em diferentes combinações de temperatura/tempo. Foram traçadas curvas características a partir das médias de densidades óticas obtidas em quatro radiografias expostas e processadas para cada grupo. Os resultados mostraram que o filme alcançou sensibilidade do grupo $F$ quando se utilizou a solução Agfa Dentus nas três diferentes combinações. Nas soluções Kodak e Sillib o filme alcançou sensibilidade do grupo E, nas diferentes combinações. O filme apresentou, em todas as soluções e combinações utilizadas, contraste dentro de uma faixa de normalidade, variando de $1,72\left(\operatorname{Kodak} 30^{\circ} \mathrm{C}\right)$ a 2,21 (Sillib $25^{\circ} \mathrm{C}$ ). A maior latitude foi observada quando se utilizou a solução Kodak na temperatura de $30^{\circ} \mathrm{C}$ e a menor, com a solução Sillib a $25^{\circ} \mathrm{C}$. O filme apresentou propriedades 
sensitométricas adequadas quando processado nas três soluções e nas diferentes combinações temperatura/tempo. Neste trabalho foi também confirmada a observação de que a obtenção das densidades óticas pode ser substituída pelo método digital, utilizando-se o programa de imagem Adobe Photoshop 5.0. Concluiu-se que a densidade ótica e a quantificação dos níveis de cinza podem ser usadas na Clínica Odontológica, no Controle de Qualidade radiográfica para verificação da atividade de soluções de processamento, visto que, sob diferentes condições utilizadas no experimento, houve grande correlação estatística entre os valores das mesmas, com um nível de confiança de $95 \%$ para todos os grupos.

A imagem digitalizada tem ampla aplicabilidade nas diferentes Especialidades Odontológicas, tendo ainda maiores perspectivas à medida que novas técnicas vão sendo desenvolvidas e dificuldades inerentes ao método, resolvidas. A utilização da imagem digital para estudo das propriedades do filme radiográfico e atividade das soluções processadoras $^{24,109}$ vem, mais uma vez, contribuir para o avanço da Radiologia Odontológica. 


\subsection{Análise morfométrica da prata}

O que ocorre nos cristais de prata da emulsão do filme radiográfico, que formarão a imagem radiográfica, é pouco conhecido. Dois trabalhos realizados no Departamento de Estomatologia da Faculdade de Odontologia de Bauru, nos anos de $1987^{70}$ e $1988^{75}$, analisaram microscopicamente estes cristais. A morfometria é um método consagrado na Histologia para contagens de células e foi utilizado nestes trabalhos para analisar o que ocorre nos cristais de prata dos filmes radiográficos, sob diferentes condições de processamento.

MATOS $^{70}$, em 1987, teve como finalidade analisar um novo método de medida, a quantidade de prata metálica formada na emulsão de filmes radiográficos, após o seu processamento. $\mathrm{O}$ método proposto na época baseava-se na determinação da densidade de volume de prata reduzida em função das variáveis: exposição aos raios $\mathrm{X}$, tipo de filme e de soluções de processamento. Foram utilizadas, para controle e comparação, as densidades óticas, obtidas em fotodensitômetro. De acordo com esta pesquisa a determinação da densidade de volume ocupado pela prata metálica baseia-se nos princípios de morfometria. Foi utilizado uma ocular com retículo de 25 pontos em um microscópio de luz, com objetiva de 97X. No microscópio, após a focalização do filme radiográfico, contaram-se os pontos coincidentes do retículo com os cristais de prata. Todas as faixas de exposição em cada um dos filmes radiográficos processados foram analisadas. A comparação do método proposto, com o já consagrado da densitometria ótica e respectivos traçados característicos, foi realizada por meio de análises estatísticas e gráficas. Os coeficientes de correlação apresentaram níveis elevados, fato este confirmado graficamente pela similaridade dos traçados característicos obtidos pelos dois métodos de 
medida. Pelos resultados alcançados, chegou-se à conclusão que o método proposto também é válido para a verificação do efeito dos raios $\mathrm{X}$ sobre a emulsão de filmes radiográficos periapicais, podendo ser utilizado, portanto, nas pesquisas que visam analisar o comportamento de filmes e processamentos radiográficos.

MENDONÇA ${ }^{75}$, em 1988, avaliou o filme Ektaspeed processado nas soluções Kodak e Inodon, por meio de análises consagradas em Radiologia Odontológica, como a densidade ótica, medidas de $\mathrm{pH}$ e cor da solução após o uso e a metodologia da quantificação de prata metálica na emulsão do filme radiográfico pela densidade de volume. Os resultados de densidade ótica permitiram a representação gráfica por meio de um traçado característico e serviram para controle e comparação com a densidade de volume de prata, tanto no experimento de processamento quanto para o teste com fins de verificar a exaustão das soluções. Verificou-se que a solução Kodak mostrou sinais indicativos de exaustão na $45^{\text {a }}$ radiografia do simulador de mandíbula, quando foi observado o aparecimento de estrias sobre a imagem radiográfica. A solução Inodon mostrou dificuldade de boa atividade reveladora e de fixação a partir da $10^{\mathrm{a}}$ radiografia. Por meio da análise microscópica dos filmes radiográficos foram constatadas alterações morfológicas e quantitativas de prata metálica formada em função do tempo de exposição, tempo de processamento e exaustão das soluções empregadas neste estudo. Com base nos resultados alcançados, concluiu-se que a quantificação da prata metálica da emulsão radiográfica realmente comprova sua eficácia como um novo método de avaliação em Radiologia, principalmente com referência aos testes realizados neste trabalho.

Em 1999, CAVALCANTE; TAVANO ${ }^{17}$ observaram a morfologia da prata metálica formada na emulsão de filmes radiográficos periapicais (Agfa M2 e Ektaspeed), processados nos líquidos convencional 
(Kodak) e monobanho (Inodon). Após a avaliação microscópica da morfologia da prata metálica, realizaram leituras das densidades óticas e confecção de curvas características. Os resultados mostraram que os cristais de prata metálica formados no filme Ektaspeed processado nas soluções Kodak e Inodon foram sempre maiores do que os do filme Agfa M2. A solução Inodon mostrou deposição dos cristais de prata, em ambos os filmes, mais irregular e desorganizada. Esta solução, por apresentar maior quantidade de revelação física, provocou o aparecimento de uma granulação de prata maior do que o da solução Kodak, em qualquer dos filmes analisados. A solução Kodak promoveu em ambos os filmes a deposição mais homogênea dos cristais de prata. As curvas características comprovaram os dados fornecidos pelos fabricantes quanto ao contraste e latitude. O filme Agfa M2 apresentou densidade base e velamento, densidade média e densidade máxima maiores do que os mesmos parâmetros do Ektaspeed. O filme Agfa M2 foi mais sensível que o Ektaspeed em ambos os processamentos. 
3. Proposição 


\section{PROPOSIÇÃO}

Utilizando filmes radiográficos periapicais da Kodak (Ultraspeed e Insight) processados em duas diferentes soluções (Kodak e Sillib), em condições variadas de temperatura/tempo $\left(20^{\circ} \mathrm{C} / 5\right.$ minutos, $25^{\circ} \mathrm{C} / 2,5$ minutos e $30^{\circ} \mathrm{C} / 1,25$ minuto para a solução Kodak e $20^{\circ} \mathrm{C} / 2$ minutos, $25^{\circ} \mathrm{C} / 1$ minuto e $30^{\circ} \mathrm{C} / 0,5$ minuto para a solução Sillib), objetivou-se:

- Estudar as propriedades sensitométricas (sensibilidade e contraste) do filme radiográfico Insight, do grupo E/F de sensibilidade e compará-las com as propriedades do filme Ultra-speed, do grupo D de sensibilidade;

Analisar qual a melhor combinação filme/solução/temperatura/tempo e a possibilidade de seu uso na clínica diária;

- Correlacionar três diferentes métodos de análise do comportamento de filmes radiográficos e da atividade das soluções de processamento (método convencional, digital e morfométrico). 
4. MATERIAL E MÉtodos 


\section{MATERIAL E MÉTODOS}

\subsection{Material}

\subsubsection{Filmes radiográficos, soluções processadoras e aparelho de raios $X$}

Utilizaram-se 48 filmes radiográficos: 24 Ultra-speed (DF-58), do grupo D de sensibilidade e 24 Insight (IP-21), do grupo E/F de sensibilidade, fabricados pela Eastman Kodak Company, Rochester, New York - USA (Figura 1).

Com o propósito de se obter um padrão de qualidade neste experimento, todos os filmes de cada tipo foram retirados de uma mesma caixa, portanto, com a mesma data de validade, que era de no mínimo um ano após o término do experimento.

Utilizaram-se as soluções de processamento radiográfico, compostas de revelador e fixador Kodak, fabricada pela Kodak do Brasil Comércio e Indústria Ltda., São José dos Campos - BR e Sillib, fabricada pela Polidental Indústria e Comércio Ltda., São Paulo - BR, seguindo as instruções dos fabricantes (Figura 2).

Utilizou-se um aparelho de raios X General Eletric, modelo 100, operando com $40 \mathrm{kVp}$ e $15 \mathrm{~mA}$, tendo uma filtragem total equivalente a 2,5 milímetros de alumínio, da Disciplina de Radiologia da Faculdade de Odontologia de Bauru - USP.

A norma PH 2.9 - 1964 da AMERICAN STANDARDS ASSOCIATION $^{7}$ recomenda que quando há variação da quilovoltagem no aparelho de raios X, deve-se utilizar aquela que permita uma redução da dose pela metade, quando se acrescentam dois milímetros de alumínio à filtragem inerente do aparelho. 
A precisão do marcador do tempo de exposição foi confirmada utilizando-se um cronômetro de raios X, da marca MRA, fabricado pela Indústria e Comércio de Eletrônica, Ribeirão Preto - BR, que tem a função de medir o tempo de exposição em função da radiação real produzida pela área focal do aparelho.

\subsubsection{Exposição aos raios $X$ e processamento radiográfico}

Utilizou-se um dispositivo para a exposição padronizada dos filmes radiográficos aos raios $\mathrm{X}$, também utilizado por IUCIF; TAVANO ${ }^{51}$, em 1995, TAVANO; CAPELOZZA; FONTÃO ${ }^{107}$ em 1996 e DEZOTTI ${ }^{23}$ 2000. Este dispositivo é composto de uma lâmina de chumbo de $17 \times 23 \mathrm{~cm}$ e $2 \mathrm{~mm}$ de espessura, onde foram realizadas aberturas, de maneira que apenas 1/5 de cada filme fosse exposto (cerca de $9 \mathrm{~mm}$ ). Esta placa de chumbo foi fixada em uma moldura de madeira de modo a centralizá-la com o feixe de raios $\mathrm{X}$ durante a exposição. Os filmes foram presos com uma fita adesiva na parte posterior da placa de chumbo, com a superfície a ser exposta, uma de cada vez, voltada para o aparelho de raios X. Este dispositivo apresenta em sua outra extremidade um suporte de madeira com um apoio para o cabeçote do aparelho de raios X, que mantém a distância foco-filme fixa em $50 \mathrm{~cm}$ (Figura 3).

O processamento dos filmes radiográficos foi realizado na câmara escura do Departamento de Radiologia da Faculdade de Odontologia de Bauru - USP, equipada com os seguintes acessórios:

- Cronômetro Gra-Lab;

- Aquecedor de imersão;

- Termômetro de imersão Premium;

- Tanques com capacidade de 20 litros para lavagem final; 
- Quatro recipientes de vidro com capacidade de $200 \mathrm{ml}$ cada um;

- Um recipiente contendo água com capacidade para 1000ml.

Para a revelação, banho intermediário e fixação, foram utilizadas colgaduras individuais. Colgaduras com 14 grampos foram utilizadas para a lavagem final no tanque de água corrente e secagem dos filmes radiográficos.

\subsubsection{Aparelho fotodensitômetro}

As leituras das Densidades Óticas (D.O.) foram realizadas em um fotodensitômetro da marca MRA (Figura 4), fabricado pela Indústria e Comércio de Eletrônica, Ribeirão Preto - BR, calibrado de acordo com as instruções do fabricante. Este aparelho apresenta as seguintes características:

- Dimensões de 31 x 26 x 21cm;

- Estabilizador eletrônico de voltagem incorporado contra variações da tensão de alimentação;

- Abertura luminosa de $1 \mathrm{~mm}$ de diâmetro;

- Mostrador digital com "leds" de 12,3mm;

- Filtro seletor rotativo;

- Leitura logarítmica direta da D.O.;

- Controle de zeragem e

- Precisão de 0,02. 


\subsubsection{Captura das imagens, microscopia e leituras computadorizadas}

Utilizou-se um computador Pentium III, 320 MB de RAM, 10 GB de HD, CD ROM 24X, com placa de vídeo de 16 MB e monitor LG, gerenciado pelo programa Windows 98, para o processamento dos dados obtidos com o fotodensitômetro (Densidade Ótica), e com o programa Adobe Photoshop 5.5. (quantificação dos níveis de cinza e Densidade de Volume de prata).

Utilizou-se um escaner de mesa ScanMaker II SP da Microtek, tendo como acessório um leitor de transparência que permitiu a varredura da imagem e a digitalização dos filmes radiográficos. As imagens foram escaneadas com 300dpi e salvas no formato jpeg, com máxima qualidade, sem perda. Estas imagens foram, então, transmitidas para a memória do computador, onde pudemos realizar a quantificação dos níveis de cinza. Para cópia de segurança dos arquivos de imagens obtidas utilizou-se um gravador de CD da Creative e um compact disc de $650 \mathrm{MB}$.

Um sistema de análise digitalizada, composto por um microscópio Zeiss Axioskop 2 com objetiva de imersão de 100X, câmera CCD-IRIS RGB - Sony e programa Kontron KS300 (Kontron Electronic GMBM), do Departamento de Histologia da Faculdade de Odontologia de Bauru foi utilizado para a captura das imagens para leitura microscópica dos cristais de prata da emulsão dos filmes radiográficos. Para tanto, foram capturadas três imagens da faixa de 1 impulso de exposição de um filme radiográfico de cada combinação solução/temperatura, selecionadas por amostragem sistemática, totalizando 36 imagens. Estas imagens foram capturadas com 72dpi e salvas no formato jpeg, com máxima qualidade, sem perda. 
Foi utilizado o programa Adobe Photoshop 5.5 (Adobe Systems Incorporated, San José, Ca 95110-2704 USA) para a quantificação dos níveis de cinza e para análise morfométrica dos cristais de prata da emulsão dos filmes radiográficos, processados nas diferentes combinações. 


\subsection{Métodos}

\subsubsection{Exposição dos filmes aos raios $X$, processamento radiográfico e leituras das Densidades Óticas}

Foram expostos 48 filmes radiográficos, 12 de cada tipo (Ultraspeed e Insight) para cada solução (Kodak e Sillib), sendo quatro para cada temperatura $\left(20^{\circ}, 25^{\circ}\right.$ e $\left.30^{\circ} \mathrm{C}\right)$, pois o experimento foi repetido quatro vezes a fim de se obter resultados mais consistentes e padronizados.

Os filmes foram expostos no dispositivo de chumbo que permitiu a exposição de apenas uma parte de cada filme (1/5) de cada vez. Os tempos de exposição utilizados foram 1, 10, 60 e 300 impulsos. Foram expostos quatro filmes de cada vez e as exposições foram realizadas em seqüência, começando da maior (300 impulsos - faixa 4), para a menor (1 impulso - faixa - 1), ficando a última faixa sem ser exposta, representando a densidade base e velamento (DBV - faixa 0), na qual foram observadas as alterações produzidas no filme radiográfico pela atuação apenas das soluções processadoras. Entre os diferentes tempos de exposição houve um intervalo de cinco minutos. Entre a exposição dos filmes e o processamento houve um intervalo de no mínimo duas horas e no máximo 24 horas, permitindo, desta maneira, que as ionizações causadas nos cristais de prata da emulsão se estabilizassem, formando uma imagem latente, de acordo com a norma PH 2.9 de 1964 da AMERICAN STANDARDS ASSOCIATION $^{7}$. O período de esvaecimento da imagem se inicia após 24 horas da exposição.

Os filmes foram identificados previamente às exposições com números de chumbo fixados em sua parte superior, correspondentes à solução processadora e à temperatura utilizada, na seguinte ordem: 


\section{Para o filme Ultra-speed:}

(4) Solução reveladora Kodak na temperatura de $20^{\circ} \mathrm{C} / 5$ minutos;

(5) Solução reveladora Kodak na temperatura de $25^{\circ} \mathrm{C} / 2,5$ minutos;

(6) Solução reveladora Kodak na temperatura de $30^{\circ} \mathrm{C} / 1,25$ minuto;

(7) Solução reveladora Sillib na temperatura de $20^{\circ} \mathrm{C} / 2$ minutos;

(8) Solução reveladora Sillib na temperatura de $25^{\circ} \mathrm{C} / 1$ minuto;

(9) Solução reveladora Sillib na temperatura de $30^{\circ} \mathrm{C} / 0,5$ minuto.

\section{Para o filme Insight:}

(1) Solução reveladora Kodak na temperatura de $20^{\circ} \mathrm{C} / 5$ minutos;

(2) Solução reveladora Kodak na temperatura de $25^{\circ} \mathrm{C} / 2,5$ minutos;

(3) Solução reveladora Kodak na temperatura de $30^{\circ} \mathrm{C} / 1,25$ minuto;

(4) Solução reveladora Sillib na temperatura de $20^{\circ} \mathrm{C} / 2$ minutos;

(5) Solução reveladora Sillib na temperatura de $25^{\circ} \mathrm{C} / 1$ minuto;

(6) Solução reveladora Sillib na temperatura de $30^{\circ} \mathrm{C} / 0,5$ minuto.

O processamento radiográfico foi realizado em câmara escura utilizando-se o método temperatura/tempo, garantindo sua precisão com o cronômetro elétrico. Durante o processamento manual dos filmes radiográficos não foram ligadas luzes de segurança. O processamento radiográfico foi realizado em uma só etapa, procurando, desta maneira, máxima padronização.

Os filmes foram processados em etapas de acordo com a solução e as temperaturas utilizadas. Inicialmente foram processadas as quatro primeiras radiografias expostas com o filme Ultra-speed. A solução utilizada foi a Kodak na temperatura de $20^{\circ} \mathrm{C}$. As radiografias foram dispostas na bancada da câmara escura e então presas em grampos individuais e levadas, duas a duas, aos recipientes de vidro com capacidade 
para $200 \mathrm{ml}$ contendo a solução reveladora a $20^{\circ} \mathrm{C}$. O tempo de revelação foi de cinco minutos para esta temperatura. $\mathrm{O}$ mesmo procedimento foi repetido para a solução Sillib nas três temperaturas, alterando-se apenas o tempo de revelação. Em seguida foram repetidos os mesmos procedimentos e sequiências para o filme Insight. Os recipientes contendo as soluções foram colocados dentro de um outro recipiente de vidro com capacidade para $1000 \mathrm{ml}$ contendo água. Dentro deste recipiente maior foi colocado um aquecedor de imersão elétrico para o aquecimento da água, mantendo as soluções em banho-maria na temperatura desejada para a realização do experimento.

Após a revelação todas as películas foram processadas da seguinte maneira:

- banho intermediário - as películas foram transferidas para um recipiente contendo água corrente, onde foram submetidas à lavagem intermediária por 20 segundos;

- a solução fixadora foi dividida em dois recipientes de vidro com capacidade para $200 \mathrm{ml}$, onde as radiografias foram fixadas duas a duas por um tempo de dez minutos;

- as películas foram removidas dos grampos individuais e transferidas para uma colgadura Kodak para 14 películas e então levadas à lavagem final em água corrente durante 20 minutos. Após secas em estufa própria, as radiografias foram acondicionadas em envelopes individuais para cada um dos grupos utilizados.

Após as exposições e o processamento padronizado dos filmes obtivemos radiografias com cinco diferentes faixas de densidade, para as duas soluções, nas temperaturas de $20^{\circ} \mathrm{C}, 25^{\circ} \mathrm{C} \mathrm{e} 30^{\circ} \mathrm{C}$ (Figura 5).

Para realizarmos as medidas da Densidade Ótica escolhemos dez pontos em cada faixa onde, então, aplicamos a área ativa do 
fotodensitômetro (Figura 4). Estas medidas foram anotadas em tabelas próprias e posteriormente realizaram-se as médias destas 10 leituras. Foram confeccionadas Curvas Características para a obtenção das propriedades sensitométricas.

\subsubsection{Construção das Curvas Características}

Os dados obtidos das leituras das Densidades Óticas, com o fotodensitômetro, depois de anotados em tabelas próprias, foram transferidos para um gráfico, para a confecção das Curvas Características e obtenção das propriedades sensitométricas.

Foram construídas 12 Curvas Características, uma para cada combinação filme/solução/temperatura/tempo. A Curva Característica foi construída da seguinte maneira: os valores de exposição foram plotados no eixo $\mathrm{X}$ (abscissa), enquanto que no eixo $\mathrm{Y}$ (ordenada) foram marcadas as Densidades Óticas obtidas das radiografias em estudo. Os valores de exposição em impulsos emitidos a cada faixa foram transformados em valores de uma escala logarítmica, de maneira a facilitar a construção das curvas, tornando o gráfico mais compacto. As Densidades Óticas correspondem a números absolutos e são funções logarítmicas da quantidade de luz que atravessa a radiografia. Uma radiografia tem Densidade Ótica igual a 1,0 quando ela deixa passar 1/10 da luz que incide sobre ela. As exposições relativas foram marcadas de acordo com os impulsos dados em cada faixa de exposições dos filmes: 300, 60, 10, 1 e 0.

O contraste radiográfico é representado por um valor numérico chamado gradiente médio, que é a tangente do ângulo formado por uma reta que liga dois pontos de densidades específicas de uma Curva Característica. Traçam-se duas retas paralelas ao eixo $\mathrm{X}$ a partir da 
Densidade Ótica 0,25 e 2,0 acima da densidade base e velamento, até encontrar a Curva Característica. Em seguida traça-se uma reta que liga estes dois pontos. A tangente do ângulo formado por esta reta e o eixo $\mathrm{X}$ refere-se ao valor de contraste.

A sensibilidade refere-se ao posicionamento da curva ao longo do eixo $\mathrm{X}$ e pode ser definida como exposição requerida para produzir a densidade de 1,0 acima da DBV. Traçou-se uma paralela ao eixo X, a partir da Densidade Ótica 1,0 mais DBV do eixo Y, até encontrar a curva. Deste cruzamento traçou-se uma paralela ao eixo $\mathrm{Y}$, até encontrar o eixo $\mathrm{X}$, ponto correspondente à sensibilidade do filme.

\subsubsection{Digitalização e análise das imagens}

Depois de obtidas as Curvas Características, realizou-se a captura de imagens dos mesmos filmes radiográficos e sua transmissão à memória do computador utilizando-se o escaner. Realizou-se, então, a leitura da quantificação dos níveis de cinza com o programa Adobe Photoshop 5.5.

As imagens dos filmes radiográficos foram avaliadas da seguinte maneira: abriu-se o programa e a imagem que se desejava examinar; após o seu aparecimento, clicou-se no ícone imagem e, em seguida, em inverter. Optou-se por realizar a análise na imagem invertida em virtude de trabalhos anteriores $^{23,24,52,80,94,109}$ mostrarem que os valores da quantificação dos níveis de cinza da imagem invertida acompanham a mesma tendência dos valores das Densidades Óticas, diferentes dos valores da quantificação dos níveis de cinza obtidos com a imagem no modo normal. Quando utilizamos a forma invertida a correlação estatística é positiva diferente da correlação negativa observada com o modo normal, quando os valores das faixas de menores densidades, apresentam valores mais altos, diferentes dos valores 
mais baixos observados na leitura da Densidade Ótica no fotodensitômetro para as mesmas faixas. A imagem tornou-se invertida e, então, escolheu-se, no item ferramenta, a forma retangular. Em seguida, em opções, colocamos forma fixa, com largura de 150 pixels e altura de 50 pixels. Depois, arrastamos a forma sobre a primeira faixa de densidade, clicamos em imagem e em seguida em histograma, que nos mostrou como resultado a média dos níveis de cinza, a mediana e o desvio padrão da área selecionada. Repetimos o mesmo procedimento para todas as faixas de diferentes exposições (impulsos) em todos os grupos (Figura 6). Estes dados foram anotados em fichas próprias para serem, então, submetidos à análise estatística e comparados com os valores obtidos de Densidades Óticas (ANEXO 25).

\subsubsection{Análise morfométrica da prata na emulsão dos filmes radiográficos}

Os filmes foram fixados em uma lamínula de vidro com uma fita adesiva. Foi utilizado o programa Kontron KS300 (Kontron Electronic GMBM) para a captura das imagens, que foram armazenadas em um compact disc de $650 \mathrm{MB}$. Foram selecionadas três áreas distintas da faixa que recebeu 1 impulso de exposição de uma radiografia de cada combinação, por ser esta a faixa que permitia a melhor visualização da disposição dos cristais de prata depositados na emulsão. A partir destas três medidas, obtivemos uma média para cada combinação solução/temperatura/tempo com cada tipo de filme (Ultra-speed e Insight). As imagens foram analisadas no programa Adobe Photoshop 5.5 onde se avaliaram, subjetivamente, o tamanho e a forma dos cristais de prata e formação de aglomerações dos cristais e, objetivamente, a Densidade de Volume de prata, por porcentagem depositada por campo (Figura 7). O 
programa foi aberto e clicou-se na imagem que se desejava examinar; após o seu aparecimento clicou-se em ajuste e escolheu-se o filtro Threshold. A imagem passou para os tons branco e preto e escolheu-se o nível de 199. Em seguida clicou-se em histograma que nos mostrou como resultado a média dos níveis de cinza, a mediana, o desvio padrão da imagem e a porcentagem de prata depositada na emulsão. Threshold é um filtro que estabelece o limite entre o objeto de interesse (cristal de prata) e o fundo (emulsão), permite que a imagem seja binarizada. O valor 199 foi escolhido, inicialmente, pela necessidade de um valor padrão e secundariamente pela necessidade em se estabelecer este adequado limite entre o preto e o branco. Este valor foi estabelecido subjetivamente, de acordo com a acuidade visual de dois observadores. Todas as imagens apresentavam 307200 pixels (Figura 8). Estes dados foram anotados em fichas próprias para serem, então, submetidos à análise estatística e comparados com os valores de Densidades Óticas e quantificação dos níveis de cinza obtidos. 


\subsubsection{Análise estatística}

Os dados obtidos de Densidades Óticas, quantificação dos níveis de cinza e de Densidade de Volume de prata, foram submetidos à análise estatística por meio do Coeficiente de Correlação de Pearson. O nível de confiança foi estabelecido em 95\%. Observou-se correlação estatística quando $\mathrm{p}<0,05$. 

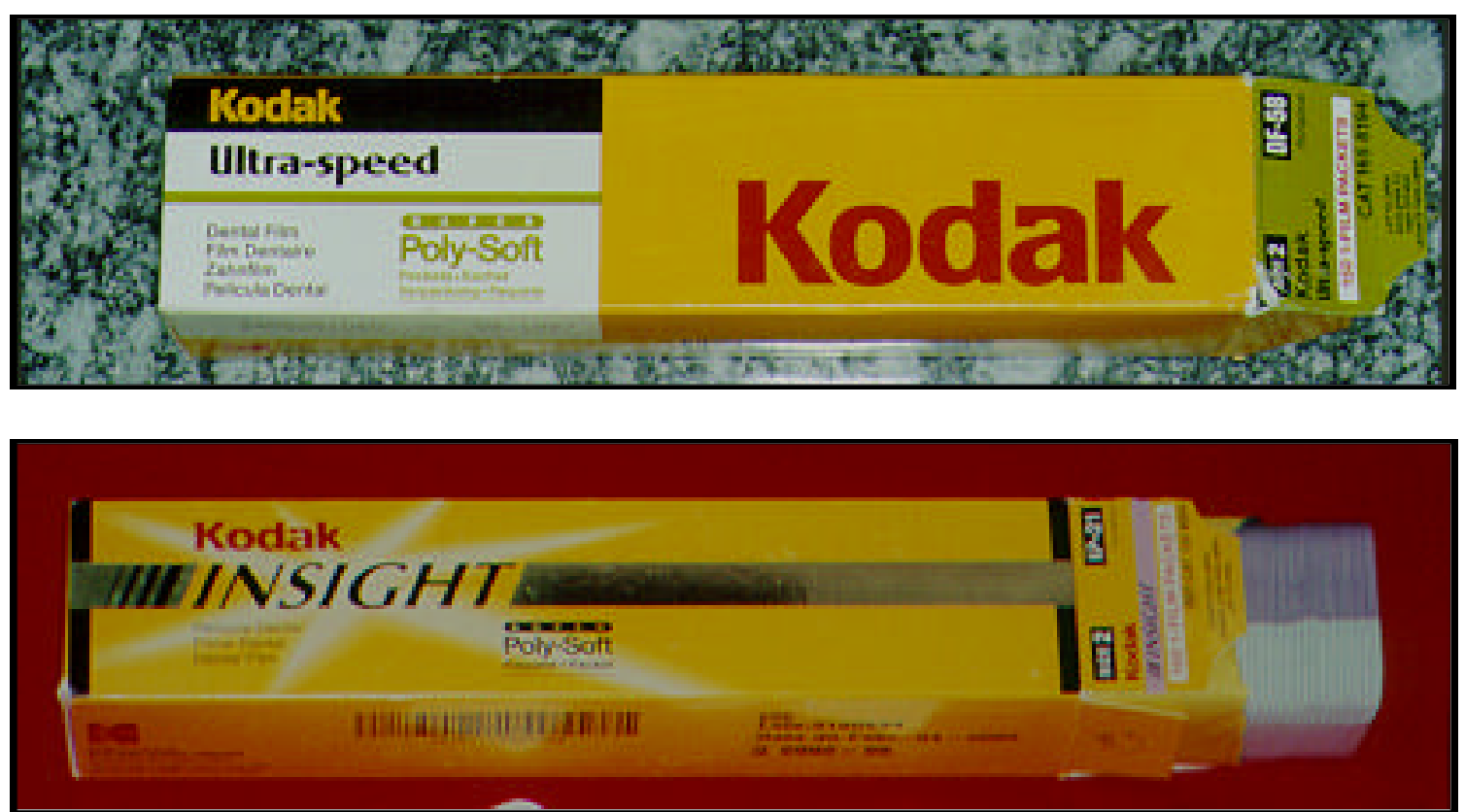

FIGURA 1 - Caixas de filmes radiográficos intrabucais Ultra-speed DF-58 e Insight IP21

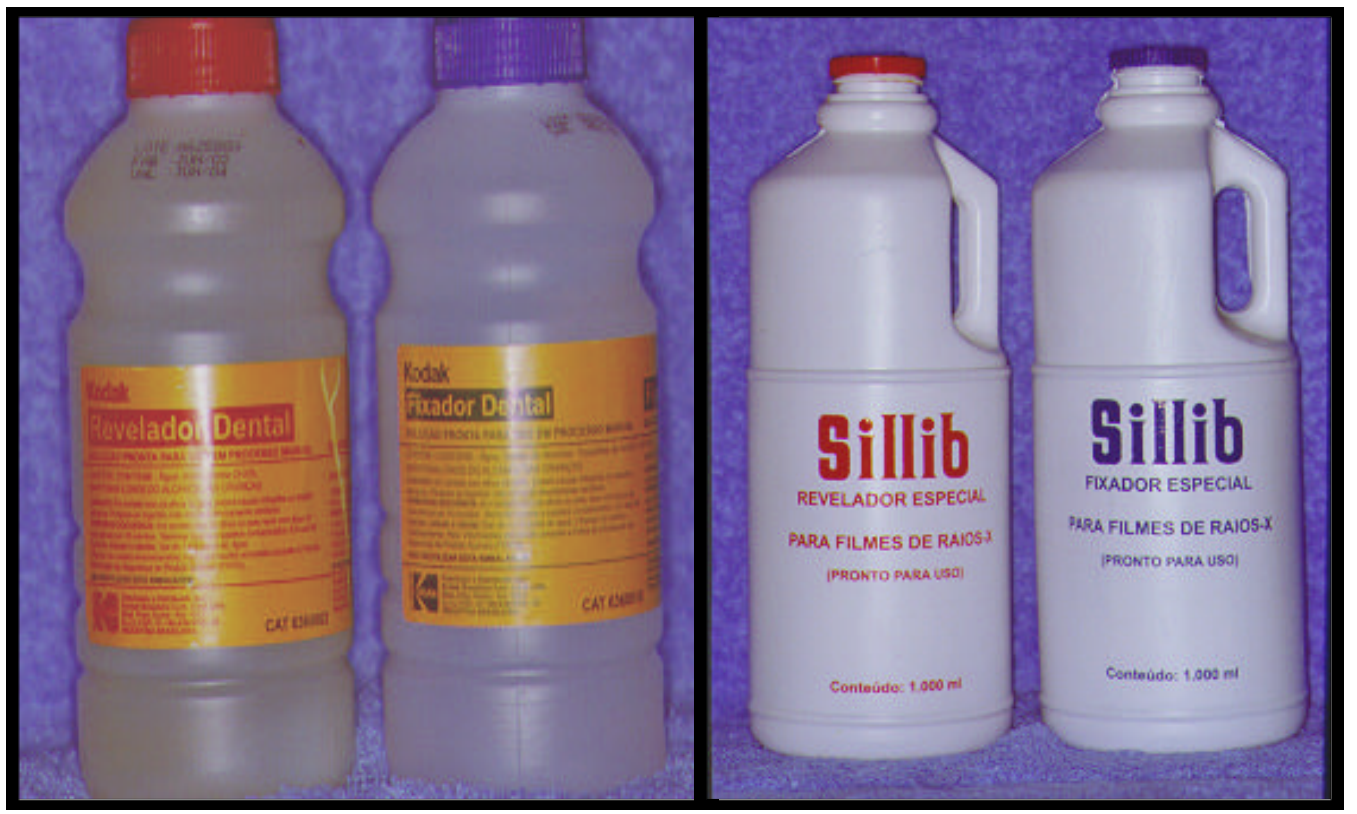

FIGURA 2 - Soluções para o processamento radiográfico manual - marcas Kodak e Sillib 

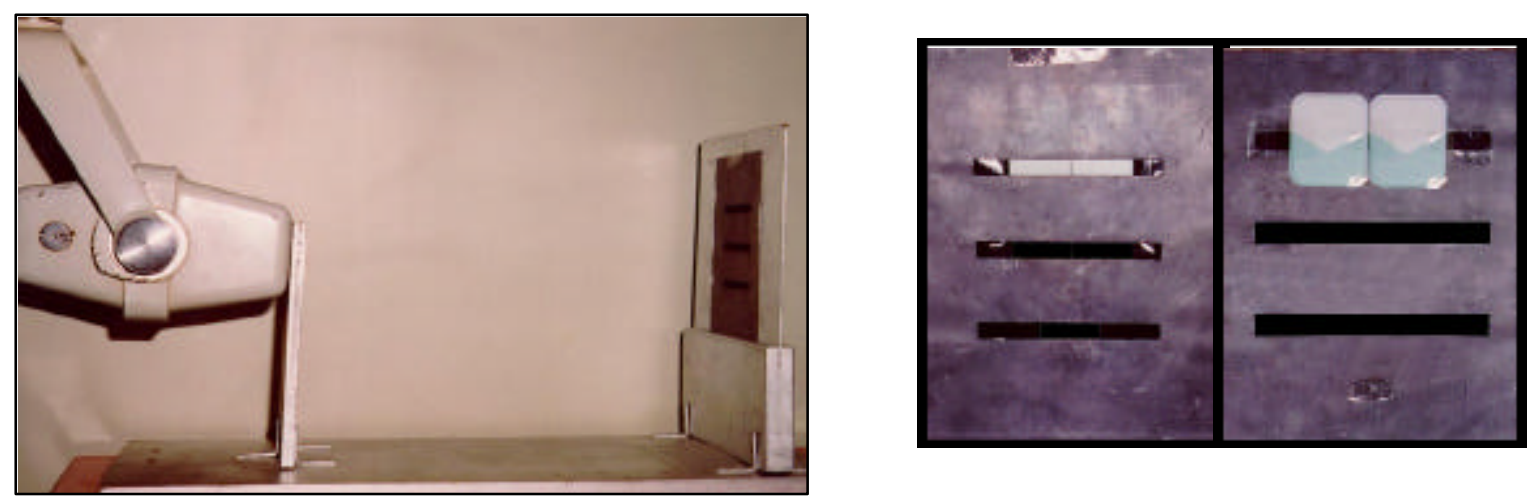

FIGURA 3 - Dispositivo de chumbo acoplado ao aparelho de raios X para manter fixa a distância foco-filme em $50 \mathrm{~cm}$. No detalhe observa-se como as radiografias foram fixadas na lâmina de chumbo, de maneira que apenas $1 / 5$ do filme fosse exposto de cada vez

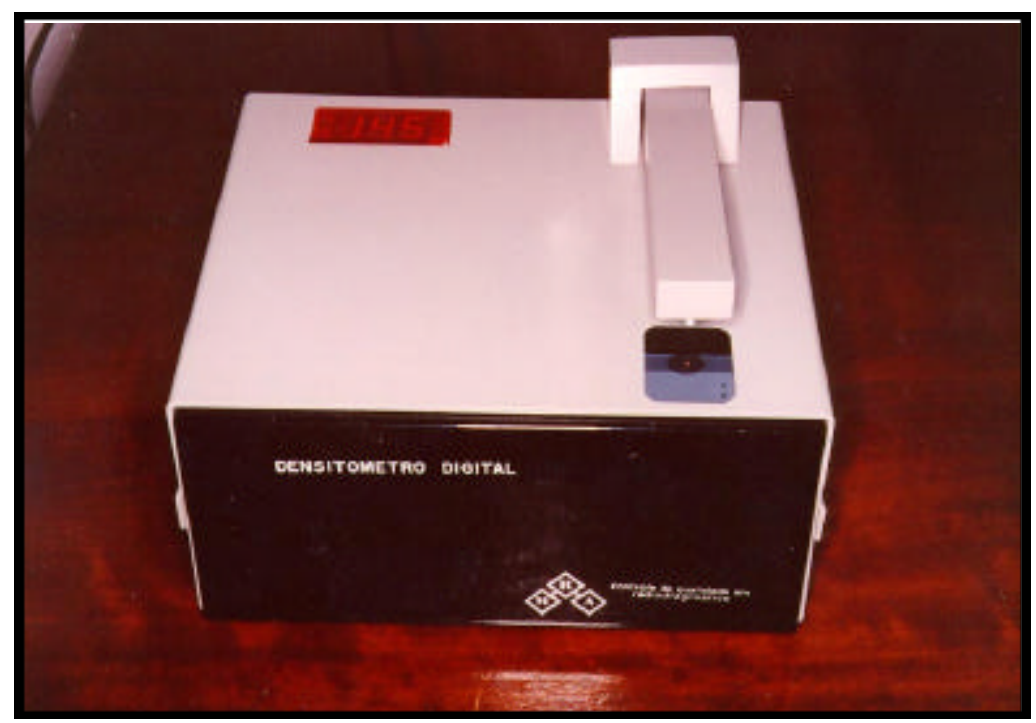

FIGURA 4 - Aparelho fotodensitômetro MRA com uma radiografia em posição, para realização da leitura da Densidade Ótica 


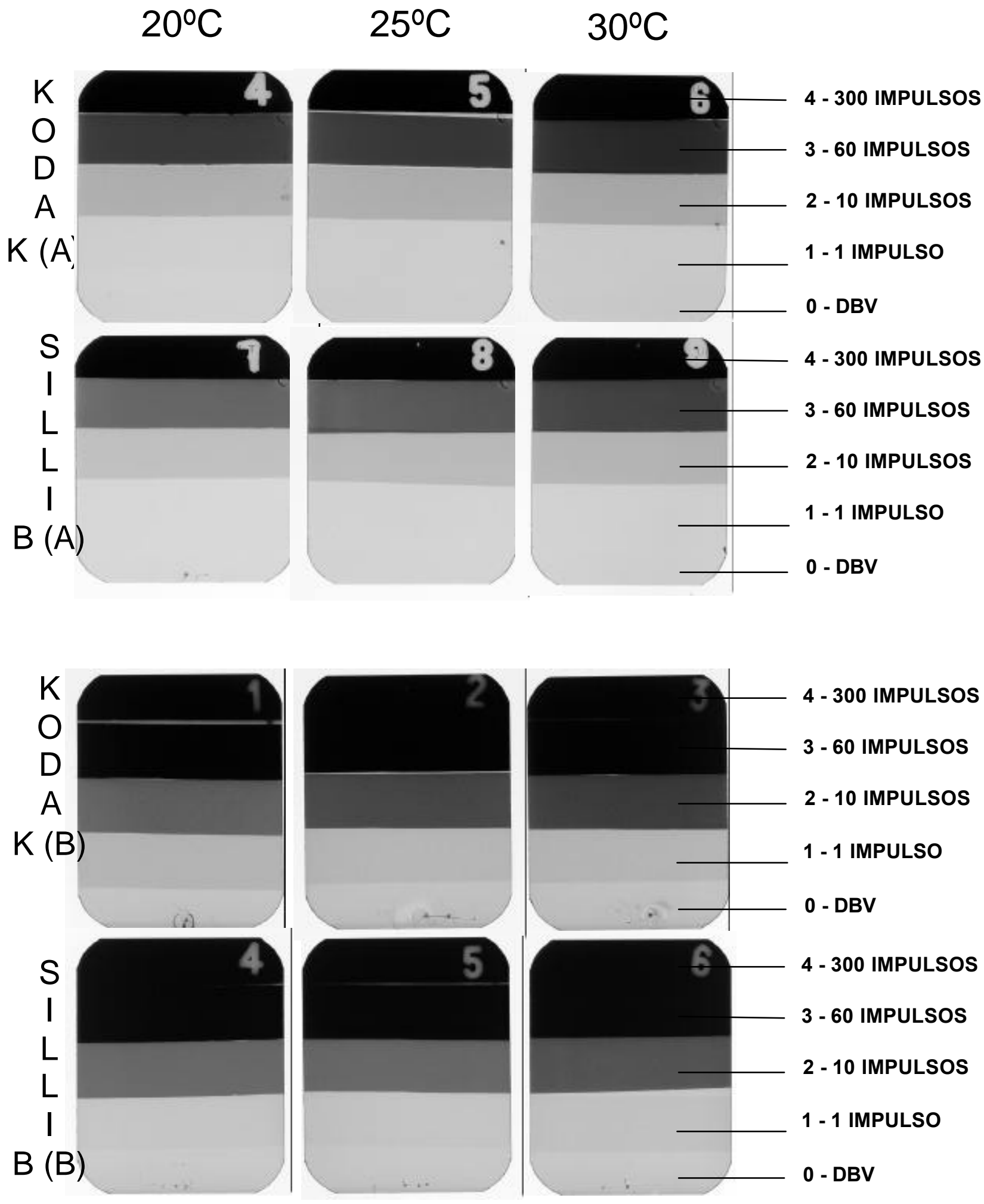

FIGURA 5 - Radiografias obtidas com os filmes Ultra-speed (A) e Insight (B) após a exposição e processamento com as soluções Kodak e Sillib nas temperaturas de $20^{\circ} \mathrm{C}, 25^{\circ} \mathrm{C}$ e $30^{\circ} \mathrm{C}$ e respectivas exposições 


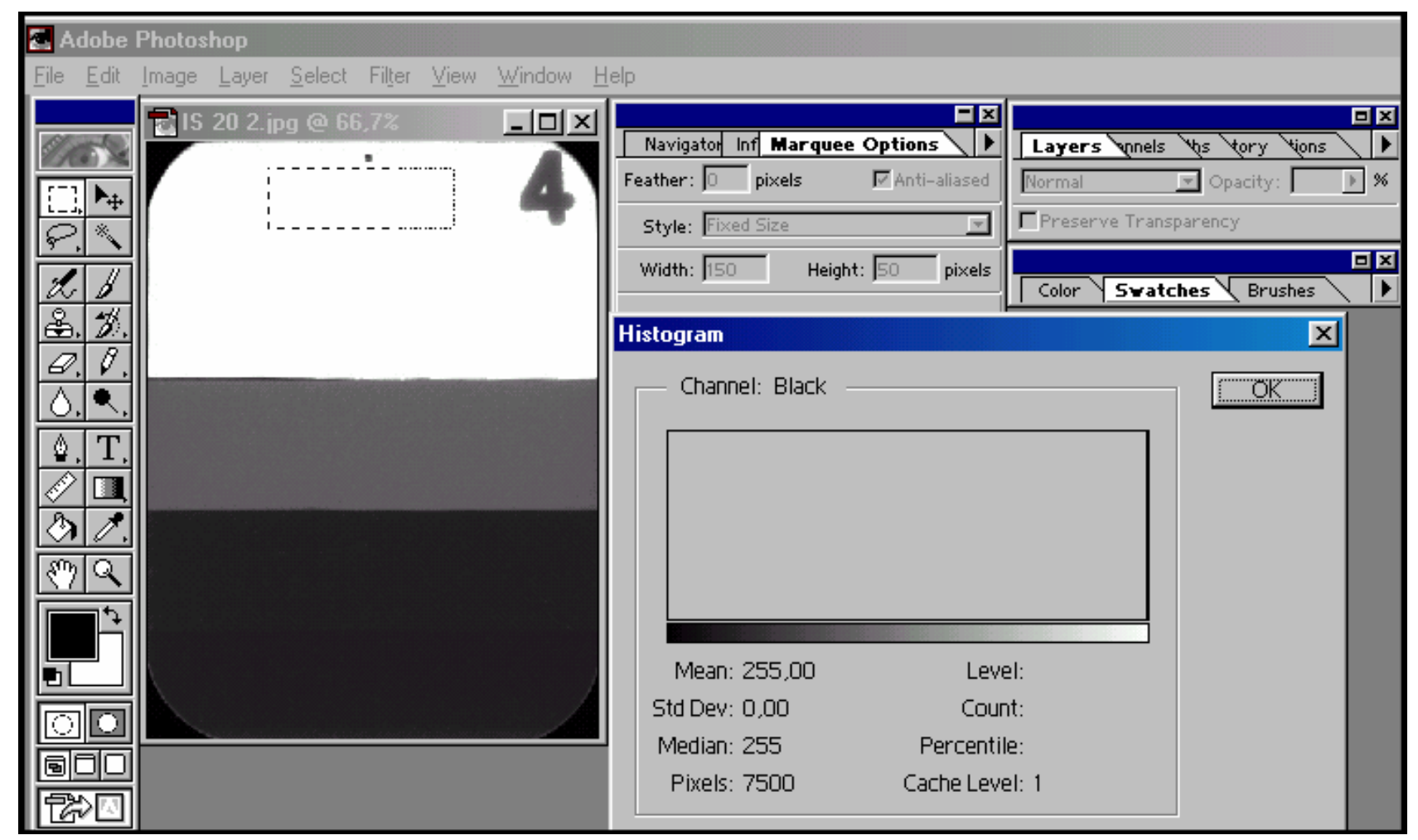

FIGURA 6 - Demonstração da tela do monitor com uma radiografia no Programa Adobe Photoshop 5.5, que mostra a média da quantificação dos níveis de cinza da área, a mediana e o desvio padrão 


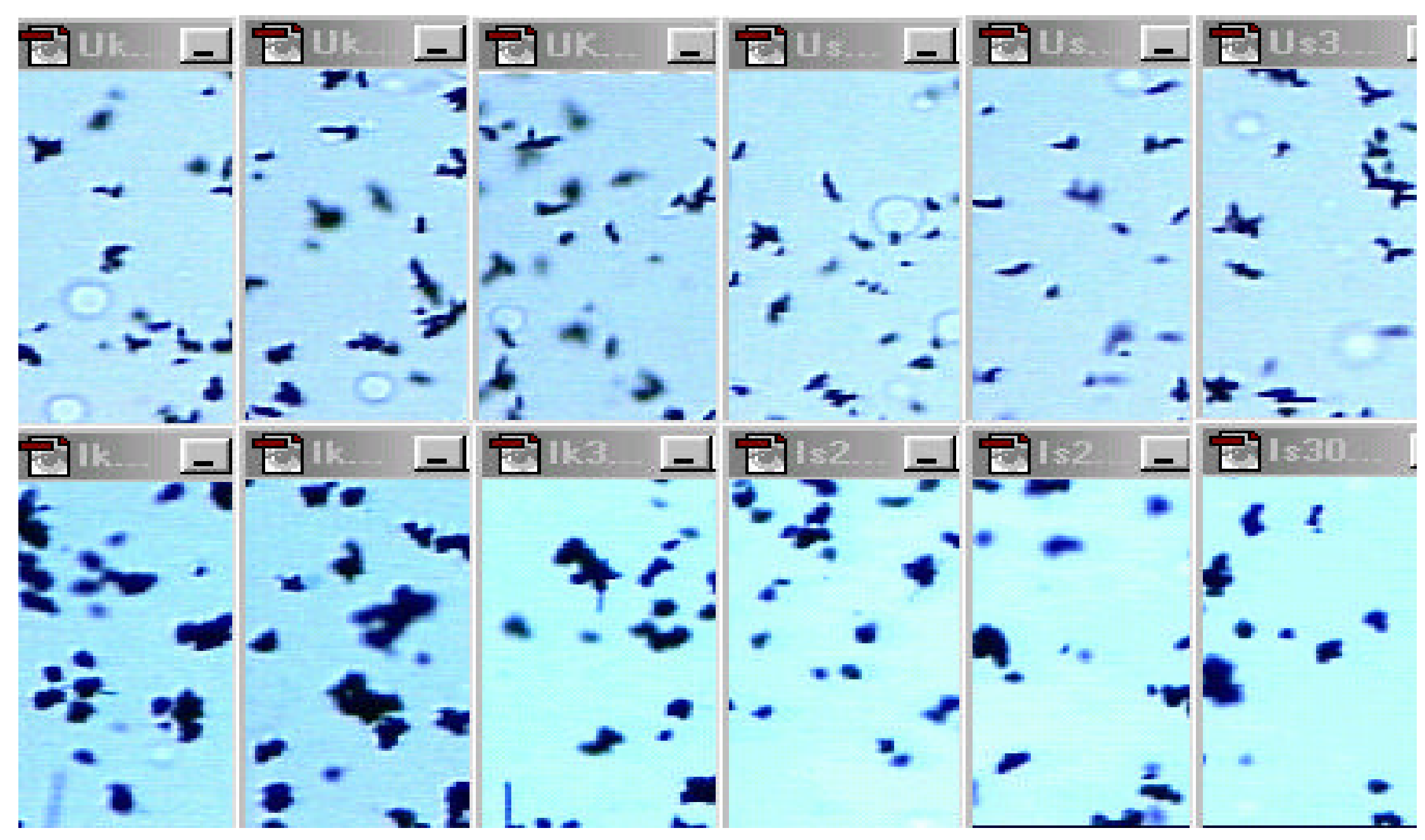

FIGURA 7 - Fotomicrografias (100X) dos cristais de prata da emulsão dos filmes radiográficos Ultra-speed e Insight, processados nas soluções Kodak e Sillib, nas temperaturas de $20^{\circ}, 25^{\circ}$ e $30^{\circ} \mathrm{C}$, na faixa de 1 impulso de exposição, observadas no Programa Adobe Photoshop 5.5 
A

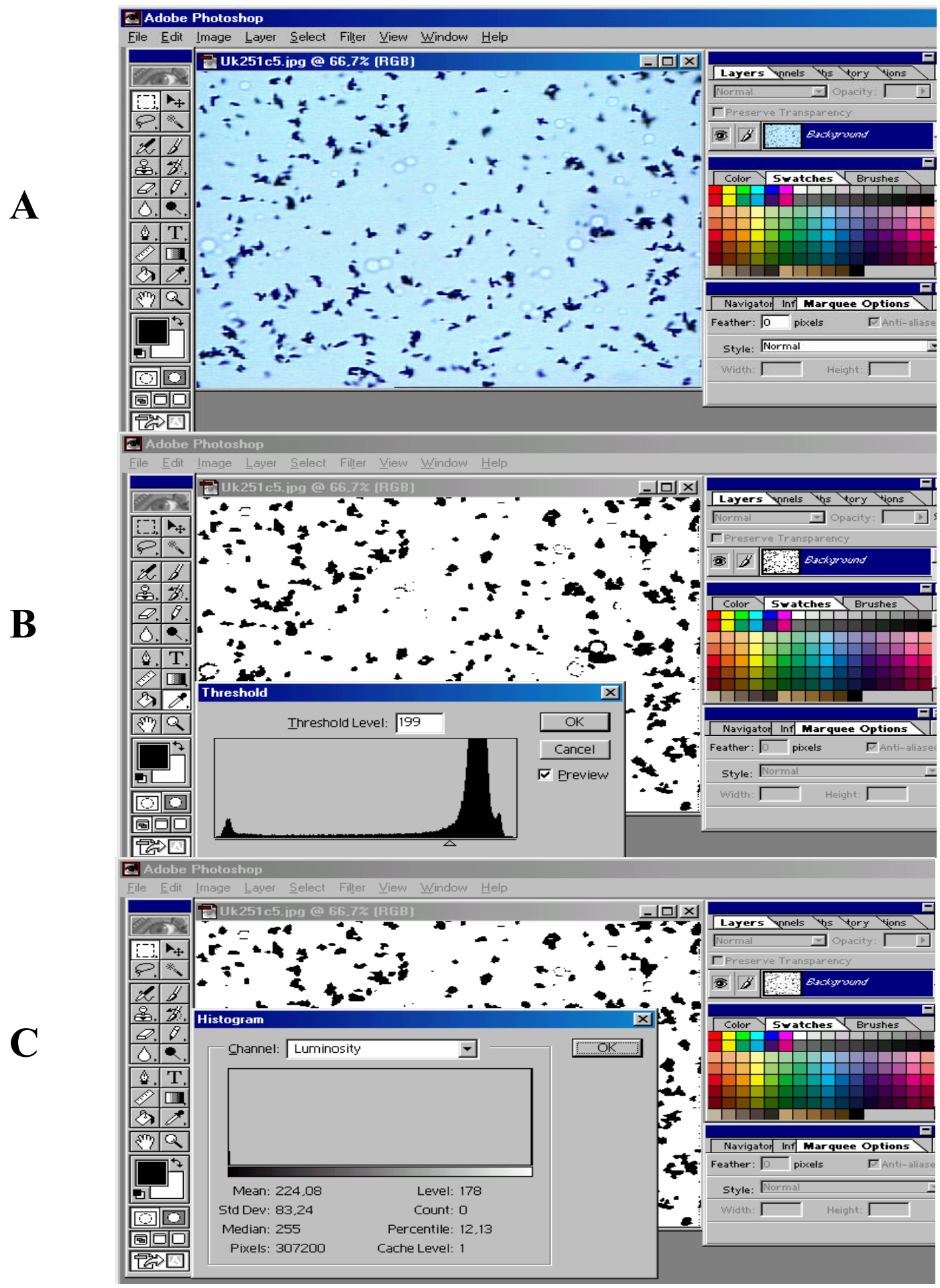

FIGURA 8 - Demonstração da tela do monitor com imagens da microscopia dos cristais de prata na emulsão dos filmes radiográficos no programa Adobe Photoshop 5.5, mostrando como foi realizada a Densidade de Volume de prata. A) Obtendo a imagem no programa Adobe Photoshop, B) Aplicando o filtro Treshold, C) Quantificando a porcentagem de prata na emulsão do filme radiográfico 
5. RESUltados 


\section{RESULTADOS}

A Tabela 1 mostra as médias das Densidades Óticas das quatro radiografias obtidas com o filme Ultra-speed processado na solução Kodak, nas três temperaturas. Estas médias foram utilizadas para a confecção das Curvas Características que forneceram as propriedades sensitométricas (Tabela 5). A Figura 9 mostra as três Curvas Características para esta solução (A, B e C) e a superposição das mesmas (D). A Tabela 2 mostra as médias das Densidades Óticas das quatro radiografias obtidas com a solução Sillib, nas três temperaturas. A Figura 10 mostra as três Curvas Características confeccionadas para esta solução (A, B e C) e superposição das mesmas (D). Na Tabela 5 observamos as propriedades sensitométricas obtidas a partir do traçado destas curvas para esta solução. A Tabela 3 fornece os dados de Densidades Óticas médias das quatro radiografias obtidas com o filme Insight na solução Kodak nas temperaturas de $20^{\circ}, 25^{\circ}$ e $30^{\circ} \mathrm{C}$. A partir destas médias foram construídas as três Curvas Características para esta solução (Figura 11A, B e C) e superposição (D). As propriedades sensitométricas do filme processado nesta solução, nas três diferentes temperaturas, estão expressas na Tabela 5. A Tabela 4 expressa as médias da Densidade Ótica das quatro radiografias obtidas com o filme Insight na solução Sillib nas temperaturas de $20^{\circ}, 25^{\circ}$ e $30^{\circ} \mathrm{C}$. A Figura 12A, B, C e D mostra as três Curvas Características para esta solução e a superposição das mesmas. A Tabela 5 mostra as propriedades sensitométricas alcançadas a partir da confecção das Curvas Características.

A Tabela 5 apresenta um comparativo das propriedades sensitométricas dos dois filmes analisados (Ultra-speed e Insight), alcançadas nas diferentes condições de temperatura/tempo, utilizando-se as 
soluções Kodak e Sillib. As propriedades sensitométricas analisadas foram a sensibilidade, apresentada em mAs e em $\mathrm{R}^{*}$ e o contraste. A sensibilidade também foi expressa em mAs somente para efeito de comparação, facilitando o raciocínio do leitor, pois quanto mais baixa a mAs, menor a quantidade de radiação necessária para expor o filme, conseqüentemente mais sensível é o filme radiográfico.

As Tabelas de 6 a 9 mostram as médias da quantificação dos níveis de cinza das quatro radiografias de todas as combinações utilizadas com os filmes Ultra-speed e Insight e as soluções Kodak e Sillib, nas quatro faixas de exposição radiográfica e densidade base e velamento.

A Tabela 10 mostra um comparativo das médias das Densidades Óticas e quantificação dos níveis de cinza das quatro radiografias em todas as combinações analisadas, nas cinco faixas de exposição. Os valores obtidos de cada radiografia (R1, R2, R3 e R4 - ANEXO 25) de cada combinação foram utilizados para a confecção da análise estatística, para correlacionar Densidade Ótica e quantificação dos níveis de cinza. A Tabela 11 mostra o resultado da análise estatística, obtida por meio do Coeficiente de Correlação de Pearson, com nível de confiança estabelecido em 95\%. Houve correlação estatisticamente significante quando $\mathrm{p}<0,05$.

A Figura 13 mostra as fotomicrografias (100X) dos cristais de prata da emulsão do filme radiográfico Ultra-speed processado nas soluções Kodak e Sillib nas três temperaturas. A faixa utilizada foi a de 1 impulso de exposição e foram realizadas análises em três áreas diferentes da faixa para cada filme para, posteriormente, obtermos uma média. Os valores destas médias estão expressos nesta figura. A Figura 14 mostra os mesmos dados para o filme Insight nas diferentes combinações.

A Tabela 12 mostra o comparativo entre os valores das médias de Densidade Ótica (D.O.), quantificação dos níveis de cinza (N.C.) e 
Densidade de Volume de prata de uma das radiografias (R2) de cada combinação analisada, na faixa de 1 impulso de exposição. A Tabela 13 mostra os resultados da análise estatística obtida por meio do Coeficiente de Correlação de Pearson, com nível de confiança de 95\%. Observou-se correlação estatística quando $\mathrm{p}<0,05$. 
TABELA 1 - Média das Densidades Óticas das quatro radiografias (Ultra-speed), nas cinco faixas de exposição, processadas a $20^{\circ}, 25^{\circ}$ e $30^{\circ} \mathrm{C}$ na solução Kodak

\begin{tabular}{|c|c|c|c|}
\hline & $20^{\circ} \mathrm{C} / 5 \mathrm{~min}$. & $25^{\circ} \mathrm{C} / 2,5 \mathrm{~min}$ & $30^{\circ} \mathrm{C} / 1,25 \mathrm{~min}$. \\
\hline $300-4$ & 3,93 & 4,16 & 4,16 \\
\hline $60-3$ & 1,04 & 1,13 & 1,20 \\
\hline $10-2$ & 0,17 & 0,18 & 0,21 \\
\hline $1-1$ & $\mathbf{0 , 0 0}$ & $\mathbf{0 , 0 1}$ & $\mathbf{0 , 0 2}$ \\
\hline DBV - 0 & 0,00 & 0,01 & 0,02 \\
\hline
\end{tabular}
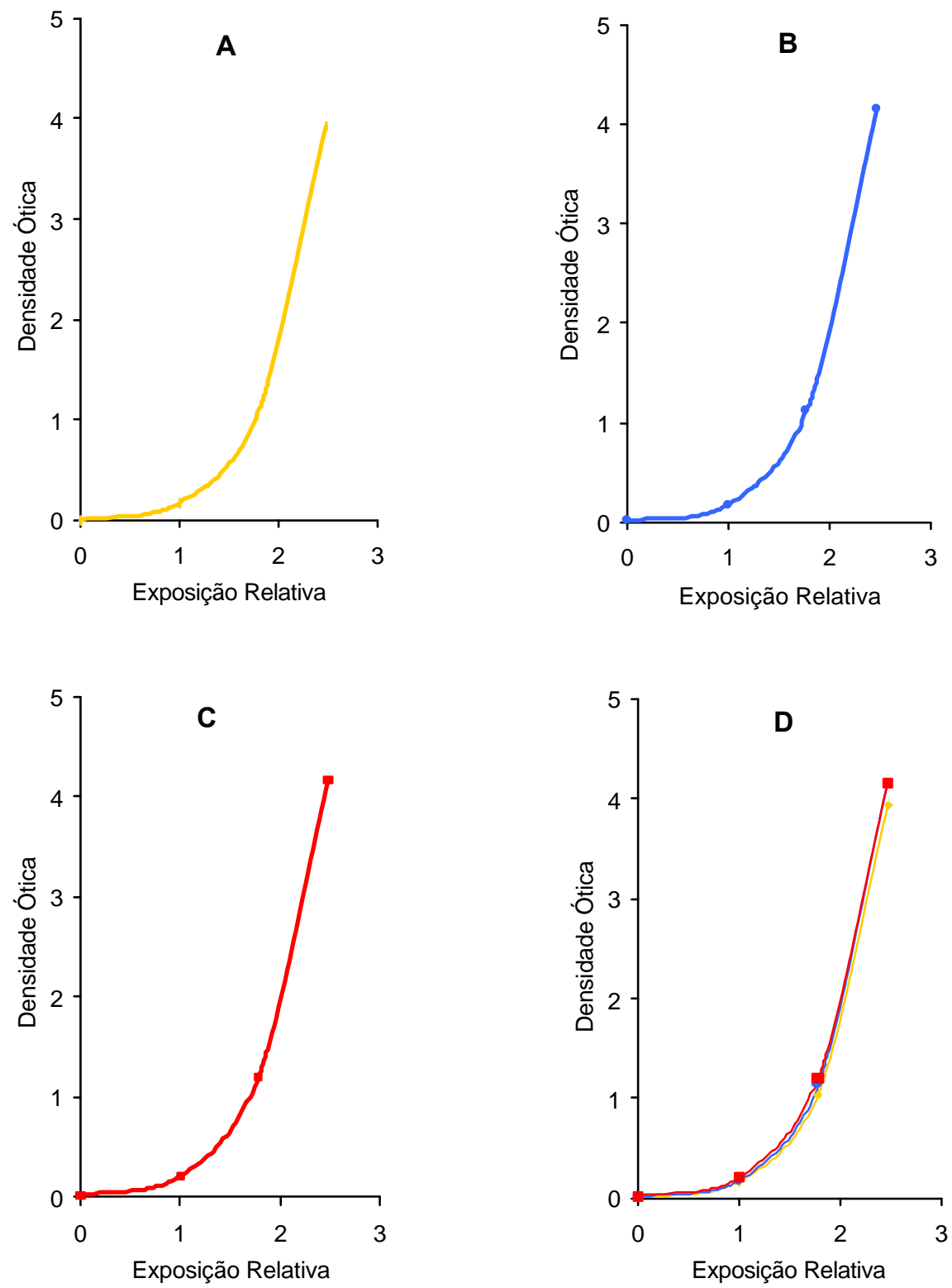

FIGURA 9 - Curvas Características do filme Ultra-speed processado na solução Kodak a $20^{\circ} \mathrm{C} / 5 \mathrm{~min}$. (A), $25^{\circ} \mathrm{C} / 2,5 \mathrm{~min}$. (B), $30^{\circ} \mathrm{C} / 1,25 \mathrm{~min}$. (C) e superposição das três combinações $(\mathrm{D})$ 
TABELA 2 - Média das Densidades Óticas das quatro radiografias (Ultra-speed), nas cinco faixas de exposição, processadas a $20^{\circ}, 25^{\circ}$ e $30^{\circ} \mathrm{C}$ na solução Sillib

\begin{tabular}{c|c|c|c}
\hline \hline & $20^{\circ} \mathrm{C} / 2 \mathrm{~min}$. & $2^{\circ} \mathrm{C} / 1 \mathrm{~min}$. & $\mathbf{3 0}^{\circ} \mathrm{C} / \mathbf{0 , 5 m i n}$. \\
\hline \hline $300-4$ & $\mathbf{3 , 2 8}$ & $\mathbf{3 , 5 1}$ & $\mathbf{3 , 4 3}$ \\
\hline $60-3$ & $\mathbf{0 , 7 9}$ & $\mathbf{0 , 8 8}$ & $\mathbf{1 , 0 0}$ \\
\hline $10-2$ & $\mathbf{0 , 1 1}$ & $\mathbf{0 , 1 4}$ & $\mathbf{0 , 1 6}$ \\
\hline $1-1$ & $\mathbf{0 , 0 0}$ & $\mathbf{0 , 0 1}$ & $\mathbf{0 , 0 2}$ \\
\hline DBV -0 & $\mathbf{0 , 0 0}$ & $\mathbf{0 , 0 1}$ & $\mathbf{0 , 0 2}$ \\
\hline
\end{tabular}
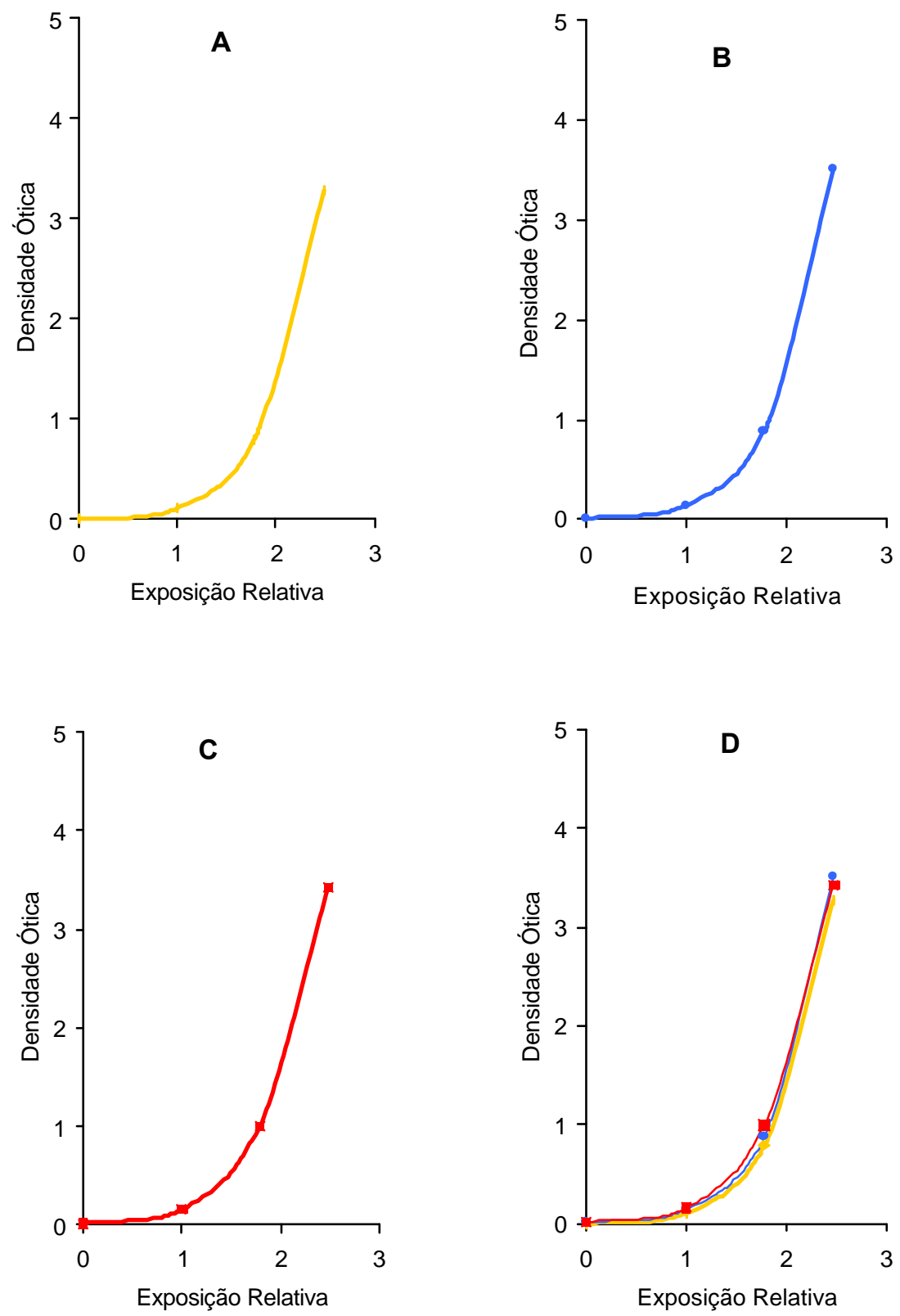

FIGURA 10 - Curvas Características do filme Ultra-speed processado na solução Sillib a $20^{\circ} \mathrm{C} / 2 \mathrm{~min}$. (A), $25^{\circ} \mathrm{C} / 1 \mathrm{~min}$. (B), $30^{\circ} \mathrm{C} / 0,5 \mathrm{~min}$. (C) e superposição das três combinações (D) 
TABELA 3 - Média das Densidades Óticas das quatro radiografias (Insight), nas cinco faixas de exposição, processadas a $20^{\circ}, 25^{\circ}$ e $30^{\circ} \mathrm{C}$ na solução Kodak

\begin{tabular}{c|c|c|c}
\hline \hline & $20^{\circ} \mathrm{C} / 5 \mathrm{~min}$. & $2^{\circ} \mathrm{C} / 2,5 \mathrm{~min}$. & $\mathbf{3 0}^{\circ} \mathrm{C} / 1,25 \mathrm{~min}$. \\
\hline \hline $300-4$ & 5,73 & 5,53 & 5,02 \\
\hline $60-3$ & 4,28 & 4,56 & 4,55 \\
\hline $10-2$ & 0,74 & 0,95 & 1,02 \\
\hline $1-1$ & 0,14 & 0,15 & 0,14 \\
\hline DBV - 0 & 0,07 & $\mathbf{0 , 1 0}$ & $\mathbf{0 , 1 0}$ \\
\hline
\end{tabular}
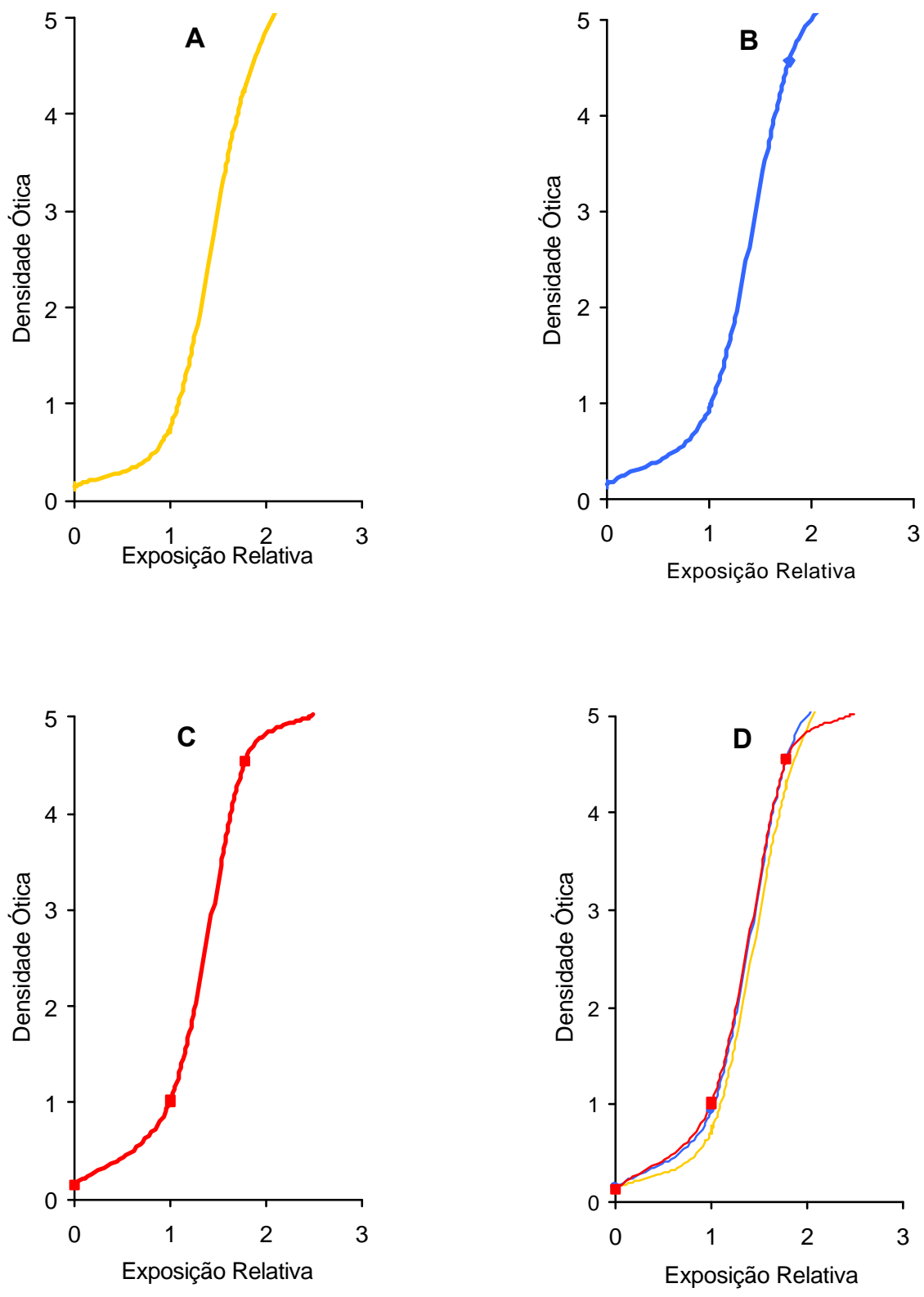

FIGURA 11 - Curvas Características do filme Insight processado na solução Kodak a $20^{\circ} \mathrm{C} / 5 \mathrm{~min}$. (A), $25^{\circ} \mathrm{C} / 2,5 \mathrm{~min}$. (B), $30^{\circ} \mathrm{C} / 1,25 \mathrm{~min}$. (C) e superposição das três combinações (D) 
TABELA 4 - Média das Densidades Óticas das quatro radiografias (Insight), nas cinco faixas de exposição, processadas a $20^{\circ}, 25^{\circ}$ e $30^{\circ} \mathrm{C}$ na solução Sillib

\begin{tabular}{c|c|c|c}
\hline \hline & $20^{\circ} \mathrm{C} / 2 \mathrm{~min}$. & $2^{\circ} \mathrm{C} / 1 \mathrm{~min}$. & $\mathbf{3 0}^{\circ} \mathrm{C} / \mathbf{0 , 5 m i n}$. \\
\hline \hline $300-4$ & 4,51 & 4,71 & $\mathbf{5 , 3 8}$ \\
\hline $60-3$ & $\mathbf{3 , 4 6}$ & $\mathbf{3 , 6 3}$ & $\mathbf{3 , 1 2}$ \\
\hline $10-2$ & $\mathbf{0 , 6 8}$ & $\mathbf{0 , 7 1}$ & $\mathbf{0 , 8 1}$ \\
\hline $1-1$ & $\mathbf{0 , 0 8}$ & $\mathbf{0 , 0 8}$ & $\mathbf{0 , 0 7}$ \\
\hline DBV -0 & $\mathbf{0 , 0 7}$ & $\mathbf{0 , 0 7}$ & $\mathbf{0 , 0 5}$ \\
\hline \hline
\end{tabular}
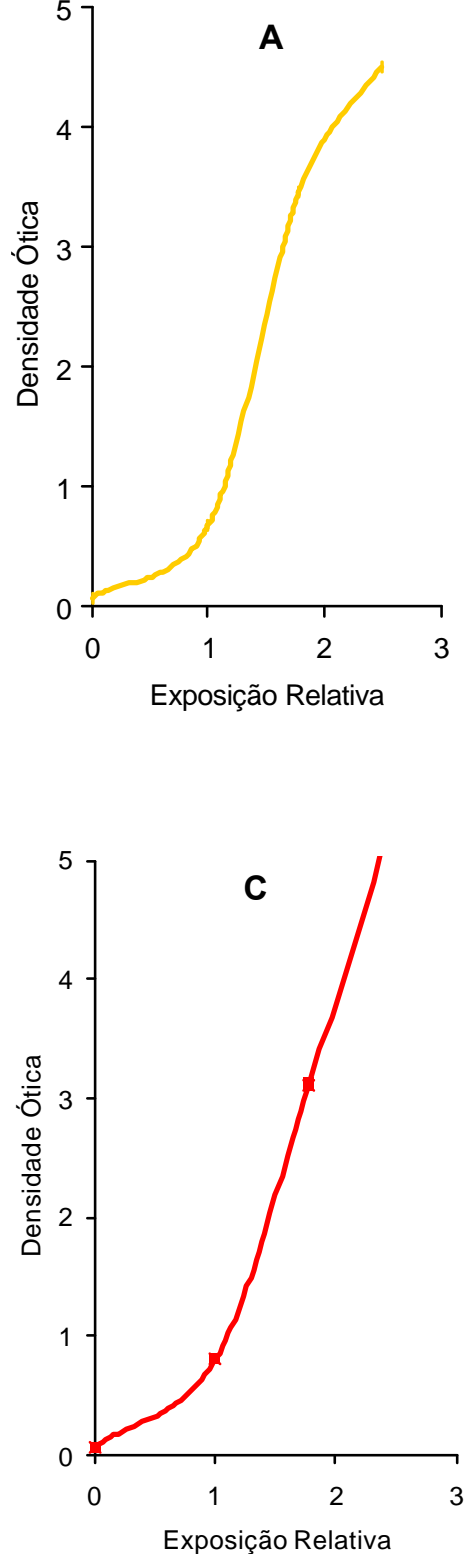
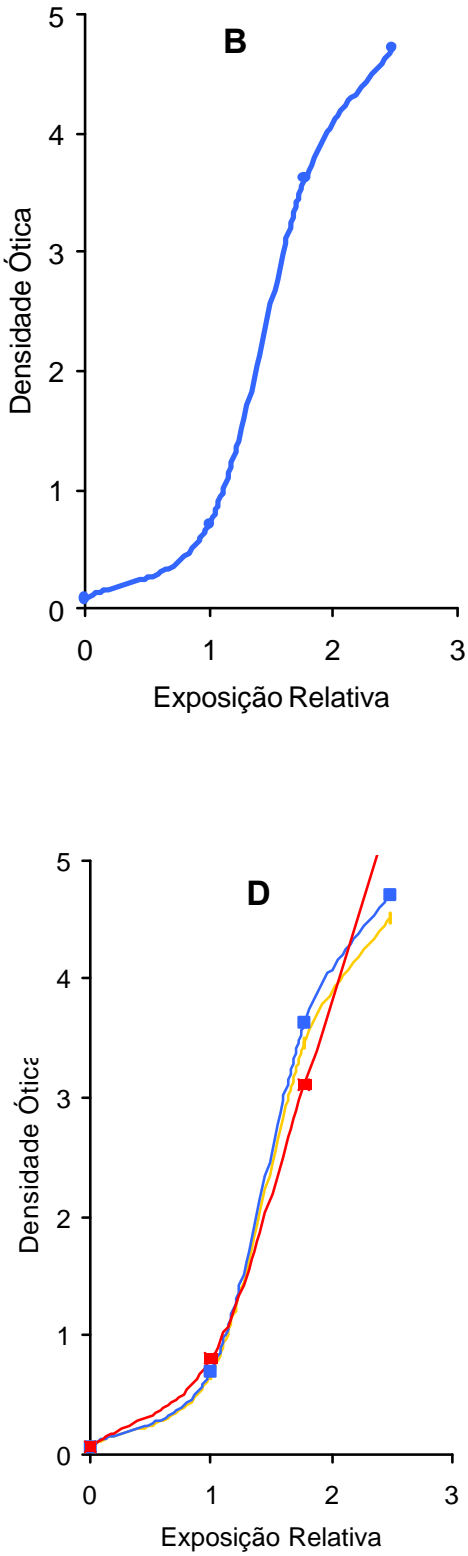

FIGURA 12 - Curvas Características do filme Insight processado na solução Sillib a $20^{\circ} \mathrm{C} / 2 \mathrm{~min}$. (A), $25^{\circ} \mathrm{C} / 1 \mathrm{~min}$. (B), $30^{\circ} \mathrm{C} / 0,5 \mathrm{~min}$. (C) e superposição das três combinações $(\mathrm{D})$ 
TABELA 5 - Comparativo das Densidades Máximas, propriedades sensitométricas (sensibilidade em mAs e R* e contraste) e densidade base e velamento (DBV) dos filmes Ultra-speed e Insight, processados nas soluções Kodak e Sillib nas temperaturas de $20^{\circ}, 25^{\circ}$ e $30^{\circ} \mathrm{C}$

\begin{tabular}{|c|c|c|c|c|c|c|c|c|c|c|c|c|}
\hline \multirow{3}{*}{$\begin{array}{c}\text { Filmes } \\
\text { Soluções } \\
\text { Temperaturas }\end{array}$} & \multicolumn{6}{|c|}{ Ultra-speed } & \multicolumn{6}{|c|}{ Insight } \\
\hline & \multicolumn{3}{|c|}{ Kodak } & \multicolumn{3}{|c|}{ Sillib } & \multicolumn{3}{|c|}{ Kodak } & \multicolumn{3}{|c|}{ Sillib } \\
\hline & $20^{\circ} \mathrm{C} / 5 \mathrm{~min}$ & $25^{\circ} \mathrm{C} / 2,5 \mathrm{~min}$ & $30^{\circ} \mathrm{C} / 1,25 \mathrm{~min}$. & $20^{\circ} \mathrm{C} / 2 \mathrm{~min}$ & $25^{\circ} \mathrm{C} / 1 \mathrm{~min}$ & $30^{\circ} \mathrm{C} / 0,5 \min$. & $20^{\circ} \mathrm{C} / 5 \mathrm{~min}$ & $25^{\circ} \mathrm{C} / 2,5 \mathrm{~min}$ & $30^{\circ} \mathrm{C} / 1,25 \mathrm{~min}$ & $20^{\circ} \mathrm{C} / 2 \mathrm{~min}$ & $25^{\circ} \mathrm{C} / 1 \mathrm{~min}$. & $30^{\circ} \mathrm{C} / \mathbf{0}, 5 \mathrm{~min}$. \\
\hline Densidade Máxima & 3,93 & 4,16 & 4,16 & 3,28 & 3,51 & 3,43 & 5,73 & 5,53 & 5,02 & 4,51 & 4,71 & 5,38 \\
\hline Sensibilidade mAs & 13,74 & 13,96 & 12,53 & 20,79 & 18,11 & 15,77 & 4,05 & $\mathbf{3 , 0 7}$ & 2,80 & 4,65 & 4,34 & 3,61 \\
\hline Sensibilidade $\mathbf{R}^{*}$ & 21,83 & 21,49 & 23,94 & 14,43 & 16,56 & 19,02 & 73,99 & 97,54 & 107 & 64,44 & 69,05 & 83 \\
\hline Contraste & 1,70 & 1,77 & 1,78 & 1,70 & 1,68 & 1,66 & 1,62 & 1,70 & 1,68 & 1,71 & 1,71 & 1,55 \\
\hline DBV & $\mathbf{0 , 0 0}$ & $\mathbf{0 , 0 1}$ & $\mathbf{0 , 0 2}$ & $\mathbf{0 , 0 0}$ & $\mathbf{0 , 0 1}$ & $\mathbf{0 , 0 2}$ & $\mathbf{0 , 0 7}$ & 0,10 & 0,10 & $\mathbf{0 , 0 7}$ & $\mathbf{0 , 0 7}$ & $\mathbf{0 , 0 5}$ \\
\hline
\end{tabular}


TABELA 6 - Média da quantificação dos níveis de cinza, em cada uma das cinco faixas de exposição, realizada no programa Adobe Photoshop 5.5, em filmes radiográficos Ultra-speed, processados na solução Kodak, nas temperaturas de $20^{\circ}, 25^{\circ}$ e $30^{\circ} \mathrm{C}$

\begin{tabular}{c|c|c|c}
\hline \hline & $20^{\circ} \mathrm{C} / 5 \mathrm{~min}$. & $2^{\circ} \mathrm{C} / 2,5 \mathrm{~min}$. & $3^{\circ} \mathrm{C} / 1,25 \mathrm{~min}$. \\
\hline \hline $300-4$ & 255 & 255 & 255 \\
\hline $60-3$ & 159 & 175 & 191 \\
\hline $10-2$ & 47 & 49 & 50 \\
\hline $1-1$ & 22 & 24 & 24 \\
\hline DBV - 0 & 22 & 24 & 24 \\
\hline \hline
\end{tabular}

TABELA 7 - Média da quantificação dos níveis de cinza, em cada uma das cinco faixas de exposição, realizada no programa Adobe Photoshop 5.5, em filmes radiográficos Ultra-speed, processados na solução Sillib, nas temperaturas de $20^{\circ}, 25^{\circ}$ e $30^{\circ} \mathrm{C}$

\begin{tabular}{c|c|c|c}
\hline \hline & $\mathbf{2 0}^{\circ} \mathrm{C} / 2 \mathrm{~min}$. & $2^{\circ} \mathrm{C} / 1 \mathrm{~min}$. & $\mathbf{3 0}^{\circ} \mathrm{C} / \mathbf{0 , 5}$ min. \\
\hline \hline $300-4$ & 255 & 255 & 255 \\
\hline $60-3$ & 118 & 131 & 145 \\
\hline $10-2$ & 37 & 41 & 43 \\
\hline $1-1$ & 19 & 20 & 21 \\
\hline DBV - 0 & 19 & 20 & 21 \\
\hline \hline
\end{tabular}

TABELA 8 - Média da quantificação dos níveis de cinza, em cada uma das cinco faixas de exposição, realizada no programa Adobe Photoshop 5.5, em filmes radiográficos Insight, processados na solução Kodak, nas temperaturas de $20^{\circ}, 25^{\circ}$ e $30^{\circ} \mathrm{C}$

\begin{tabular}{c|c|c|c}
\hline \hline & $\mathbf{2 0}^{\circ} \mathrm{C} / 5 \min$. & $2^{\circ} \mathrm{C} / 2,5 \mathrm{~min}$. & $\mathbf{3 0}^{\circ} \mathrm{C} / \mathbf{1}, 25 \mathrm{~min}$. \\
\hline \hline $300-4$ & 255 & 255 & 255 \\
\hline $60-3$ & 255 & 255 & 255 \\
\hline $10-2$ & 104 & 129 & 143 \\
\hline $1-1$ & 38 & 35 & 39 \\
\hline DBV - 0 & 29 & 31 & 33 \\
\hline \hline
\end{tabular}

TABELA 9 - Média da quantificação dos níveis de cinza, em cada uma das cinco faixas de exposição, realizada no programa Adobe Photoshop 5.5, em filmes radiográficos Insight, processados na solução Sillib, nas temperaturas de $20^{\circ}, 25^{\circ}$ e $30^{\circ} \mathrm{C}$

\begin{tabular}{c|c|c|c}
\hline \hline & $20^{\circ} \mathrm{C} / 2 \mathrm{~min}$. & $2^{\circ} \mathrm{C} / 1 \mathrm{~min}$. & $\mathbf{3 0}^{\circ} \mathrm{C} / 0,5 \mathrm{~min}$. \\
\hline \hline $300-4$ & 255 & 255 & 255 \\
\hline $60-3$ & 255 & 255 & 255 \\
\hline $10-2$ & 94 & 97 & 118 \\
\hline $1-1$ & 27 & 28 & 34 \\
\hline DBV - 0 & 26 & 26 & 31 \\
\hline \hline
\end{tabular}


TABELA 10 - Comparativo entre Densidade Ótica (D.O.) e quantificação dos níveis de cinza (N.C.), da média das quatro radiografias processadas em todas as combinações utilizadas, nas cinco faixas de exposição, com os filmes Ultra-speed e Insight

\begin{tabular}{|c|c|c|c|c|c|c|c|c|c|c|c|c|c|c|c|c|c|c|c|c|c|c|c|c|}
\hline \multirow{3}{*}{$\begin{array}{c}\text { Filmes/Soluções } \\
\text { Temperaturas } \\
\text { Impulsos }\end{array}$} & \multicolumn{6}{|c|}{ Ultra-speed/Kodak } & \multicolumn{6}{|c|}{ Ultra-speed/Sillib } & \multicolumn{6}{|c|}{ Insight/Kodak } & \multicolumn{6}{|c|}{ Insight/Sillib } \\
\hline & \multicolumn{2}{|c|}{$20^{\circ} \mathrm{C} / 5 \mathrm{~min}$} & \multicolumn{2}{|c|}{$25^{\circ} \mathrm{C} / 2,5 \mathrm{~min}$} & \multicolumn{2}{|c|}{$30^{\circ} \mathrm{C} / 1,25 \mathrm{~min}}$. & \multicolumn{2}{|c|}{$20^{\circ} \mathrm{C} / 2 \mathrm{~min}$} & \multicolumn{2}{|c|}{$25^{\circ} \mathrm{C} / 1 \mathrm{~min}$} & \multicolumn{2}{|c|}{$30^{\circ} \mathrm{C} / 0,5 \min }$. & \multicolumn{2}{|c|}{$20^{\circ} \mathrm{C} / 5 \mathrm{~min}$} & \multicolumn{2}{|c|}{$25^{\circ} \mathrm{C} / 2,5 \mathrm{~min}$} & \multicolumn{2}{|c|}{$30^{\circ} \mathrm{C} / 1,25 \mathrm{~min}$} & \multicolumn{2}{|c|}{$20^{\circ} \mathrm{C} / 2 \mathrm{~min}$} & \multicolumn{2}{|c|}{$25^{\circ} \mathrm{C} / 1 \mathrm{~min}$} & \multicolumn{2}{|c|}{$30^{\circ} \mathrm{C} / 0,5 \mathrm{~min}}$. \\
\hline & D.O. & N.C. & D.O. & N.C. & D.O. & N.C. & D.O. & N.C. & D.O. & N.C. & D.O. & N.C. & D.O. & N.C. & D.O. & N.C. & D.O. & N.C. & D.O. & N.C. & D.O. & N.C. & D.O. & N.C. \\
\hline 300 & (3,93 & 255 & 4,16 & 255 & 4,16 & 255 & 3,28 & 255 & $\mathbf{3 , 5 1}$ & 255 & 3,43 & 255 & "5,73 & 255 & 5,53 & 255 & 5,02 & 255 & 4,51 & 255 & 4,71 & 255 & $5, \mathbf{3 8}$ & 255 \\
\hline 60 & 1,04 & 159 & 1,13 & 175 & 1,20 & 191 & $\mathbf{0 , 7 9}$ & 118 & $\mathbf{0 , 8 8}$ & 131 & 1,00 & 145 & 4,28 & 255 & 4,56 & 255 & 4,55 & 255 & 3,46 & 255 & 3,63 & 255 & 3,12 & 255 \\
\hline 10 & $\mathbf{0 , 1 7}$ & 47 & $\mathbf{0 , 1 8}$ & 49 & 0,21 & 50 & 0,11 & 37 & 0,14 & 41 & 0,16 & 43 & 0,74 & 104 & 0,95 & 129 & 1,02 & 143 & 0,68 & 94 & 0,71 & 97 & $\mathbf{0 , 8 1}$ & 118 \\
\hline 1 & $\mathbf{0 , 0 0}$ & 22 & $\mathbf{0 , 0 1}$ & 24 & $\mathbf{0 , 0 2}$ & 24 & $\mathbf{0 , 0 0}$ & 19 & $\mathbf{0 , 0 1}$ & 20 & $\mathbf{0 , 0 2}$ & 21 & $\mathbf{0 , 1 4}$ & 38 & 0,15 & 35 & 0,14 & 39 & $\overline{0,08}$ & 27 & $\overline{0,08}$ & 28 & $\mathbf{0 , 0 7}$ & 34 \\
\hline DBV & $\mathbf{0 , 0 0}$ & 22 & $\mathbf{0 , 0 1}$ & 24 & $\overline{0,02}$ & 24 & $\mathbf{0 , 0 0}$ & 19 & $\overline{0,01}$ & 20 & $\mathbf{0 , 0 2}$ & 21 & $\mathbf{0 , 0 7}$ & 29 & $\mathbf{0 , 1 0}$ & 31 & $\mathbf{0 , 1 0}$ & 33 & $\mathbf{0 , 0 7}$ & 26 & $\mathbf{0 , 0 7}$ & 26 & 0,05 & 31 \\
\hline
\end{tabular}


TABELA 11 - Coeficiente de Correlação de Pearson entre Densidade Ótica (D.O.) e quantificação dos níveis de cinza (N.C.) para todos os grupos conjuntamente e para as combinações Ultra-speed/Kodak, Ultraspeed/Sillib, Insight/Kodak e Insight/Sillib, em todas as temperaturas, separadamente, com nível de confiança de $95 \%$

\begin{tabular}{c|c|c}
\hline \hline COMBINAÇÃO & D.O. X N.C. & $\mathbf{p}^{*}$ \\
\hline \hline TODOS OS GRUPOS & $\mathbf{0 , 9 4}$ & $<\mathbf{0 , 0 0 0 1}$ \\
\hline ULTRA-SPEED/KODAK & $\mathbf{0 , 9 3}$ & $<\mathbf{0 , 0 0 0 1}$ \\
\hline ULTRA-SPEED/SILLIB & $\mathbf{0 , 9 7}$ & $<\mathbf{0 , 0 0 0 1}$ \\
\hline INSIGHT/KODAK & $\mathbf{0 , 9 6}$ & $<\mathbf{0 , 0 0 0 1}$ \\
\hline INSIGHT/SILLIB & $\mathbf{0 , 9 6}$ & $<\mathbf{0 , 0 0 0 1}$ \\
\hline \hline
\end{tabular}

*Correlação estatisticamente significante quando $\mathrm{p}<0,05$. 


\section{Análise dos cristais de prata}

O filme Ultra-speed mostrou menor formação de aglomerados de cristais de prata em comparação ao Insight. Os cristais mostraram-se mais afilados e na maior parte, eram fusiformes. Observou-se uma deposição uniforme dos cristais quando se utilizaram as soluções Kodak e Sillib nas três temperaturas. Os cristais mostraram-se pequenos e regulares na maior parte da faixa analisada para todas as combinações. Notamos maior porcentagem de prata com o aumento da temperatura de ambas as soluções. A solução Kodak mostrou maior deposição de prata metálica em comparação com a solução Sillib, o que podemos confirmar tanto visualmente como por meio da análise dos valores da porcentagem de prata depositados na emulsão: 11,64, 13,05 e 16,05, respectivamente para as temperaturas de $20^{\circ}, 25^{\circ}$ e $30^{\circ} \mathrm{C}$ na solução Kodak e 5,85, 8,02 e 9,08, respectivamente, para a solução Sillib. A combinação que ofereceu maior deposição de prata foi solução Kodak a $30^{\circ} \mathrm{C}$ por 1,25 minuto de revelação $(16,05)$ e a menor, solução Sillib a $20^{\circ} \mathrm{C}$ por dois minutos de revelação $(5,85)$.

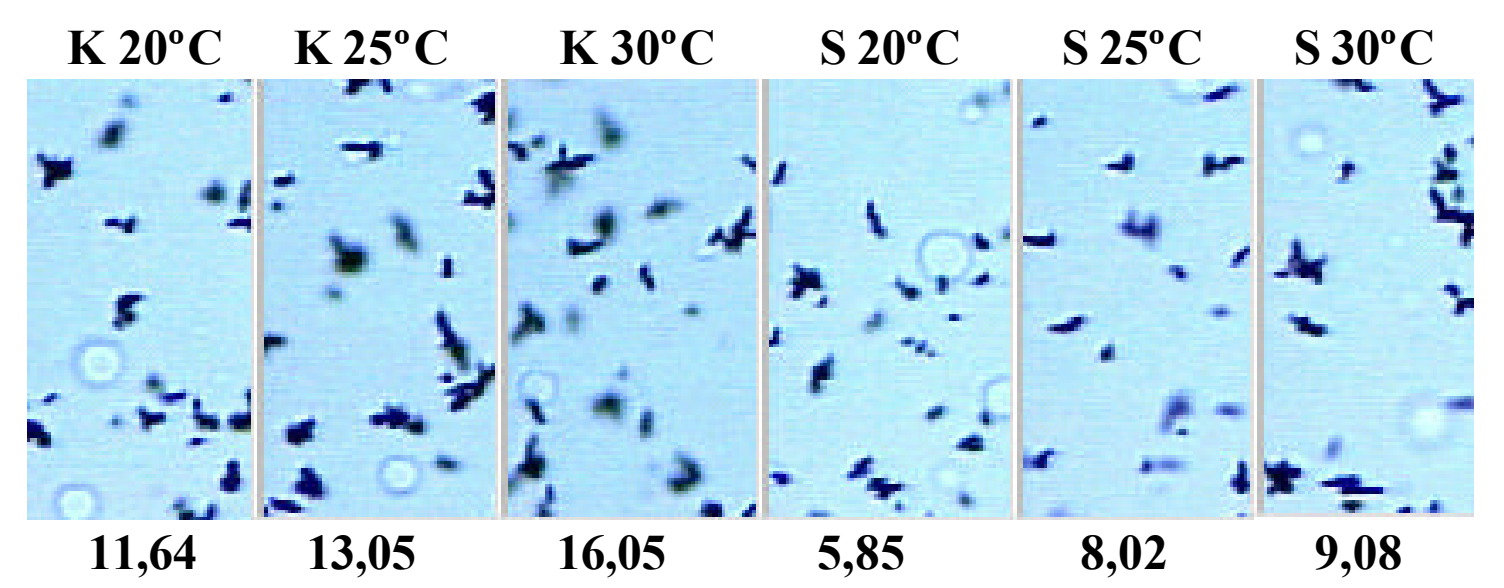

FIGURA 13 - Fotomicroscopia (100X) da emulsão do filme radiográfico Ultra-speed processado nas soluções Kodak (K) a $20^{\circ}, 25^{\circ}$ e $30^{\circ} \mathrm{C}$ e $\operatorname{Sillib}(\mathrm{S})$ a $20^{\circ}$, $25^{\circ}$ e $30^{\circ} \mathrm{C}$ e respectivas médias das porcentagens de prata depositada 
O filme Insight mostrou aglomeração maior de cristais de prata e com forma esférica em relação ao Ultra-speed. Observou-se maior deposição destes cristais quando se utilizou a solução Kodak nas temperaturas de $25^{\circ} \mathrm{C}$ e $30^{\circ} \mathrm{C}$, o que pode ser observado analisando os valores da porcentagem de prata depositada. Os cristais apresentaram-se menos regulares e maiores do que os do filme Ultra-speed. A solução Kodak, em todas as combinações estudadas, mostrou maior deposição e maior aglomeração de cristais de prata em comparação à solução Sillib, em todas as temperaturas. A solução Sillib em todas as combinações promoveu menor deposição de cristais de prata, sendo estes menores e mais regulares, com menor formação de aglomerados em comparação com a solução Kodak. A combinação com maior porcentagem de prata depositada foi a solução Kodak a $25^{\circ} \mathrm{C}$ por 2,5 minutos de revelação $(22,04)$ e, a menor, solução Sillib a $20^{\circ} \mathrm{C}$ por dois minutos de revelação $(10,16)$. Não houve diferença significativa, subjetivamente, em relação à deposição, tamanho e forma dos cristais de prata, nas diferentes soluções e temperaturas quando se utilizou o filme Insight. Não houve aumento da deposição de cristais de prata com o aumento da temperatura das soluções.

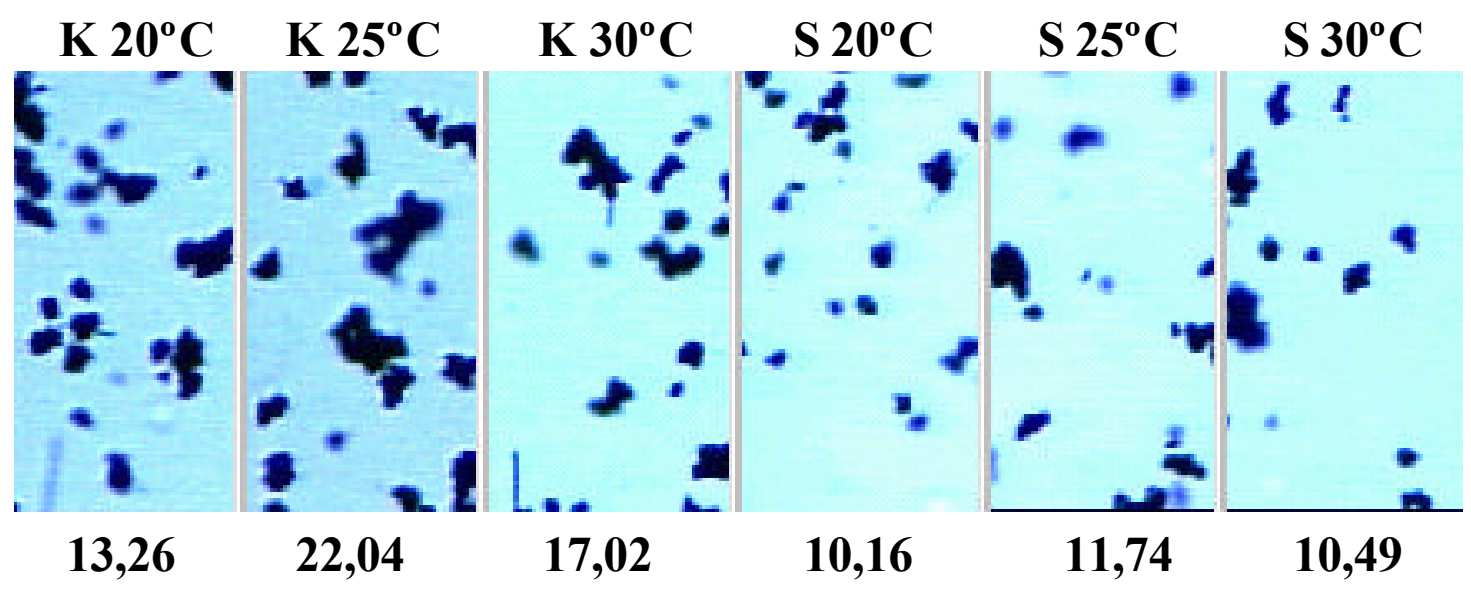

FIGURA 14 - Fotomicroscopia (100X) da emulsão do filme radiográfico Insight processado nas soluções Kodak (K) a $20^{\circ}, 25^{\circ}$ e $30^{\circ} \mathrm{C}$ e Sillib (S) a $20^{\circ}$, $25^{\circ}$ e $30^{\circ} \mathrm{C}$ e respectivas médias das porcentagens de prata depositada 
TABELA 12 - Comparativo entre os valores de Densidade Ótica (D.O.), quantificação dos níveis de cinza (N.C.) e Densidade de Volume de prata (D.V.), na faixa de 1 impulso de exposição em uma radiografia de cada combinação

\begin{tabular}{|c|c|c|c|c|c|c|c|c|c|c|c|c|c|c|c|c|c|c|}
\hline \multirow{3}{*}{$\begin{array}{c}\text { Soluções } \\
\text { Temperaturas } \\
\text { Filmes } \\
\end{array}$} & \multicolumn{9}{|c|}{ Kodak } & \multicolumn{9}{|c|}{ Sillib } \\
\hline & \multicolumn{3}{|c|}{$20^{\circ} \mathrm{C} / 5 \mathrm{~min}}$. & \multicolumn{3}{|c|}{$25^{\circ} \mathrm{C} / 2,5 \mathrm{~min}}$. & \multicolumn{3}{|c|}{$30^{\circ} \mathrm{C} / 1,25 \mathrm{~min}$} & \multicolumn{3}{|c|}{$20^{\circ} \mathrm{C} / 2 \mathrm{~min}$} & \multicolumn{3}{|c|}{$25^{\circ} \mathrm{C} / 1 \mathrm{~min}$} & \multicolumn{3}{|c|}{$30^{\circ} \mathrm{C} / 0,5 \mathrm{~min}}$. \\
\hline & D.O. & N.C. & D.V. & D.O. & N.C. & D.V. & D.O. & N.C. & D.V. & D.O. & N.C. & D.V. & D.O. & N.C. & D.V. & D.O. & N.C. & D.V. \\
\hline Ultra-speed & 0,00 & 22 & 11,64 & 0,01 & 24 & 13,05 & 0,03 & 26 & 16,05 & 0,00 & 19 & 5,85 & 0,01 & 20 & 8,02 & 0,02 & 21 & 9,08 \\
\hline Insight & 0,14 & 37 & 13,26 & 0,15 & 37 & 22,04 & 0,14 & 36 & 17,02 & 0,08 & 24 & 10,16 & 0,09 & 33 & 11,74 & 0,08 & 34 & 10,49 \\
\hline
\end{tabular}

TABELA 13 - Coeficiente de Correlação de Pearson entre Densidade Ótica (D.O.) e Densidade de Volume de prata (D.V.) e quantificação dos níveis de cinza (N.C.) e Densidade de Volume de prata em todos os grupos conjuntamente, com nível de confiança de $95 \%$

\begin{tabular}{c|c|c|c|c}
\hline \hline COMBINAÇÃO & \multicolumn{2}{|c|}{ D.O. X D.V. } & \multicolumn{2}{c}{ N.C. X D.V. } \\
\hline \hline \multirow{3}{*}{ TODOS OS GRUPOS } & $\mathrm{r}$ & $\mathrm{p}^{*}$ & $\mathrm{r}$ & $\mathrm{p}^{*}$ \\
\cline { 2 - 5 } & $\mathrm{0,66}$ & $\mathrm{0,019}$ & $\mathbf{0 , 6 9}$ & 0,012 \\
\hline \hline
\end{tabular}

*Correlação estatisticamente significante quando $\mathrm{p}<0,05$.

r - correlação 
6. DisCUSSÃo 


\section{DISCUSSÃO}

Utilizamos no presente trabalho os filmes radiográficos Ultraspeed e Insight, ambos da Kodak, processados em duas soluções processadoras, em diferentes temperaturas $\left(20^{\circ} \mathrm{C}, 25^{\circ} \mathrm{C}\right.$ e $\left.30^{\circ} \mathrm{C}\right)$ e diferentes tempos de revelação. O filme Ultra-speed utilizado pertence ao grupo D de sensibilidade e é, ainda, considerado por muitos profissionais, como o filme que oferece melhor qualidade de imagem ${ }^{39,64}$. Muitos trabalhos correlacionam os achados dos filmes mais recentemente lançados no mercado com os resultados bem estabelecidos encontrados para o filme Ultra-speed, podendo este filme ser considerado padrão em termos de qualidade de imagem. Muitos outros trabalhos falharam em mostrar a superioridade ou igualdade do filme Ektaspeed Plus e outros filmes lançados no mercado, de maior sensibilidade, em relação ao Ultra-speed.

O filme Insight, recentemente lançado no Brasil, é um filme do grupo $\mathrm{E} / \mathrm{F}$ de sensibilidade de acordo com as condições de processamento. Apresenta uma redução da dose de radiação que pode variar de $20 \%$ a $25 \%$ em relação ao Ektaspeed Plus ${ }^{37,66,102}$ e é comparável a ele quanto à qualidade de imagem (contraste, resolução, medidas endodônticas e detecção de cárie $)^{64,84,92}$. Em relação ao filme Ultra-speed, apresenta uma redução da dose de radiação de até $60 \%$ quando processado automaticamente $^{66}$. Alguns trabalhos mostraram que este novo filme apresenta algumas características que o tornam estável sob diferentes condições de processamento ${ }^{37,66}$. Há necessidade de se estudar este novo filme sob condições variadas de processamento e compará-las às propriedades de um filme bem estabelecido entre os profissionais quanto à qualidade de imagem. 
As soluções usadas para o processamento manual dos filmes radiográficos foram Kodak e Sillib. A solução Kodak é amplamente usada no Brasil e é considerada uma solução padrão, quando utilizada na temperatura de $20^{\circ} \mathrm{C}$ por cinco minutos ${ }^{1,16,32,50,51,107}$. A solução Sillib é considerada uma solução para processamento rápido, requerendo-se um total de dois minutos de revelação na temperatura de $20^{\circ} \mathrm{C}$, segundo as recomendações do fabricante. Muitos trabalhos mostraram a boa qualidade de imagem produzida por esta solução, apesar de ser considerada uma solução enérgica e os resultados mostrarem-se levemente inferiores aos da solução considerada padrão $25,97,103$.

O ajuste do tempo de revelação, de acordo com a temperatura das soluções, representa uma importante etapa do processamento radiográfico, pois além de influenciar na qualidade da imagem final, impede que ocorram superexposição e sub-revelação dos filmes, impedindo que o paciente seja exposto à radiação desnecessária ${ }^{32}$.

É sabido que o aumento na temperatura da solução pode resultar em diferenças nas propriedades sensitométricas dos filmes radiográficos analisados, pois ela afeta o processo de revelação, acelerando-o ou retardando-o, à medida que a mesma aumenta ou diminui $1^{34}$. Muitos trabalhos analisando o efeito da variação das temperaturas das soluções reveladoras sobre as propriedades sensitométricas dos filmes radiográficos concordam com esta afirmativa $a^{2,25,44,57,71,73,95,103,107}$. Estes trabalhos acrescentam ainda, que é necessário alterar as condições de processamento quando se testa um novo tipo de filme, alcançando assim, a melhor combinação para ser utilizada com o novo material.

O processamento dos filmes radiográficos Ultra-speed e Insight, em todas as combinações, foi realizado sob rígidas condições de 
padronização. O experimento foi repetido quatro vezes (radiografias 1, 2, 3 e 4) para maior precisão dos resultados alcançados.

Buscamos, com este experimento, as propriedades sensitométricas dos filmes radiográficos Ultra-speed e Insight, sob diferentes condições de processamento. As análises das tabelas e Curvas Características permitiram uma discussão sobre as propriedades dos filmes nas diferentes soluções e temperaturas utilizadas. Esta discussão foi organizada em tópicos de acordo com: Densidade base e velamento, Densidade Máxima e propriedades sensitométricas (sensibilidade e contraste) dos dois tipos de filmes em cada solução de maneira a organizar os dados e facilitar a leitura. Os dados referentes à Densidade Ótica, quantificação dos níveis de cinza e Densidade de Volume de prata com as respectivas análises estatísticas estão separados em tópicos colocados posteriormente.

\subsection{Densidade base e velamento}

Uma densidade base e velamento maior que 0,25, para filmes periapicais, é normalmente inaceitável pela maioria dos autores ${ }^{53}$. Analisando a Tabela 5 observamos que a densidade base e velamento em todas as combinações para os filmes Ultra-speed e Insight ficou bem abaixo da faixa de DBV considerada limite pela ISO $5799^{48}$ e ISO $3665^{49}(0,25$ para filmes do grupo D de sensibilidade e 0,35 para os filmes do grupo E/F). O filme Ultra-speed apresentou valores de DBV extremamente baixos nas soluções Kodak e Sillib em todas as temperaturas $(0,00,0,01$ e 0,02). Já o filme Insight mostrou valores mais elevados de DBV, sendo que o mais alto valor foi obtido com a solução Kodak nas temperaturas de $25^{\circ} \mathrm{C}$ e $30^{\circ} \mathrm{C}$ $(0,10)$ e o menor valor com a solução Sillib a $30^{\circ} \mathrm{C}(0,05)$. Os resultados 
encontrados por SYRIOPOULOS ${ }^{102}$ et al, em 2001 e LUDLOW; PLATIN; $\mathrm{MOL}^{66}$, em 2001, mostraram valores de DBV bem acima para o filme Insight $(0,24$ e 0,22 , respectivamente). A diferença entre os valores de DBV para os filmes Ultra-speed e Insight era esperado e confirmado por outros autores, onde se observa com freqüência, que os valores de DBV para o filme Ultra-speed são inferiores aos alcançados por qualquer outro filme ${ }^{66,84,100}$. Não houve diferença significativa entre estes valores com relação ao tipo de processamento utilizado.

\subsection{Densidade Máxima}

O maior valor de Densidade Máxima foi observado quando se utilizou o filme Insight processado na solução Kodak na temperatura de $20^{\circ} \mathrm{C}(5,73)$, seguido pela combinação Kodak a $25^{\circ} \mathrm{C}(5,53)$ e Sillib a $30^{\circ} \mathrm{C}$ $(5,38)$. A Densidade Máxima de menor valor foi alcançada quando se utilizou o filme Ultra-speed na combinação solução Sillib a $20^{\circ} \mathrm{C}(3,28)$. Os valores de Densidade Ótica para esta faixa de exposição, ficaram dentro de uma variação aceitável para todas as combinações, sendo que as diferenças observadas são pouco percebidas pelo olho humano e não apresentam significado prático no uso rotineiro da clínica. Foi observado que os filmes mais rápidos da Kodak, Ektaspeed, por exemplo, não alcançavam valores altos de Densidade Máxima ${ }^{108}$. Não foi observada tendência significante no aumento da Densidade Ótica de acordo com o aumento na temperatura da solução. O filme Ultra-speed quando processado na solução Kodak apresentou leve tendência no aumento da D.O., com o aumento das temperaturas $\left(20^{\circ} \mathrm{C}=3,93,25^{\circ} \mathrm{C}=4,16,30^{\circ} \mathrm{C}=4,16\right)$. Nas faixas de exposição de 60, 10 e 1 impulso, observa-se aumento da D.O. com o aumento da temperatura $(1,04,1,13$ e 1,$20 ; 0,17,0,18$ e 0,21;0,00, 0,01 e 
0,02). Já a solução Sillib apresentou inicialmente, a $20^{\circ} \mathrm{C}$, valor de D.O. igual a 3,28 , subindo para 3,51 a $25^{\circ} \mathrm{C}$ e caindo para 3,43 a $30^{\circ} \mathrm{C}$. Nas outras faixas de exposição o aumento da temperatura causou conseqüente aumento da D.O. O filme Insight na solução Kodak, apresentou, inicialmente, a $20^{\circ} \mathrm{C}$, D.O. de 5,73 , caindo para 5,53 a $25^{\circ} \mathrm{C}$ e para 5,02 a $30^{\circ} \mathrm{C}$. Na faixa de 60 impulsos houve um aumento de 4,28 para 4,56 à medida que se aumentou a temperatura de $20^{\circ}$ para $25^{\circ} \mathrm{C}$, sendo que a $30^{\circ} \mathrm{C}$ a D.O. se manteve (4,55). Na faixa de 10 impulsos de exposição observouse aumento da D.O. com o aumento da temperatura $(0,74,0,95$ e 1,02). Na faixa de 1 impulso a D.O. se manteve $(0,14,0,15$ e 0,14 , respectivamente, para as temperaturas de $20^{\circ}, 25^{\circ}$ e $30^{\circ} \mathrm{C}$ ). Já na solução Sillib, observou-se aumento progressivo da Densidade Máxima de acordo com o aumento da solução $\left(20^{\circ} \mathrm{C}-4,51,25^{\circ} \mathrm{C}-4,71\right.$ e $\left.30^{\circ} \mathrm{C}-5,38\right)$. Na faixa de 60 impulsos observou-se aumento da D.O. quando se aumentou a temperatura de $20^{\circ} \mathrm{C}$ $(3,46)$ para $25^{\circ} \mathrm{C}(3,63)$ e redução a $30^{\circ} \mathrm{C}(3,12)$. Na faixa de 10 impulsos a D.O. aumentou à medida que a temperatura aumentou $(0,68,0,71$ e 0,81$)$. Na faixa de 1 impulso a D.O. se manteve $(0,08,0,08$ e 0,07).

\subsection{Sensibilidade}

A Tabela 5 mostra que a combinação que apresentou a mais alta sensibilidade foi filme Insight processado na solução Kodak a $30^{\circ} \mathrm{C}$ $\left(107 R^{*}\right)$. Todas as combinações utilizando o filme Insight alcançaram sensibilidades dentro do grupo $\mathrm{F}$ sendo que, dentro deste grupo, a combinação menos sensível foi solução Sillib a $20^{\circ} \mathrm{C}\left(64,44 R^{*}\right)$. Estes valores estão de acordo com a norma ISO $5799^{48}$ e ISO $3665^{49}$ para sensibilidade de filmes radiográficos, onde filmes radiográficos intrabucais do grupo $\mathrm{F}$ de sensibilidade devem apresentar valores de 56 a 112R*. O 
interessante, nesta pesquisa, é observar que todas as combinações ofereceram ao filme Insight valores dentro do grupo $\mathrm{F}$ de sensibilidade e que o processamento realizado foi o manual. De acordo com as especificações do fabricante este filme se comporta dentro do grupo $\mathrm{F}$ de sensibilidade apenas quando processado automaticamente. $\mathrm{O}$ limite inferior para este grupo de sensibilidade é de $56 \mathrm{R}^{*}$, sendo que os valores aqui encontrados ficaram bem acima do mesmo. Já o limite superior é de 112R* e a combinação Kodak a $30^{\circ} \mathrm{C}$ mostrou valor bem próximo. A Figura 11 mostra a superposição das Curvas Características do filme Insight processado na solução Kodak nas temperaturas de $20^{\circ}, 25^{\circ}$ e $30^{\circ} \mathrm{C}$. Podemos observar que a $30^{\circ} \mathrm{C}$ a curva se posiciona mais à esquerda em relação às outras, mostrando a maior sensibilidade alcançada com esta combinação. A $25^{\circ} \mathrm{C}$, a curva se posiciona mais à esquerda quando comparada à curva de $20^{\circ} \mathrm{C}$, mostrando sua maior sensibilidade. Os recentes trabalhos analisando as propriedades sensitométricas do filme Insight mostraram valores de sensibilidade inferiores aos encontrados por nós, mesmo quando este filme foi processado automaticamente. SYRIOPOULOS ${ }^{102}$ et al, em 2001, encontraram valores de sensibilidade de 53,3 (E) para o filme Insight no processamento manual e 64,5 (F) no processamento automático. Muitas vezes este filme permanece dentro do limite superior do grupo $\mathrm{E}$ de sensibilidade ou no limite inferior do grupo $\mathrm{F}$ de sensibilidade. PRICE ${ }^{84}$, em 2001, mostrou que quando o filme Insight foi processado automaticamente, em química da Kodak a $28^{\circ} \mathrm{C}$, a sensibilidade foi de 56,2, justamente no limite inferior do grupo $\mathrm{F}$ de sensibilidade. Nossos resultados, quando utilizamos a química da Kodak a $25^{\circ}$ e $30^{\circ} \mathrm{C}$, no processamento manual, mostraram valores de 97,54 e $107 R^{*}$. GEIST; BRAND ${ }^{37}$, em 2001, tiveram valores de sensibilidade para 
o filme Insight de 66,1 (F) e 62,6 (F), quando processado em química nova e usada, respectivamente. $\mathrm{O}$ processamento realizado foi automático.

Na Figura 12 podemos observar a tendência de posicionamento das Curvas Características obtidas das combinações utilizando o filme Insight e a solução Sillib. A superposição destas curvas nos mostra que a combinação a $30^{\circ} \mathrm{C}$ posiciona-se mais à esquerda em relação às demais, em virtude da maior sensibilidade apresentada por esta combinação (83R*). A temperatura de $25^{\circ} \mathrm{C}\left(69,05 R^{*}\right)$ mostra um posicionamento mais à esquerda em relação à combinação de $20^{\circ} \mathrm{C}\left(64,44 R^{*}\right)$ e mais à direita em relação a $30^{\circ} \mathrm{C}\left(83 R^{*}\right)$, mostrando a menor sensibilidade de ambas.

O filme Ultra-speed apresentou sensibilidade do grupo D em todas as combinações, sendo mais sensível quando se utilizou a solução Kodak na temperatura de $30^{\circ} \mathrm{C}$, o que pode ser observado analisando a Figura 9, onde a curva referente a esta combinação apresenta-se mais à esquerda em relação às demais. A combinação menos sensível foi obtida com a solução Sillib a $25^{\circ} \mathrm{C}$, quando observamos, na Figura 9, a posição mais à direita desta curva em relação às demais. Analisando a Tabela 5, observamos que os valores de sensibilidade para o filme Ultra-speed ficaram dentro da faixa de variação proposta pela ISO $5799^{48}$ e ISO $3665^{49}$ para sensibilidade de filmes radiográficos (14 a 28R* para filmes do grupo D). A combinação Ultra-speed/Sillib a $20^{\circ} \mathrm{C}$ ficou no limite inferior desta faixa de variação, mostrando o quão baixa foi a sensibilidade deste filme. Nenhuma combinação se apresentou próxima ao limite máximo desta faixa de variação. Apesar de excelente qualidade de imagem, este filme requer uma quantidade de radiação muito alta para produzir imagem radiográfica e o seu uso atualmente é contra-indicado em Radiologia Odontológica, principalmente quando várias regiões do mesmo paciente devem ser radiografadas. Quando utilizamos a solução Kodak para o processamento 
do filme Ultra-speed, em todas as temperaturas, alcançamos valores de sensibilidades semelhantes aos relatados na literatura ${ }^{66,84,101}$.

Observou-se que, em todas as combinações utilizadas, para os dois tipos de filmes, houve um aumento da sensibilidade à medida que se aumentou a temperatura das soluções.

A solução Kodak ofereceu a ambos os tipos de filmes maiores valores de sensibilidades quando comparada à solução Sillib, em todas as temperaturas. Para o filme Ultra-speed podemos observar, na Tabela 5, que os valores de sensibilidade para a solução Kodak, nas temperaturas de $20^{\circ}$, $25^{\circ}$ e $30^{\circ} \mathrm{C}$, foram, respectivamente, $21,83,21,49$ e $23,94 R^{*}$ e para a solução Sillib, 14,43, 16,56 e 19,02R*. Para o filme Insight estes valores foram: solução $\operatorname{Kodak}(73,99,97,54$ e 107R*) e para a solução Sillib $\left(64,44,69,05\right.$ e $\left.83 R^{*}\right)$. Estes valores podem ser observados, graficamente, pela posição das Curvas Características das Figuras 9, 10, 11 e 12. Quando a curva se posiciona mais à esquerda nota-se a maior sensibilidade produzida ao filme pelo tipo de combinação temperatura/tempo de processamento.

\subsection{Contraste}

O contraste radiográfico de todas as combinações para ambos os filmes apresentou-se dentro de uma faixa aceitável de variação para este fator radiográfico que, de acordo com a norma ISO $5799^{48}$ e $3665^{49}$, deve ser de 1,8. A combinação que apresentou maior valor de contraste foi o filme Ultra-speed processado na solução Kodak a $30^{\circ} \mathrm{C}(1,78)$, valor mais próximo encontrado a ISO $5799^{48}$ e $3665^{49}$. Este valor de contraste pode ser observado analisando a Curva Característica da Figura 9. Nota-se uma menor inclinação da curva referente a este grupo em relação à inclinação 
das demais. Já a combinação filme Insight processado na solução Sillib a $30^{\circ} \mathrm{C}$, apresentou o valor mais baixo de contraste $(1,55)$, observado pela maior inclinação da Curva Característica para este grupo (Figura 12). Isto pode ter sido decorrente do pouco tempo de permanência do filme sob a atuação da solução de processamento, o que não permitiu que se trabalhasse adequadamente o contraste radiográfico. As demais combinações ofereceram contraste dentro desta faixa de variação, não havendo diferenças significativas entre os valores. Quando se utilizou a solução Kodak observou-se leve tendência no aumento do contraste à medida que se aumentava a temperatura da solução (filme Ultra-speed a $20^{\circ}, 25^{\circ}$ e $30^{\circ} \mathrm{C}$, respectivamente, $1,70,1,77$ e 1,78), filme Insight (1,62, 1,70 e 1,68). Estes resultados concordam com os encontrados por TAMBURÚS $^{103}$ em 1987, quando afirmou que todas as temperaturas avaliadas, $20^{\circ}, 22^{\circ}, 24^{\circ}$ e $26^{\circ} \mathrm{C}$, não alteraram substancialmente o contraste radiográfico, mantendo-se todos os valores dentro de uma faixa aceitável de variação. Já os resultados encontrados por $\mathrm{KOGON}^{57}$ et al, em 1985, mostraram que o aumento na temperatura de processamento acima de $22^{\circ} \mathrm{C}$, reduziu substancialmente o contraste, o que discorda dos nossos achados em relação à solução Kodak. A solução Sillib mostrou leve tendência em redução do contraste radiográfico à medida que se aumentava a temperatura da solução para ambos os tipos de filmes (filme Ultra-speed a $20^{\circ}, 25^{\circ}$ e $30^{\circ} \mathrm{C}$, respectivamente, $1,70,1,68$ e 1,66) e filme Insight $(1,71,1,71 \mathrm{e}$ 1,55), estando estes resultados de acordo com $\mathrm{KOGON}^{57}$ et al em 1985 Estas pequenas diferenças encontradas em relação ao contraste radiográfico não são notadas pelo profissional que examina uma radiografia ao negatoscópio $^{5}$. Os resultados mais próximos das especificações ISO $5799^{48}$ e $3665^{49}$ foram encontrados quando se utilizou o filme Ultra-speed processado na solução Kodak em todas as temperaturas (1,70, 1,77 e 1,78), 
porém estes resultados não diferem significativamente dos demais. Para GEIST; BRAND ${ }^{37}$, em 2001, que encontraram valores de contraste de 1,67 e 1,69 para o processamento automático de filmes Insight, em soluções novas e usadas, respectivamente, na faixa de densidade ótica de 0,25 a 2,0, é necessário examinar o contraste em diferentes faixas de variação de densidade ótica. Eles avaliaram também o contraste na faixa de variação de densidade entre 0,5 e 1,0, afirmando que em baixas densidades, cáries de esmalte incipientes podem ser identificadas. O contraste entre 0,7 e 1,3 é útil porque cáries e radiolucências periapicais freqüentemente exibem densidades nesta faixa. Segundo estes autores, o contraste em regiões mais escuras da imagem é uma boa medida das características do filme. BOERE; VAN $\mathrm{AKEN}^{9}$, em 1990, mostraram que diferenças entre os filmes tornamse mais pronunciadas em áreas de alta densidade da curva característica. Quando o contraste foi calculado entre 1,0 e 2,5, que é o limite superior de variação útil para diagnóstico, o contraste do Insight foi levemente maior que o do Ektaspeed Plus naquele estudo. SYRIOPOULOS ${ }^{101}$ et al, em 1999, mostraram resultados de contraste para o filme Ultra-speed processados em cinco diferentes soluções no processamento manual, bem superiores aos por nós encontrados. Na solução Kodak a $20^{\circ} \mathrm{C}$ por cinco minutos, o contraste foi de 2,08. Já PRICE ${ }^{84}$, em 2001, encontrou o valor de 1,84 para o contraste radiográfico deste filme quando processado automaticamente em química da Kodak. SYRIOPOULOS ${ }^{102}$ et al, em 2001, observaram contraste comparável para o Insight e Ultra-speed independentemente do processamento utilizado, estando nossos resultados de acordo com estes. 


\subsection{Quantificação dos níveis de cinza}

A quantificação dos níveis de cinza analisados pelo programa de imagem Adobe Photoshop 5.5 está representada nas Tabelas de 6 a 9, respectivamente para as combinações Ultra-speed/Kodak a $20^{\circ}, 25^{\circ}$ e $30^{\circ} \mathrm{C}$, Ultra-speed/Sillib a $20^{\circ}, 25^{\circ}$ e $30^{\circ} \mathrm{C}$, Insight/Kodak a $20^{\circ}, 25^{\circ}$ e $30^{\circ} \mathrm{C}$ e Insight/Sillib a $20^{\circ}, 25^{\circ}$ e $30^{\circ} \mathrm{C}$. Analisando estas tabelas podemos observar que os valores se apresentaram dentro de uma faixa normal de variação em todas as combinações utilizadas para o processamento de ambos os filmes, seguindo os valores de Densidade Ótica alcançados com o fotodensitômetro. Podemos observar que nas faixas de exposição de 60, 10 e 1 impulso, assim como na DBV, houve aumento dos valores da quantificação dos níveis de cinza à medida que se aumentou a temperatura das soluções Kodak e Sillib, quando se utilizou o filme Ultra-speed. Quando se utilizou o filme Insight na solução Kodak observou-se aumento do valor na faixa de 10 impulsos $(104,129$ e 143) e na faixa de DBV (29, 31 e 33). Na solução Sillib observou-se aumento do valor da quantificação dos níveis de cinza à medida que a temperatura aumentava nas faixas de 10 e 1 impulso de exposição, assim como na faixa de DBV. Estas tendências observadas nos valores da quantificação dos níveis de cinza para todas as combinações estão em concordância com a literatura pertinente ${ }^{18,23,24,52,80,94}$. Os valores de Densidade Ótica e da quantificação dos níveis de cinza das quatro radiografias de cada combinação com os dois tipos de filmes e dois tipos de soluções, nas cinco faixas de exposição, foram submetidos à análise estatística por meio do Coeficiente de Correlação de Pearson (Tabelas 10 e 11). 


\subsection{Densidade Ótica X Quantificação dos níveis de cinza}

O Coeficiente de Correlação de Pearson mostrou correlação estatisticamente significante entre os valores de Densidade Ótica e quantificação dos níveis de cinza em todos os grupos analisados conjuntamente $(0,94)$ e, em cada um deles, separadamente, com nível de confiança de 95\%. Para o filme Ultra-speed processado na solução Kodak em todas as temperaturas, a correlação foi de 0,93 e com a solução Sillib foi de 0,97. A correlação com o filme Insight na solução Kodak foi de 0,96, assim como para a solução Sillib. A correlação foi estatisticamente significante quando $p<0,05$ e em todas as combinações $p<0,0001$. Estes dados podem ser observados na Tabela 11. Os resultados da análise estatística estão de acordo com os encontrados na literatura ${ }^{23,24,52,80,94,109}$.

\subsection{Densidade de Volume de prata}

Analisando as Figuras 13 e 14 podemos observar a forma, o tamanho, a deposição e a formação de aglomerações dos cristais de prata na emulsão dos filmes radiográficos Ultra-speed e Insight em todas as combinações. Como era por nós esperado e, de acordo com a literatura pertinente ${ }^{17,70,75}$, pudemos observar que os cristais de prata da emulsão do filme radiográfico Ultra-speed apresentaram-se com formato fusiforme, menores e depositados mais uniformemente em relação ao filme Insight em ambas as soluções. A formação de aglomerados de prata foi menor para este filme. Observamos ainda que a porcentagem de prata depositada foi menor em todas as combinações em que se utilizou este filme e as soluções Kodak e Sillib. 
Já o filme Insight apresentou maior aglomeração de cristais de prata depositados na emulsão. Estes eram mais arredondados, maiores e mais irregulares que os do filme Ultra-speed, o que era esperado em virtude da maior sensibilidade deste filme. Estes resultados concordam com os encontrados na literatura ${ }^{17,70,75}$.

A solução Kodak mostrou deposição de cristais maiores, mais irregulares e maior formação de aglomerados em comparação à solução Sillib em todas as combinações, com ambos os filmes, talvez, em virtude do pouco tempo de ação da solução Sillib sobre os filmes radiográficos.

A leitura da porcentagem de prata na emulsão dos filmes radiográficos está representada na Tabela 12. Pela análise dos dados podemos observar que a maior deposição de prata foi observada na combinação filme Insight processado na solução Kodak a $25^{\circ} \mathrm{C}(22,04 \%)$, seguido das combinações Insight/Kodak a $30^{\circ} \mathrm{C}$ (17,02\%), Ultraspeed/Kodak a $30^{\circ} \mathrm{C}(16,05 \%)$, Insight/Kodak a $20^{\circ} \mathrm{C}(13,26 \%)$, Ultraspeed/Kodak a $25^{\circ} \mathrm{C}(13,05 \%)$, Insight/Sillib a $25^{\circ} \mathrm{C}(11,74 \%)$, Ultraspeed/Kodak a $20^{\circ} \mathrm{C}$ (11,64\%), Insight/Sillib a $30^{\circ} \mathrm{C} \quad(10,49 \%)$, Insight/Sillib a $20^{\circ} \mathrm{C}(10,16 \%)$, Ultra-speed/Sillib a $30^{\circ} \mathrm{C}(9,08)$, Ultraspeed/Sillib a $25^{\circ} \mathrm{C}(8,02 \%)$ e Ultra-speed/Sillib a $20^{\circ} \mathrm{C}(5,85 \%)$. A solução Sillib mostrou os menores valores de porcentagem de prata depositada na emulsão de ambos os filmes, o que não era por nós esperado, em virtude desta solução ser mais enérgica. Acreditamos que o tempo de permanência dos filmes radiográficos sob a ação da solução Sillib não foi suficiente para reduzir os cristais de prata à prata metálica tão eficientemente quanto à solução Kodak. Estes dados foram submetidos à análise estatística para correlacioná-los com os valores de Densidade Ótica e quantificação dos níveis de cinza, na faixa de 1 impulso de exposição em uma das radiografias de cada tipo de combinação. 


\subsection{Densidade Ótica X Quantificação dos níveis de cinza X Densidade de Volume de prata}

O Coeficiente de Correlação de Pearson mostrou correlação estatisticamente significante entre os valores de Densidade Ótica e Densidade de Volume de prata $(0,66)$ e entre quantificação dos níveis de cinza e Densidade de Volume de prata $(0,69)$ em todos os grupos estudados. Estes valores podem ser analisados na Tabela 13. Houve alta correlação estatística quando $\mathrm{p}<0,05 \mathrm{e}$, em ambos os casos, $\mathrm{p}=0,019$ e 0,012 , respectivamente. 


\section{CoNCLUSÕES}




\section{CONCLUSÕES}

Após a metodologia empregada na presente pesquisa onde se analisaram as propriedades sensitométricas de filmes radiográficos intrabucais Ultra-speed e Insight, ambos da Kodak, processados em diferentes condições de processamento nas soluções Kodak e Sillib e se correlacionaram três diferentes métodos de análise de filmes radiográficos e soluções de processamento, concluiu-se que:

- O filme Insight apresentou propriedades sensitométricas de excelentes qualidades quando processado nas soluções Kodak e Sillib, nas três temperaturas. $\mathrm{O}$ filme permaneceu dentro do grupo $\mathrm{F}$ de sensibilidade em todas as combinações utilizadas para o processamento manual, variando de $107 \mathrm{R}^{*}$ para a combinação Kodak a $30^{\circ} \mathrm{C}$ a $64,44 \mathrm{R}^{*}$ para a solução Sillib a $20^{\circ} \mathrm{C}$. O contraste manteve-se dentro de uma faixa aceitável de variação para este fator radiográfico, sendo que o maior valor foi obtido com a solução Sillib nas temperaturas de $20^{\circ} \mathrm{C}(1,71)$ e $25^{\circ} \mathrm{C}(1,71)$ e o menor valor foi alcançado quando se utilizou a solução Sillib a $30^{\circ} \mathrm{C}(1,55)$;

- A solução Kodak a $30^{\circ} \mathrm{C}$ ofereceu ao filme Insight a maior sensibilidade $\left(107 R^{*}\right)$ aliada a um contraste médio $(1,68)$, seguida das combinações solução Kodak a $25^{\circ} \mathrm{C}$ e solução Sillib a $25^{\circ} \mathrm{C}$ e a $20^{\circ} \mathrm{C}$, que aliaram alta sensibilidade com alto valor de contraste;

- O filme Insight mostrou-se bastante estável sob variadas condições de processamento;

- Quando se utilizou o filme Ultra-speed, a melhor combinação foi alcançada com a solução Kodak a $30^{\circ} \mathrm{C}$, que ofereceu ao filme o maior valor de sensibilidade $\left(23,94 \mathrm{R}^{*}\right)$ aliado ao maior valor de contraste $(1,78)$; 
- Houve alta correlação estatística entre os valores de Densidade Ótica e quantificação dos níveis de cinza, Densidade Ótica e Densidade de Volume de prata e quantificação dos níveis de cinza e Densidade de Volume de prata em todas as combinações com as soluções Kodak e Sillib para o processamento dos filmes Ultra-speed e Insight;

- Os três métodos de análises de filmes radiográficos e atividade de soluções de processamento mostraram alta correlação, com nível de confiança de $95 \%$ e podem ser utilizados no Controle de Qualidade em Radiologia Odontológica. 
REFERÊNCIAS BIBLIOGRÁFICAS 


\section{REFERÊNCIAS BIBLIOGRÁFICAS ${ }^{*}$}

1 - ACHUTTI, N.L.A.; TAVANO, O.; ALVARES, L.C. Estudo comparativo das propriedades sensitométricas de dois reveladores para filmes radiográficos periapicais: rápido (Gecker) e convencional. Estomat. Cult., v.11, n.1, p.47-59, jan./jun. 1977.

2 - AKDENIZ, B.G.; LOMÇALI, G. Densitometric evaluation of four radiographic processing solutions. Dentomaxillofac. Radiol., v.27, n.2, p.102-6, Mar. 1998.

3 - ALVARES, A.L.G.; ALVARES, L.C.; TAVANO, O. Estudo comparativo entre os filmes radiográficos dentais Agfa-Gevaert, Kodak Ultraspeed e Kodak Ektaspeed processados na solução Kodak. Estomat. Cult., v.16, n.1, p.8-13, jan./jun. 1986.

4 - ALVARES, L.C.; FREITAS, J.A.S. Da imprecisão dos marcadores de tempo de aparelhos de RX odontológicos. Rev. Fac. Odont. USP, v.5, n.3, p.275-84, jul./set. 1967.

5 - ALVARES, L.C.; FREITAS, J.A.S.; ESTEVAM, E. Alguns reveladores para filmes radiográficos dentais, estudados através da curva característica. Arq. Cent. Est. Fac. Odont., v.6, n.2, p.209-22, jul./dez. 1969.

6 - AMERICAN ACADEMY OF DENTAL RADIOLOGY QUALITY ASSURANCE COMMITTEE. Recomendations for quality

\footnotetext{
* Normas recomendadas para uso no âmbito da Universidade de São Paulo, com base no documento "Referências Bibliográficas: exemplos", emanado do Conselho Supervisor do Sistema Integrado de Bibliotecas da USP, em reunião de 20 de setembro de 1990.
} 
assurance in dental radiography. Oral Surg., v.55, n.4, p.421-6, Apr. 1983.

7 - AMERICAN STANDARDS ASSOCIATION. American standard method for the sensitometry of medical X-ray films: PH 2.9 1964. New York, ASA, 1964. p.6-10.

8 - BARATIERI, N.M.M.; TAVANO, O.; NAGEM FILHO, H. Análise do processo de exaustão do revelador e reforçador rápido Kodak para raios X. Estomat. Cult., v.14, n.1/2, p.61-7, jan./jun. 1984.

9 - BOERE, G.; VAN AKEN, J. Sensitometric properties of direct exposure dental x-ray films in relation to the characteristic curve. Dentomaxillofac. Radiol., v.19, p.49-54, May 1990.

10 - BORG, E.; GRÖNDAHL, H.G. On the dynamic range of different X ray photon detectors in intra-oral radiography. A comparison of image quality in film, charge-couple device and storage phosphor systems. Dentomaxillofac. Radiol., v.25, n.2, p.82-8, Apr. 1996.

11 - BRIDGMAN, J.B.; CAMPBELL, D.J. An update on dental radiology: quality and safety. N. z. dent. J., v.91, n.403, p.16-21, Mar.1995.

12 - BROOKS, S.L.; MILES, D.A. Advances in diagnostic imaging in dentistry. Dent. Clin. N. Amer., v.37, n.1, p.91-111, Jan. 1993.

13 - BROWN JÚNIOR, C.E. et al. Degradation of dental radiographic processing solutions. J. Amer. dent. Ass., v.87, n.6, p.1200-5, Nov. 1973.

14 - BRÜCKER, M.R.; TAVANO, O.; COSTA, N.P. Análise do comportamento das soluções RPX-Omat da Kodak através do 
método sensitométrico. Odonto. Cienc., v.7, n.13, p.37-52, jan. 1992.

15 - CASANOVA, M.L.S. Análise comparativa das variações de tempos de exposição, tipo de processamento e do efeito da degradação das soluções processadoras na qualidade da imagem radiográfica. Piracicaba, 2002, 153p. Dissertação (Mestrado) Faculdade de Odontologia de Piracicaba, Universidade Estadual de Campinas.

16 - CAStelo, M.P.G.; TAVANO, O.; LOPES, E.S. Comparação sensitométrica de um revelador rápido (Rayonal) com um revelador convencional (Kodak) para filmes radiográficos periapicais. Estomat. Cult., v.13, n.1, p.12-19, jan./jun. 1983.

17 - CAVAlCANTE, A.S.R.; TAVANO, O. Estudo da morfologia da prata metálica, formada em filmes periapicais, por ação de soluções de processamento convencional e monobanho. Rev. Odontol. UNESP., v.28, n.2, p.415-27, 1999.

18 - CHEN, S.K.; CHIANG, T.C. Digitizing of radiographs with a rollertype CCD scanner. Oral Surg., v.83, n.6, p.719-24, June 1997.

19 - CHONG, M.P.; DOCKING, A.R. The sensitometric properties of dental x ray films. Aust. dent. J., v.10, n.5, p.354-60, Oct. 1965.

20 - CONOVER, G.L.; HILDEBOLT, C.F.; ANTHONY, D. A comparison of six intra-oral X-ray films. Dentomaxillofac. Radiol., v.24, n.3, p.169-72, Aug. 1995. 
21 - CONOVER, G.L.; HILDEBOLT, C.F.; ANTHONY, D. Objective and subjective evaluations of Kodak Ektaspeed Plus dental x-ray film. Oral Surg., v.70, n.2, p.246-50, Feb. 1995.

22 - CZAJKA, J. et al. Sensitometric and image quality performance of "rapid" intraoral film processing techniques. Brit. J. Radiol., v.69, n.817, p.49-58, Jan. 1996.

23 - DEZOTTI, M.S.G. Avaliação da densidade ótica e das densidades radiográficas, utilizando filmes radiográficos Agfa Dentus M2 “Comfort" processados em três soluções de processamento em diferentes temperaturas. Bauru, 2000. 145p. Dissertação (Mestrado) - Faculdade de Odontologia de Bauru, Universidade de São Paulo.

24 - DEZOTTI, M.S.G.; TAVANO, O. Comparações das densidades óticas e digital radiográfica do filme periapical Agfa Dentus M2 "Comfort" processado na solução Agfa Dentus em três temperaturas. Rev. ABRO, v.3, n.1, p.19-28, jan./jun. 2002.

25 - DEZOTTI, M.S.G.; TAVANO, O. Propriedades sensitométricas do filme Agfa Dentus M2 "Comfort” processado na solução Sillib em três diferentes temperaturas. Rev. ABRO, v.1, n.3, p.27-35, set./dez. 2000.

26 - DUNN, M.S; KANTOR, M.L. Digital radiology: facts and fictions. J. Amer. dent. Ass., v.124, n.2, p.39-47, Dec. 1993.

27 - EASTMAN KODAK COMPANY. Sensitometric properties of x-ray films. Rochester, New York, 1974. p.3-18. 
28 - FARMAN, A.G. et al. In vivo comparison of Visualix-2 and Ektaspeed Plus in the assessment of periradicular lesion dimensions. Oral Surg., v.85, n.2, p.203-9, Feb. 1998.

29 - FARMAN, T.T.; FARMAN, A.G. Evaluation of a new F speed dental X-ray film. The effect of processing solutions and a comparison with D and E speed films. Dentomaxillofac. Radiol., v.29, n.1, p.41-5, Jan. 2000.

30 - FERREIRA, R.A. Odontologia em imagens. Rev. Ass. paul. cirurg. Dent., v.50, n.3, p.218-28, maio/jun. 1996.

31 - FLETCHER, J.C. A comparison of Ektaspeed and Ultra-speed films using manual and automatic processing solutions. Oral Surg., v.63, n.1, p.94-102, Jan. 1987.

32 - FONTÃO, F.N.G.K. et al. Estudo sensitométrico de filme periapical, processado em soluções Kodak, à temperatura de $40^{\circ} \mathrm{C}$, com diferentes tempos de revelação. Salusvita, v.16, n.1, p.77-85, 1997.

33 - FREDHOLM, V.; JULIN, P. Rapid developing of ektaspeed dental film by increase of temperature. Swed. dent. J., v.11, n.2, p.1216, 1987.

34 - FUCHS, A.W. X-ray film. In: . Principles of radiographic exposure and processing. 2.ed. Springfield, Thomas, 1979. p.119.

35 - FUJITA, M. et al. Digital image processing of dentomaxillofacial radiographs. Oral Surg., v.64, n.4, p.485-93, Oct. 1987. 
36 - FUJITA, M. et al. Digital image processing of periapical radiographs. Oral Surg., v.65, n.4, p.490-4, Apr. 1988.

37 - GEIST, J.R.; BRAND, J.W. Sensitometric comparison of speed group E and F dental radiographic films. Dentomaxillofac. Radiol., v.30, n.3, p.147-52, May 2001.

38 - GEIST, J.G.; GLEASON, M.J. Densitometric properties of rapid manual processing solutions: Abbreviated versus complete rapid processing. J. Endod., v.21, n.4, p.180-4, Apr. 1995.

39 - GEIST, J.R.; KATZ, J.O. Radiation dose-reduction techniques in North American dental schools. Oral Surg., v.93, n.4, p.496-505, Apr. 2002.

40 - GHILARDI NETO, T. et al. Características sensitométricas de filmes utilizados em radiologia odontológica. Odont. mod., v.15, n.2, p.6-12, mar. 1988.

41 - GOAZ, P.W.; WHITE, S.C. Processing X-ray film. In: Oral radiology, principles and interpretation. 3.ed. St. Louis, Mosby, 1994. p.106-25.

42 - GRATT, B.M.; BEIDEMAN, R.W. Quality assurance. In: GOAZ, P.W.; WHITE, S.C. Oral radiology: principles and interpretation. 2.ed. St. Louis, Mosby, 1987. p.142-60.

43 - GRATT, B.M.; GOULD, R.G. Clinical trials of dental radiographic quality control system. Dentomaxillofac. Radiol., v.12, n.1, p.358, 1983.

44 - HASHIMOTO, K.; THUNTHY, K.H.; WEINBERG, R. Automatic processing: effects of temperature and time change on 
sensitometric properties of Ultraspeed and Ektaspeed films. Oral Surg., v.71, n.1, p.120-4, Jan. 1991.

45 - HINTZE, H.; WENZEL, A.; JONES, C. In vitro comparison of D and E speed film radiography, RVG, and Visualix digital radiography for the detection of enamel approximal and dentinal occlusal caries lesions. Caries Res., v.28, n.5, p.363-7, Sept./Oct. 1994.

46 - HUDA, W. et al. Comparison of a photostimulable phosphor system with film for dental radiology. Oral Surg., v.83, n.6, p.725-31, June 1997.

47 - HURTER, F.; DRIFFIELD, V.C. Photo-chemical investigations and a new method of determination of the sensitiveness of photographic plates. J. Soc. Chem. Industr., v.9, n.31, p.455-96, May 1890.

48 - INTERNATIONAL ORGANIZATION FOR STANDARDIZATION. International Standard ISO 5799. International standard for photography - direct exposing medical and dental radiographic film/process systems. Determination of ISO speed and ISO average gradient. $2^{\text {nd }}$ ed. ISO, 1991.

49 - INTERNATIONAL ORGANIZATION FOR STANDARDIZATION. International Standard ISO 3665. Photography - Intraoral dental radiographic film - Specification. $2^{\text {nd }}$ ed. ISO, 1996.

50 - IUCIF, P.P. Análise da solução Agfa dentus D e F utilizada para processamento manual de filmes radiográficos periapicais. Bauru, 1994. 124p. Dissertação (Mestrado) - Faculdade de Odontologia de Bauru, Universidade de São Paulo. 
51 - IUCIF, P.P.; TAVANO, O. Avaliação da solução Agfa Dentus D e F quando utilizada no processamento manual do filme radiográfico periapical Agfa M2 "Comfort". Rev. Fac. Odont. Bauru, v.3, n.1/4, p.81-6, jan./dez. 1995.

52 - IWAKI, L.C.V. Estudo comparativo das densidades ótica e radiográficas de tiras sensitométricas obtidas no sensitômetro IDIM. Bauru, 2000. 95p. Dissertação (Mestrado) - Faculdade de Odontologia de Bauru, Universidade de São Paulo.

53 - KAFFE, I. et al. Densitometric evaluation of three x-ray films with five different developing solutions. Oral Surg., v.57, n.2, p.20711, Feb. 1984.

54 - KAFFE, I.; LITTNER, M.M.; KUSPET, M.E. Densitometric evaluation of intraoral $\mathrm{X}$ ray films: ektaspeed versus ultraspeed. Oral Surg., v.57, n.3, p.338-42, Mar. 1984.

55 - KAFFE, I.; LITTNER, M.M.; TAMSE, A. Densitometric evaluation of three x-ray films with five different developing solutions. Oral Surg., v.2, n.57, p.207-11, Feb. 1984.

56 - KERBAUY, W.D.; MORAES, L.C. Processamento digital de imagens de radiografias periapicais subexpostas aos raios X. Rev. Odont. UNESP, v. 25, p.157-70, 1996. Número especial.

57 - KOGON, S. et al. The effects of processing variables on the contrast of type D and type E dental film. Dentomaxillofac. Radiol., v.14, n.1, p.65-8, Jan./June 1985. 
58 - LANGLAND, O.E.; SIPPY, F.H.; LANGLAIS, R.P. Attenuation and recording the radiographic image. In: . Textbook of dental radiology. 3. ed. Illinois, Thomas, 1984. p.88-129.

59 - LANGLAND, O.E.; SIPPY, F.H.; LANGLAIS, R.P. Diagnostic quality of dental radiographs. In: . Textbook of dental radiology. 2.ed. Springfield, Thomas, 1984. p.130-52.

60 - LILIENTHAL, B. Minimizing radiation exposure in dental radiology.Hazards and precautions. Aust. dent. J., v.19, n.5, p.302-12, Oct. 1974.

61 - LOUZADA, M.J.Q. Avaliações de densidade óssea em imagens radiográficas: estudo em peças ósseas de cães. Rev. bras. Eng., v.14, n.1, p.47-64, jan./jun. 1998.

62 - LOUZADA, M.J.Q. Metodologia para avaliação de densidade em imagem radiográfica. Rev. bras. Eng., v.14, n.2, p.37-47, jul./dez. 1998.

63 - LUDLOW, J.B. et al. The efficacy of caries detection using three intraoral films under different processing conditions. J. Amer. dent. Ass., v.128, n.10, p.1401-7, Oct. 1997.

64 - LUDLOW, J.B.; ABREU JR, M.; MOL, A. Performance of a new Fspeed film caries detection. Dentomaxillofac. Radiol., v.30, n.2, p.110-3, Mar. 2001.

65 - LUDLOW, J.B.; PLATIN, E.; HILL, C. Densitometric comparisons of Ultra-speed, Ektaspeed and Ektaspeed Plus intraoral films for two processing conditions. Oral Surg., v.79, n.1, p.105-13, Jan. 1995. 
66 - LUDLOW, J.B.; PLATIN, E.; MOL, A. Characteristics of Kodak Insight, an F-speed intraoral film. Oral Surg., v.91, n.1, p.120-9, Jan. 2001.

67 - MACDAVID, W.D.; TAYLOR, E.E. Quality assurance. In: LANGLAND, O.E.; SIPPY, F.H.; LANGLAIS, R.P. Textbook of dental radiology. 2.ed. Springfield, Thomas, 1984. p.352-66.

68 - MADDALOZZO, D.; KNOEPPEL, R.O.; SCHOENFELD, C.M. Performance of seven rapid radiographic processing solutions. Oral Surg., v.69, n.3, p.382-7, Mar. 1990.

69 - MANSON-HING, L.R.; PATEL, J.R. Densitometric evaluation of quick X ray developing solutions. Oral Surg., v.43, n.3, p.467-72, Mar. 1977.

70 - MATOS, A.S.R.C. Estudo do comportamento da prata metálica, através das densidades ópticas e de volume, com filmes radiográficos processados nas soluções convencional e monobanho. Bauru, 1987. 218p. Tese (Doutorado) - Faculdade de Odontologia de Bauru, Universidade de São Paulo.

71 - MATTHEE, M.J.; BECKER, P.J.; SEELIGER, J.E. The effect of varying processing solution temperature on radiographic contrast and relative film speed of dental film. J. dent. Ass. S. Africa, v.45, n.12, p.525-8, Dec. 1990.

72 - MATTHEE, M.J.; SEELIGER, J.E. Densitometric evaluation of seven dental film processing solutions. J. dent. Ass. S. Africa, v.45, n.1, p.31-3, Feb. 1990. 
73 - MATTHEE, M.J; SEELIGER, J.E. Densitometric evaluation of four rapid dental film processing solutions. J. dent. Ass. S. Africa, v.46, n.9, p.467-9, Sept. 1991.

74 - MATTHEE, M.J. et al. Influence of time and exposure to air on radiographic contrast and relative film speed of three rapid dental film processing solutions. J. dent. Ass. S. Africa, v.48, n.1, p.58, Jan. 1993.

75 - MENDONÇA, E.F. Estudo do processamento e da exaustão do filme periapical Ektaspeed, nas soluções Kodak (convencional) e Inodon (monobanho), através da análise subjetiva e das densidades óptica e de volume de prata. Bauru, 1988. 217p. Tese (Doutorado) - Faculdade de Odontologia de Bauru, Universidade de São Paulo.

76 - MILES, D.A.; RAZZANO, M.R. The future of digital imaging in dentistry. Dent. Clin. N. Amer., v.44, n.2, p.427-38, Apr. 2000.

77 - MONTEBElO FILHO, A.; TAVANO, O. Degradação da solução Kodak dental em recipientes de plástico com tampas (protegidos) e em recipientes de vidro transparentes (desprotegidos). Rev. Odont. USP, v.7, n.1, p.55-62, jan./mar. 1993.

78 - MOYSTAD, A. et al. Detection of approximal caries with a storage phosphor system. A comparison of enhanced digital images with dental X-ray film. Dentomaxillofac. Radiol., v.25, n.4, p.202-6, Sept. 1996.

79 - NAIR, M.K.; NAIR, U.P. An vitro evaluation of Kodak Insight and Ektaspeed Plus film with a CMOS detector for natural proximal 
caries: ROC analysis. Caries Res., v.35, n.5, p.354-9, Sept./Oct. 2001.

80 - PAVAN, A.J. Avaliação da solução Kodak quando utilizada para o processamento de filmes intrabucais DF-58, no que se refere às densidades ótica $\mathrm{e}$ radiográficas analisadas pelo fotodensitômetro MRA e pelo sistema digital Digora. Bauru, 1999. 95p. Tese (Doutorado) - Faculdade de Odontologia de Bauru, Universidade de São Paulo.

81 - PINHO, M.B.; TAVANO, O.; LOPES, E.S. Análise das variações dos tempos de exposição e de revelação dos filmes periapicais Kodak (Ektaspeed) e Agfa Gevaert (Dentus M2). Rev. Odont. USP, v.1, n.1, p.21-30, jan./mar. 1987.

82 - PRICE, C. A method of determining the sensitometric properties of emulsions and processing techniques in dental radiography. Oral Surg., v.50, n.1, p.94-8, July 1980.

83 - PRICE, C. Sensitometric evaluation of a new E-speed dental radiographic film. Dentomaxillofac. Radiol., v.24, n.1, p.30-6, Feb. 1995.

84 - PRICE, C. Sensitometric evaluation of a new F-speed dental radiographic film. Dentomaxillofac. Radiol., v.30, n.1, p.29-34, Jan. 2001.

85 - RIBEIRO, A.; TAVANO, O.; PEREIRA, P.P.I. Avaliação do comportamento da solução Hexa, e de sua degradação, através do método sensitométrico. Rev. Odont. USP, v.2, n.2, p.68-73, maio/jun. 1994. 
86 - RIBEIRO, R.F.; TAVANO, O. Avaliação da exaustão da solução reveladora Ray em câmara escura portátil de processamento. Rev. Odont. USP, v.7, n.3, p.167-71, jul./set. 1993.

87 - RODRIGUES, C.B.F.; TAVANO, O. Avaliação sensitométrica de filmes radiográficos da Kodak processados na processadora automática Dupont Cronex T4, utilizando solução Kodak RPX OMat em diferentes temperaturas. Rev. Fac. Odont. Bauru, v.2, n.2, p.14-22, abr./jun. 1994.

88 - ROUT, P.G.J. et al. A comparison of manual and automatic processing in general dental practice. Brit. dent. J., v.181, n.3, p.99-101, Aug. 1996.

89 - RUSHTON, V.E.; HORNER, K. The impact of quality control on radiography in general dental practice. Brit. dent. J., v.179, n.7, p.254-61, Oct. 1995.

90 - SÁ, M.S.H.; ALVARES, L.C.; TAVANO, O. Análise comparativa de variações de tempos de exposição e revelação no filme radiográfico periapical DF-58. Estomat. Cult., v.16, n.1, p.1-7, jan./mar. 1986.

91 - SANDERINK, G.C.H. Imaging: new versus traditional technological. Int. dent. J., v.43, n.4, p.335-42, Aug. 1993.

92 - SHEAFFER, J.C. et al. A comparison of D-, E-, and F-speed conventional intraoral radiographic films in endodontic measurement. Oral Surg., v.93, n.3, p.321-7, Mar. 2002.

93 - SILHA, R.E. The new Kodak ektaspeed dental X ray film. Dent. Radiogr. Photogr., v.54, n.2, p.32-5, 1981. 
94 - SILVA, P.G. Comparação das densidades Óticas e Radiográficas analisadas pelo fotodensitômetro MRA e pelo "Software" Adobe Photoshop 4.0 dos filmes Kodak TMS-1 processados na solução Kodak RP X-OMAT, a diferentes temperaturas na processadora CRONEX T4. Bauru, 1999. 113p. Tese (Doutorado) - Faculdade de Odontologia de Bauru, Universidade de São Paulo.

95 - SILVEIRA, V.M. et al. Avaliação objetiva do comportamento de filmes radiográficos panorâmicos em diferentes condições de processamento. Rev. ABRO, v.3, n.2, p.63-9, jul./dez. 2002.

96 - SONODA, M. et al. Computed radiography utilizing scanning laser stimulated luminescence. Radiology, v.148, n.3, p.833-8, Sept. 1983.

97 - SPOSTO, M.R.; TAVANO, O.; LOPES, E.S. Avaliação do comportamento de dois reveladores (Kodak e Sillib) utilizados para filmes radiográficos periapicais, através de estudo sensitométrico. Estomat. Cult., v.13, n.1, p.61-7, jan./jun. 1983.

98 - SULEIMAN, O.H. et al. Radiographic trends of dental officies and dental schools. J. Amer. dent. Ass., v.130, n.5, p. 1104-10, July 1999.

99 - SWART, T.J.P.; SEELIGER, J.E. Densitometric evaluation of intraoral radiographic film-processing solution combinations. J. dent. Ass. S. Africa, v.44, n.7, p.281-3, July 1989.

100 - SYRIOPOULOS, K. et al. Effects of developer exhaustion on the sensitometric properties of four dental films. Dentomaxillofac. Radiol., v.28, n.2, p.80-8, Mar. 1999. 
101 - SYRIOPOULOS, K. et al. Sensitometric evaluation of four dental xray films using five processing solutions. Dentomaxillofac. Radiol., v.28, n.2, p.73-9, Mar. 1999.

102 - SYRIOPOULOS, K. et al. Sensitometric and clinical evaluation of a new F-speed dental X-ray film. Dentomaxillofac. Radiol., v.30, n.1, p.40-4, Jan. 2001.

103 - TAMBURÚS, J.R. Efeitos das variações da temperatura do revelador sobre o contraste e a densidade radiográfica. Rev. Ass. paul. Cirurg. Dent., v.41, n.4, p.218-21, jul./ago. 1987.

104 - TAMBURÚS, J.R.; LAVRADOR, M.A.S. Radiographic contrast. A comparative study of three dental X-ray films. Dentomaxillofac. Radiol., v.26, n.4, p.201-5, July 1997.

105 - TAVANO, O. Estudo do comportamento de filmes radiográficos periapicais (Rinn, Flow e Kodak) quando processados nos líquidos Continental Hexa, Sillib e Kodak. Determinação das mudanças de $\mathrm{pH}$ e cor e da exaustão destas soluções de processamento. Bauru, 1981. 139p. Tese (Livre Docência) Faculdade de Odontologia de Bauru, Universidade de São Paulo.

106 - TAVANO, O.; ALVARES, L.C. Comparação das propriedades sensitométricas de dois reveladores rápidos (Gecker e Tiplimatic), com um convencional, para filmes radiográficos dentais. Ars curandi Odont., v.4, n.11, p.39-47, fev. 1978.

107 - TAVANO, O.; CAPELOZZA, A.L.; FONTÃO, F.N.G.K. Análise sensitométrica de filmes periapicais, processados à temperatura de $35^{\circ} \mathrm{C}$ com diferentes tempos de revelação. Rev. Fac. Odont. Bauru, v.4, n.3/4, p.63-8, jul./dez. 1996. 
108 - TAVANO, O.; DEZOTTI, M.S.G. Filmes radiográficos Ektaspeed e Ultraspeed, processados em soluções Kodak, em diferentes concentrações. Rev. ABRO, v.1, n.3, p.7-15, set./dez. 2000.

109 - TAVANO, O.; DEZOTTI, M.S.G.; IWAKI, L.C.V. Comparação entre a densidade ótica obtida pelo método convencional e densidade radiográfica obtida pelo programa Adobe Photoshop 5.0 em filmes radiográficos Kodak TMS-1. Rev. ABRO, v.1, n.2, maio/ago. 2000.

110 - TAVANO, O.; ESTEVAM, E. A imagem radiológica. In: ALVARES, L.C.; TAVANO, O. Curso de radiologia em odontologia. 4. ed. São Paulo, Editora Santos, 1998. p.17-43.

111 - THOROGOOD, D.; HORNER, K.; SMITH, N.J.D. Quality control in the processing of dental radiographs. A pratical guide to sensitometry. Brit. dent. J., v.164, n.9, p.282-7, May 1988.

112 - THUNTHY, K.H.; WEINBERG, R. Sensitometric comparison of Kodak Ektaspeed Plus, Ektaspeed, and Ultra-speed dental films. Oral Surg., v.79, n.1, p.114-6, Jan. 1995.

113 - TJELMELAND, E.M. et al. A perceptibility curve comparison of Ultraspeed and Ektaspeed Plus films. Oral Surg., v.85, n.4, p.485-8, Apr. 1998.

114 - VAN DER STELT, P.F. Modern radiographic methods in the diagnosis of periodontal disease. Adv. dent. Res., v.7, n.2, p.158-62, Aug. 1993.

115 - VAN DER STELT, P.F. Principles of digital imaging. Dent. Clin. N. Amer., v.44, n.2, p.237-48, Apr. 2000. 
116 - VAN DIS, M.L.; BECK, F.M.; MILES, D.A. Video enhancement of dental radiographic films. Oral Surg., v.68, n.2, p.226-31, Aug. 1989.

117 - VANDRE, R.H.; WEBBER, R.L. Future trends in dental radiology. Oral Surg., v.80, n.4, p.471-8, Oct. 1995.

118 - WAKOH, M. et al. Comparing the sensitometric properties of dental X-ray films. J. Amer. dent. Ass., v.126, n.3, p.341-4, Mar. 1995.

119 - WELANDER, U. et al. Basic technical properties of a system for direct acquisition of digital intraoral radiographs. Oral Surg., v.75, n.4, p.506-16, Apr. 1993.

120 - WENZEL, A. Current trends in radiographic caries imaging. Oral Surg., v.80, n.5, p.527-39, Feb. 1995.

121 - WENZEL, A. Effect of image enhancement for detectability of bone lesions in digitized intraoral radiographs. Scand. J. dent. Res., v.96, p.149-60, 1988.

122 - WENZEL, A. Effect of varying gray-scale resolution for detectability of bone lesions in intraoral radiographs digitized for teletransmission. Scand. J. dent. Res., v.95, p.483-92, 1987.

123 - WENZEL, A.; GRÖNDAHL, H.G. Direct digital radiography in the dental office. Int. dent. J., v.45, n.1, p.27-34, Feb. 1995.

124 - WHITE, S.C.; YOON, D.C. Comparison of sensitometric and diagnostic performance of two films. Comp. Cont. Educ. Dent., v.21, n.6, p.530-9, June 2000. 
125 - WHITE, S.C. et al. Parameters of radiologic care: an official report of the American Academy of Oral and Maxillofacial Radiology. Oral Surg., v.91, n.5, p.498-511, May 2001.

126 - YACOVENCO, A. et al. Programa de garantia de qualidade em radiologia diagnóstica. Rev. bras. Eng., v.10, n.2, p.7-18, 1995.

127 - YACOVENCO, A. et al. Radiología diagnóstica y programa de garantía de calidad: evaluación crítica. Rev. bras. Eng., v.13, n.3, p.69-80, jul. 1997.

128 - YAKOUMAKIS, E.N. et al. Image quality assessment and radiation doses in intraoral radiography. Oral Surg., v.91, n.3, p.362-8, Mar. 2001.

129 - ZENÓBIO, E.G.; FERREIRA, A.F. Estudo das perdas ósseas periodontais através da imagem radiográfica digitalizada. Rev. gaúcha Odont., v.45, n.1, p.12-4, jan./fev. 1997.

130 - ZUBERY, Y.; DOVE, S.B.; EBERSOLE, J. An in vitro study of the characteristics of a computer-aided radiographic evaluation (CARE) system for longitudinal assessment of density changes.

J. Periodont. Res., v.28, n.4, p.233-40, July 1993. 
AbStraCt 


\section{ABSTRACT}

Appraising the behavior of radiographic films and the activity of processing solutions is one of the stages of the Quality Control, which should be implemented in all Oral Radiology clinics. Modern Oral Radiology evolves continuously in what relates to the manufacture of materials and the updating of techniques which can reduce even further the dose of radiation emitted to the patient. A concrete example of that is the wide acceptance of image acquisition digital systems and the release of increasingly sensitive radiographic films. The objective of the present work was to evaluate the sensitometric properties of the novel film released by Kodak, the Insight (IP-21), processed in different combinations of solutions/temperature/time, comparing them to the characteristics of the Ultra-speed (DF-58) film. Three different methods of analysis of the behavior of films and processing solutions were used in this appraisal, aiming to correlate them. The methods used were: conventional, when we obtained the Optical Densities from a photodensitometer; digital, which evaluates the amount of gray levels of the image after the digitalization of a radiographic film and morphometric, which evaluates the shape, the size and the percentage of silver crystals deposited on the emulsion of a radiographic film after its processing. The periapical films under examination were exposed in the standard mode and processed in Kodak solution at $20^{\circ} \mathrm{C}$ for 5 minutes, at $25^{\circ} \mathrm{C}$ for 2,5 minutes and at $30^{\circ} \mathrm{C}$ for 1,25 minute, and Sillib solution at $20^{\circ} \mathrm{C}$ for 2 minutes, at $25^{\circ} \mathrm{C}$ for 1 minute and at $30^{\circ} \mathrm{C}$ for 0,5 minute. For the reading of the Optical Densities it was used a photodensitometer MRA. For the quantification of gray levels and morphometry of the crystals it was used the software Adobe Photoshop 5.5. The outcomes showed that the Insight film presented group F sensitivity in 
all combinations evaluated, even in manual processing, being more sensitive in the Kodak solution at $30^{\circ} \mathrm{C}$ and less sensitive in the Sillib solution at $20^{\circ} \mathrm{C}$. The Ultra-speed film presented sensitivity within group D, being more sensitive in the Kodak solution at $30^{\circ} \mathrm{C}$ and less sensitive in the Sillib solution at $20^{\circ} \mathrm{C}$. Just as for the Insight film, the Kodak solution yielded to Ultra-speed sensitivity values higher than those of Sillib solution. The radiographic contrast remained within a variation band acceptable for this factor, varying from 1,55 (Insight/Sillib at $30^{\circ} \mathrm{C}$ ) to 1,78 (Ultra-speed/Kodak at $30^{\circ} \mathrm{C}$ for). Statistical analysis showed high correlation between the values of Optical Density and quantification of gray levels in the five exposure bands in all radiographs tested for each combination. There was high statistical correlation between the values of Optical Density, quantification of gray levels and Volume Density of silver in the band of 1 pulse of exposure of one radiograph of each combination evaluated. It was concluded that the Insight film is very promising keeping adequate sensitometric properties for clinic use in radiology. The three methods of analysis of radiographic films and the activity of processing solutions showed high statistical correlation, demonstrating that all of them may be used in the Quality Control in Oral Radiology. 
AnEXos 


\section{ANEXOS}

ANEXO 1 - Tabela com o valor médio das dez leituras das Densidades Óticas, realizadas com o fotodensitômetro MRA em cada uma das cinco faixas nas quatro radiografias obtidas com filmes Ultra-speed, da Kodak, processados na solução Kodak, na temperatura de $20^{\circ} \mathrm{C}$, por 5 minutos

\begin{tabular}{c|c|c|c|c}
\hline \hline & R1 & R2 & R3 & R4 \\
\hline \hline $300-4$ & $\mathbf{3 , 8 5}$ & $\mathbf{4 , 0 4}$ & $\mathbf{3 , 8 2}$ & $\mathbf{4 , 0 3}$ \\
\hline $\mathbf{6 0}-3$ & $\mathbf{0 , 9 9}$ & $\mathbf{1 , 0 9}$ & $\mathbf{0 , 9 9}$ & $\mathbf{1 , 0 9}$ \\
\hline $10-2$ & $\mathbf{0 , 1 6}$ & $\mathbf{0 , 1 7}$ & $\mathbf{0 , 1 6}$ & $\mathbf{0 , 1 8}$ \\
\hline $1-1$ & $\mathbf{0 , 0 0}$ & $\mathbf{0 , 0 0}$ & $\mathbf{0 , 0 0}$ & $\mathbf{0 , 0 1}$ \\
\hline DBV $-\mathbf{0}$ & $\mathbf{0 , 0 0}$ & $\mathbf{0 , 0 0}$ & $\mathbf{0 , 0 0}$ & $\mathbf{0 , 0 0}$ \\
\hline \hline
\end{tabular}

ANEXO 2 - Tabela com o valor médio das dez leituras das Densidades Óticas, realizadas com o fotodensitômetro MRA em cada uma das cinco faixas nas quatro radiografias obtidas com filmes Ultra-speed, da Kodak, processados na solução Kodak, na temperatura de $25^{\circ} \mathrm{C}$, por 2,5 minutos

\begin{tabular}{c|c|c|c|c}
\hline \hline & R1 & R2 & R3 & R4 \\
\hline \hline $300-4$ & 4,04 & 4,23 & 4,28 & 4,10 \\
\hline $60-3$ & 1,08 & 1,16 & 1,17 & 1,11 \\
\hline $10-2$ & 0,17 & 0,19 & 0,19 & $\mathbf{0 , 1 8}$ \\
\hline $1-1$ & $\mathbf{0 , 0 1}$ & $\mathbf{0 , 0 1}$ & $\mathbf{0 , 0 2}$ & $\mathbf{0 , 0 2}$ \\
\hline DBV - 0 & $\mathbf{0 , 0 1}$ & $\mathbf{0 , 0 1}$ & $\mathbf{0 , 0 1}$ & $\mathbf{0 , 0 1}$ \\
\hline \hline
\end{tabular}

ANEXO 3 - Tabela com o valor médio das dez leituras das Densidades Óticas, realizadas com o fotodensitômetro MRA em cada uma das cinco faixas nas quatro radiografias obtidas com filmes Ultra-speed, da Kodak, processados na solução Kodak, na temperatura de $30^{\circ} \mathrm{C}$, por 1,25 minuto

\begin{tabular}{c|c|c|c|c}
\hline \hline & R1 & R2 & R3 & R4 \\
\hline \hline $300-4$ & 4,01 & 4,12 & 4,20 & 4,30 \\
\hline $60-3$ & 1,12 & 1,16 & 1,25 & 1,26 \\
\hline $10-2$ & 0,19 & 0,20 & 0,21 & $\mathbf{0 , 2 3}$ \\
\hline $1-1$ & $\mathbf{0 , 0 2}$ & $\mathbf{0 , 0 3}$ & $\mathbf{0 , 0 2}$ & $\mathbf{0 , 0 2}$ \\
\hline DBV - 0 & $\mathbf{0 , 0 2}$ & $\mathbf{0 , 0 2}$ & $\mathbf{0 , 0 2}$ & $\mathbf{0 , 0 3}$ \\
\hline \hline
\end{tabular}


ANEXO 4 - Tabela com o valor médio das dez leituras das Densidades Óticas, realizadas com o fotodensitômetro MRA em cada uma das cinco faixas nas quatro radiografias obtidas com filmes Ultra-speed, da Kodak, processados na solução Sillib, na temperatura de $20^{\circ} \mathrm{C}$, por 2 minutos

\begin{tabular}{c|c|c|c|c}
\hline \hline & R1 & R2 & R3 & R4 \\
\hline \hline $300-4$ & $\mathbf{3 , 2 2}$ & $\mathbf{3 , 2 0}$ & $\mathbf{3 , 3 6}$ & $\mathbf{3 , 3 5}$ \\
\hline $\mathbf{6 0}-3$ & $\mathbf{0 , 7 6}$ & $\mathbf{0 , 7 6}$ & $\mathbf{0 , 8 4}$ & $\mathbf{0 , 8 1}$ \\
\hline $10-2$ & $\mathbf{0 , 1 1}$ & $\mathbf{0 , 1 0}$ & $\mathbf{0 , 1 1}$ & $\mathbf{0 , 1 2}$ \\
\hline $1-1$ & $\mathbf{0 , 0 0}$ & $\mathbf{0 , 0 0}$ & $\mathbf{0 , 0 0}$ & $\mathbf{0 , 0 0}$ \\
\hline DBV $-\mathbf{0}$ & $\mathbf{0 , 0 0}$ & $\mathbf{0 , 0 0}$ & $\mathbf{0 , 0 0}$ & $\mathbf{0 , 0 0}$ \\
\hline \hline
\end{tabular}

ANEXO 5 - Tabela com o valor médio das dez leituras das Densidades Óticas, realizadas com o fotodensitômetro MRA em cada uma das cinco faixas nas quatro radiografias obtidas com filmes Ultra-speed, da Kodak, processados na solução Sillib, na temperatura de $25^{\circ} \mathrm{C}$, por 1 minuto

\begin{tabular}{c|c|c|c|c}
\hline \hline & R1 & R2 & R3 & R4 \\
\hline \hline $300-4$ & 3,53 & $\mathbf{3 , 6 7}$ & $\mathbf{3 , 4 5}$ & $\mathbf{3 , 4 0}$ \\
\hline $60-3$ & $\mathbf{0 , 9 2}$ & $\mathbf{0 , 9 4}$ & $\mathbf{0 , 8 4}$ & $\mathbf{0 , 8 4}$ \\
\hline $10-2$ & $\mathbf{0 , 1 4}$ & $\mathbf{0 , 1 5}$ & $\mathbf{0 , 1 3}$ & $\mathbf{0 , 1 3}$ \\
\hline $1-1$ & $\mathbf{0 , 0 1}$ & $\mathbf{0 , 0 1}$ & $\mathbf{0 , 0 1}$ & $\mathbf{0 , 0 1}$ \\
\hline DBV $-\mathbf{0}$ & $\mathbf{0 , 0 1}$ & $\mathbf{0 , 0 1}$ & $\mathbf{0 , 0 1}$ & $\mathbf{0 , 0 1}$ \\
\hline \hline
\end{tabular}

ANEXO 6 - Tabela com o valor médio das dez leituras das Densidades Óticas, realizadas com o fotodensitômetro MRA em cada uma das cinco faixas nas quatro radiografias obtidas com filmes Ultra-speed, da Kodak, processados na solução Sillib, na temperatura de $30^{\circ} \mathrm{C}$, por 0,5 minuto

\begin{tabular}{c|c|c|c|c}
\hline \hline & R1 & R2 & R3 & R4 \\
\hline \hline $300-4$ & $\mathbf{3 , 4 6}$ & $\mathbf{3 , 4 9}$ & $\mathbf{3 , 5 0}$ & $\mathbf{3 , 2 8}$ \\
\hline $\mathbf{6 0}-3$ & $\mathbf{1 , 0 2}$ & $\mathbf{0 , 9 5}$ & $\mathbf{1 , 0 5}$ & $\mathbf{0 , 9 7}$ \\
\hline $10-2$ & $\mathbf{0 , 1 6}$ & $\mathbf{0 , 1 5}$ & $\mathbf{0 , 1 7}$ & $\mathbf{0 , 1 5}$ \\
\hline $1-1$ & $\mathbf{0 , 0 2}$ & $\mathbf{0 , 0 2}$ & $\mathbf{0 , 0 2}$ & $\mathbf{0 , 0 1}$ \\
\hline DBV $-\mathbf{0}$ & $\mathbf{0 , 0 2}$ & $\mathbf{0 , 0 2}$ & $\mathbf{0 , 0 2}$ & $\mathbf{0 , 0 1}$ \\
\hline \hline
\end{tabular}


ANEXO 7 - Tabela com o valor médio das dez leituras das Densidades Óticas, realizadas com o fotodensitômetro MRA em cada uma das cinco faixas nas quatro radiografias obtidas com filmes Insight, da Kodak, processados na solução Kodak, na temperatura de $20^{\circ} \mathrm{C}$, por 5 minutos

\begin{tabular}{c|c|c|c|c}
\hline \hline & R1 & R2 & R3 & R4 \\
\hline \hline $300-4$ & 5,71 & 5,72 & 5,75 & $\mathbf{5 , 7 4}$ \\
\hline $60-3$ & 4,39 & 4,31 & 4,22 & 4,22 \\
\hline $10-2$ & 0,76 & 0,74 & 0,73 & $\mathbf{0 , 7 5}$ \\
\hline $1-1$ & $\mathbf{0 , 1 4}$ & $\mathbf{0 , 1 4}$ & $\mathbf{0 , 1 4}$ & $\mathbf{0 , 1 4}$ \\
\hline DBV -0 & $\mathbf{0 , 0 7}$ & $\mathbf{0 , 0 7}$ & $\mathbf{0 , 0 7}$ & $\mathbf{0 , 0 8}$ \\
\hline \hline
\end{tabular}

ANEXO 8 - Tabela com o valor médio das dez leituras das Densidades Óticas, realizadas com o fotodensitômetro MRA em cada uma das cinco faixas nas quatro radiografias obtidas com filmes Insight, da Kodak, processados na solução Kodak, na temperatura de $25^{\circ} \mathrm{C}$, por 2,5 minutos

\begin{tabular}{c|c|c|c|c}
\hline \hline & R1 & R2 & R3 & R4 \\
\hline \hline $300-4$ & 5,68 & 5,69 & 5,43 & 5,33 \\
\hline $60-3$ & 4,49 & 4,47 & 4,61 & 4,69 \\
\hline $10-2$ & 0,93 & 0,93 & 0,97 & 0,98 \\
\hline $1-1$ & 0,14 & 0,15 & 0,15 & 0,15 \\
\hline DBV -0 & 0,09 & 0,11 & 0,11 & 0,11 \\
\hline \hline
\end{tabular}

ANEXO 9- Tabela com o valor médio das dez leituras das Densidades Óticas, realizadas com o fotodensitômetro MRA em cada uma das cinco faixas nas quatro radiografias obtidas com filmes Insight, da Kodak, processados na solução Kodak, na temperatura de $30^{\circ} \mathrm{C}$, por 1,25 minuto

\begin{tabular}{c|c|c|c|c}
\hline \hline & R1 & R2 & R3 & R4 \\
\hline \hline $300-4$ & 4,87 & 5,02 & 5,05 & 5,13 \\
\hline $60-3$ & 4,41 & 4,56 & 4,62 & 4,62 \\
\hline $10-2$ & 1,03 & 1,00 & 1,05 & 1,02 \\
\hline $1-1$ & 0,15 & 0,14 & 0,15 & 0,14 \\
\hline DBV -0 & 0,11 & 0,10 & 0,10 & 0,09 \\
\hline \hline
\end{tabular}


ANEXO 10 - Tabela com o valor médio das dez leituras das Densidades Óticas, realizadas com o fotodensitômetro MRA em cada uma das cinco faixas nas quatro radiografias obtidas com filmes Insight, da Kodak, processados na solução Sillib, na temperatura de $20^{\circ} \mathrm{C}$, por 2 minutos

\begin{tabular}{c|c|c|c|c}
\hline \hline & R1 & R2 & R3 & R4 \\
\hline \hline $300-4$ & 4,46 & 4,50 & 4,62 & 4,47 \\
\hline $60-3$ & 3,48 & 3,45 & 3,49 & 3,42 \\
\hline $10-2$ & 0,69 & 0,68 & 0,68 & 0,67 \\
\hline $1-1$ & $\mathbf{0 , 0 8}$ & $\mathbf{0 , 0 8}$ & $\mathbf{0 , 0 8}$ & $\mathbf{0 , 0 8}$ \\
\hline DBV -0 & $\mathbf{0 , 0 7}$ & $\mathbf{0 , 0 6}$ & $\mathbf{0 , 0 7}$ & $\mathbf{0 , 0 7}$ \\
\hline \hline
\end{tabular}

ANEXO 11 - Tabela com o valor médio das dez leituras das Densidades Óticas, realizadas com o fotodensitômetro MRA em cada uma das cinco faixas nas quatro radiografias obtidas com filmes Insight, da Kodak, processados na solução Sillib, na temperatura de $25^{\circ} \mathrm{C}$, por 1 minuto

\begin{tabular}{c|c|c|c|c}
\hline \hline & R1 & R2 & R3 & R4 \\
\hline \hline $300-4$ & 4,66 & 4,70 & 4,71 & 4,76 \\
\hline $60-3$ & 3,65 & 3,63 & 3,59 & 3,66 \\
\hline $10-2$ & 0,73 & 0,72 & 0,69 & 0,72 \\
\hline $1-1$ & $\mathbf{0 , 0 9}$ & 0,09 & 0,08 & $\mathbf{0 , 0 8}$ \\
\hline DBV - 0 & $\mathbf{0 , 0 8}$ & $\mathbf{0 , 0 8}$ & $\mathbf{0 , 0 7}$ & $\mathbf{0 , 0 7}$ \\
\hline \hline
\end{tabular}

ANEXO 12 - Tabela com o valor médio das dez leituras das Densidades Óticas, realizadas com o fotodensitômetro MRA em cada uma das cinco faixas nas quatro radiografias obtidas com filmes Insight, da Kodak, processados na solução Sillib, na temperatura de $30^{\circ} \mathrm{C}$, por 0,5 minuto

\begin{tabular}{c|c|c|c|c}
\hline \hline & R1 & R2 & R3 & R4 \\
\hline \hline $300-4$ & $\mathbf{5 , 3 9}$ & $\mathbf{5 , 3 5}$ & $\mathbf{5 , 3 9}$ & $\mathbf{5 , 4 1}$ \\
\hline $60-3$ & $\mathbf{3 , 2 1}$ & $\mathbf{3 , 0 9}$ & $\mathbf{3 , 0 6}$ & $\mathbf{3 , 1 1}$ \\
\hline $10-2$ & $\mathbf{0 , 8 2}$ & $\mathbf{0 , 8 1}$ & $\mathbf{0 , 8 0}$ & $\mathbf{0 , 8 0}$ \\
\hline $1-1$ & $\mathbf{0 , 0 7}$ & $\mathbf{0 , 0 8}$ & $\mathbf{0 , 0 7}$ & $\mathbf{0 , 0 8}$ \\
\hline DBV - 0 & $\mathbf{0 , 0 5}$ & $\mathbf{0 , 0 7}$ & $\mathbf{0 , 0 5}$ & $\mathbf{0 , 0 5}$ \\
\hline \hline
\end{tabular}


ANEXO 13 - Tabela com o valor da quantificação dos níveis de cinza, realizada em cada uma das cinco faixas de exposição, nas quatro radiografias, utilizando-se o programa de imagem Adobe Photoshop 5.5, em filmes radiográficos Ultra-speed, processados na solução Kodak, na temperatura de $20^{\circ} \mathrm{C}$, por 5 minutos

\begin{tabular}{c|c|c|c|c}
\hline \hline & R1 & R2 & R3 & R4 \\
\hline \hline $300-4$ & 255 & 255 & 255 & 255 \\
\hline $60-3$ & 168 & 151 & 152 & 167 \\
\hline $10-2$ & 48 & 46 & 46 & 48 \\
\hline $1-1$ & 23 & 22 & 22 & 23 \\
\hline DBV -0 & 22 & 22 & 22 & 22 \\
\hline \hline
\end{tabular}

ANEXO 14 - Tabela com o valor da quantificação dos níveis de cinza, realizada em cada uma das cinco faixas de exposição, nas quatro radiografias, utilizando-se o programa de imagem Adobe Photoshop 5.5, em filmes radiográficos Ultra-speed, processados na solução Kodak, na temperatura de $25^{\circ} \mathrm{C}$, por 2,5 minutos

\begin{tabular}{c|c|c|c|c}
\hline \hline & R1 & R2 & R3 & R4 \\
\hline \hline $300-4$ & 255 & 255 & 255 & 255 \\
\hline $60-3$ & 189 & 168 & 166 & 178 \\
\hline $10-2$ & 50 & 49 & 48 & 50 \\
\hline $1-1$ & 24 & 24 & 24 & 24 \\
\hline DBV -0 & 24 & 24 & 24 & 24 \\
\hline \hline
\end{tabular}

ANEXO 15 - Tabela com o valor da quantificação dos níveis de cinza, realizada em cada uma das cinco faixas de exposição, nas quatro radiografias, utilizando-se o programa de imagem Adobe Photoshop 5.5, em filmes radiográficos Ultra-speed, processados na solução Kodak, na temperatura de $30^{\circ} \mathrm{C}$, por 1,25 minuto

\begin{tabular}{c|c|c|c|c}
\hline \hline & R1 & R2 & R3 & R4 \\
\hline \hline $300-4$ & 255 & 255 & 255 & 255 \\
\hline $60-3$ & 190 & 211 & 154 & 211 \\
\hline $10-2$ & 51 & 51 & 45 & 53 \\
\hline $1-1$ & 25 & 26 & 22 & 24 \\
\hline DBV -0 & 25 & 24 & 22 & 27 \\
\hline \hline
\end{tabular}


ANEXO 16 - Tabela com o valor da quantificação dos níveis de cinza, realizada em cada uma das cinco faixas de exposição, nas quatro radiografias, utilizando-se o programa de imagem Adobe Photoshop 5.5, em filmes radiográficos Ultra-speed, processados na solução Sillib, na temperatura de $20^{\circ} \mathrm{C}$, por 2 minutos

\begin{tabular}{c|c|c|c|c}
\hline \hline & R1 & R2 & R3 & R4 \\
\hline \hline $300-4$ & 255 & 255 & 255 & 255 \\
\hline $60-3$ & 114 & 123 & 114 & 120 \\
\hline $10-2$ & 37 & 37 & 36 & 37 \\
\hline $1-1$ & 19 & 19 & 19 & 18 \\
\hline DBV -0 & 20 & 19 & 19 & 19 \\
\hline \hline
\end{tabular}

ANEXO 17 - Tabela com o valor da quantificação dos níveis de cinza, realizada em cada uma das cinco faixas de exposição, nas quatro radiografias, utilizando-se o programa de imagem Adobe Photoshop 5.5, em filmes radiográficos Ultra-speed, processados na solução Sillib, na temperatura de $25^{\circ} \mathrm{C}$, por 1 minuto

\begin{tabular}{c|c|c|c|c}
\hline \hline & R1 & R2 & R3 & R4 \\
\hline \hline $300-4$ & 255 & 255 & 255 & 255 \\
\hline $60-3$ & 138 & 125 & 126 & 136 \\
\hline $10-2$ & 41 & 40 & 40 & 42 \\
\hline $1-1$ & 20 & 20 & 21 & 21 \\
\hline DBV -0 & 20 & 20 & 20 & 22 \\
\hline \hline
\end{tabular}

ANEXO 18 - Tabela com o valor da quantificação dos níveis de cinza, realizada em cada uma das cinco faixas de exposição, nas quatro radiografias, utilizando-se o programa de imagem Adobe Photoshop 5.5, em filmes radiográficos Ultra-speed, processados na solução Sillib, na temperatura de $30^{\circ} \mathrm{C}$, por 0,5 minuto

\begin{tabular}{c|c|c|c|c}
\hline \hline & R1 & R2 & R3 & R4 \\
\hline \hline $300-4$ & 255 & 255 & 255 & 255 \\
\hline $60-3$ & 149 & 142 & 154 & 137 \\
\hline $10-2$ & 44 & 41 & 45 & 41 \\
\hline $1-1$ & 21 & 21 & 22 & 20 \\
\hline DBV -0 & 21 & 20 & 22 & 22 \\
\hline \hline
\end{tabular}


ANEXO 19 - Tabela com o valor da quantificação dos níveis de cinza, realizada em cada uma das cinco faixas de exposição, nas quatro radiografias, utilizando-se o programa de imagem Adobe Photoshop 5.5, em filmes radiográficos Insight, processados na solução Kodak, na temperatura de $20^{\circ} \mathrm{C}$, por 5 minutos

\begin{tabular}{c|c|c|c|c}
\hline \hline & R1 & R2 & R3 & R4 \\
\hline \hline $300-4$ & 255 & 255 & 255 & 255 \\
\hline $60-3$ & 255 & 255 & 255 & 255 \\
\hline $10-2$ & 101 & 107 & 105 & 104 \\
\hline $1-1$ & 37 & 37 & 39 & 38 \\
\hline DBV -0 & 29 & 29 & 30 & 29 \\
\hline \hline
\end{tabular}

ANEXO 20 - Tabela com o valor da quantificação dos níveis de cinza, realizada em cada uma das cinco faixas de exposição, nas quatro radiografias, utilizando-se o programa de imagem Adobe Photoshop 5.5, em filmes radiográficos Insight, processados na solução Kodak, na temperatura de $25^{\circ} \mathrm{C}$, por 2,5 minutos

\begin{tabular}{c|c|c|c|c}
\hline \hline & R1 & R2 & R3 & R4 \\
\hline \hline $300-4$ & 255 & 255 & 255 & 255 \\
\hline $60-3$ & 255 & 255 & 255 & 255 \\
\hline $10-2$ & 134 & 125 & 134 & 123 \\
\hline $1-1$ & 36 & 37 & 35 & 34 \\
\hline DBV - 0 & 32 & 31 & 31 & 29 \\
\hline \hline
\end{tabular}

ANEXO 21 - Tabela com o valor da quantificação dos níveis de cinza, realizada em cada uma das cinco faixas de exposição, nas quatro radiografias, utilizando-se o programa de imagem Adobe Photoshop 5.5, em filmes radiográficos Insight, processados na solução Kodak, na temperatura de $30^{\circ} \mathrm{C}$, por 1,25 minuto

\begin{tabular}{c|c|c|c|c}
\hline \hline & R1 & R2 & R3 & R4 \\
\hline \hline $300-4$ & 255 & 255 & 255 & 255 \\
\hline $60-3$ & 255 & 255 & 255 & 255 \\
\hline $10-2$ & 142 & 144 & 138 & 147 \\
\hline $1-1$ & 36 & 36 & 41 & 42 \\
\hline DBV -0 & 29 & 37 & 31 & 37 \\
\hline \hline
\end{tabular}


ANEXO 22 - Tabela com o valor da quantificação dos níveis de cinza, realizada em cada uma das cinco faixas de exposição, nas quatro radiografias, utilizando-se o programa de imagem Adobe Photoshop 5.5, em filmes radiográficos Insight, processados na solução Sillib, na temperatura de $20^{\circ} \mathrm{C}$, por 2 minutos

\begin{tabular}{c|c|c|c|c}
\hline \hline & R1 & R2 & R3 & R4 \\
\hline \hline $300-4$ & 255 & 255 & 255 & 255 \\
\hline $60-3$ & 255 & 255 & 255 & 255 \\
\hline $10-2$ & 99 & 95 & 91 & 93 \\
\hline $1-1$ & 31 & 24 & 30 & 24 \\
\hline DBV -0 & 29 & 28 & 24 & 24 \\
\hline \hline
\end{tabular}

ANEXO 23 - Tabela com o valor da quantificação dos níveis de cinza, realizada em cada uma das cinco faixas de exposição, nas quatro radiografias, utilizando-se o programa de imagem Adobe Photoshop 5.5, em filmes radiográficos Insight, processados na solução Sillib, na temperatura de $25^{\circ} \mathrm{C}$, por 1 minuto

\begin{tabular}{c|c|c|c|c}
\hline \hline & R1 & R2 & R3 & R4 \\
\hline \hline $300-4$ & 255 & 255 & 255 & 255 \\
\hline $60-3$ & 255 & 255 & 255 & 255 \\
\hline $10-2$ & 96 & 95 & 94 & 103 \\
\hline $1-1$ & 26 & 33 & 25 & 27 \\
\hline DBV -0 & 25 & 25 & 24 & 32 \\
\hline \hline
\end{tabular}

ANEXO 24 - Tabela com o valor da quantificação dos níveis de cinza, realizada em cada uma das cinco faixas de exposição, nas quatro radiografias, utilizando-se o programa de imagem Adobe Photoshop 5.5, em filmes radiográficos Insight, processados na solução Sillib, na temperatura de $30^{\circ} \mathrm{C}$, por 0,5 minuto

\begin{tabular}{c|c|c|c|c}
\hline \hline & R1 & R2 & R3 & R4 \\
\hline \hline $300-4$ & 255 & 255 & 255 & 255 \\
\hline $60-3$ & 255 & 255 & 255 & 255 \\
\hline $10-2$ & 116 & 121 & 117 & 120 \\
\hline $1-1$ & 34 & 34 & 34 & 35 \\
\hline DBV -0 & 30 & 31 & 32 & 33 \\
\hline \hline
\end{tabular}


ANEXO 25 - Comparativo entre Densidade Ótica (D.O.) e quantificação dos níveis de cinza (N.C.), das quatro radiografias processadas em todas as combinações utilizadas, nas cinco faixas de exposição, com os filmes Ultra-speed e Insight

\begin{tabular}{|c|c|c|c|c|c|c|c|c|c|c|c|c|c|c|c|c|c|c|c|c|c|c|c|c|c|}
\hline & \multirow{3}{*}{$\begin{array}{c}\text { Filmes/Soluções } \\
\text { Temperaturas } \\
\text { Impulsos } \\
\end{array}$} & \multicolumn{6}{|c|}{ Ultra-speed/Kodak } & \multicolumn{6}{|c|}{ Ultra-speed/Sillib } & \multicolumn{6}{|c|}{ Insight/Kodak } & \multicolumn{6}{|c|}{ Insight/Sillib } \\
\hline & & \multicolumn{2}{|c|}{$20^{\circ} \mathrm{C} / 5 \mathrm{~min}}$. & \multicolumn{2}{|c|}{$25^{\circ} \mathrm{C} / 2,5 \mathrm{~min}}$. & \multicolumn{2}{|c|}{$30^{\circ} \mathrm{C} / 1,25 \mathrm{~min}}$. & \multicolumn{2}{|c|}{$20^{\circ} \mathrm{C} / 2 \mathrm{~min}}$. & \multicolumn{2}{|c|}{$25^{\circ} \mathrm{C} / 1 \mathrm{~min}}$. & \multicolumn{2}{|c|}{$33^{\circ} \mathrm{C} / 0,5 \mathrm{~min}}$. & \multicolumn{2}{|c|}{$20^{\circ} \mathrm{C} / 5 \min }$. & \multicolumn{2}{|c|}{$25^{\circ} \mathrm{C} / 2,5 \mathrm{~min}}$. & \multicolumn{2}{|c|}{$30^{\circ} \mathrm{C} / 1,25 \mathrm{~min}}$. & \multicolumn{2}{|c|}{$20^{\circ} \mathrm{C} / 2 \mathrm{~min}$} & \multicolumn{2}{|c|}{$25^{\circ} \mathrm{C} / 1 \mathrm{~min}}$. & \multicolumn{2}{|c|}{$30^{\circ} \mathrm{C} / 0,5 \mathrm{~min}}$. \\
\hline & & D.O. & N.C. & D.O. & N.C. & D.O. & N.C. & D.O. & N.C. & D.O. & N.C. & D.O. & N.C. & D.O. & N.C. & D.O. & N.C. & D.O. & N.C. & D.O. & N.C. & D.O. & N.C. & D.O. & N.C. \\
\hline \multirow{4}{*}{ R1 } & 300 & 3,85 & 255 & 4,04 & 255 & 4,01 & 255 & 3,22 & 255 & $\overline{3,53}$ & 255 & 3,46 & 255 & $\overline{5,71}$ & 255 & $\begin{array}{l}5,68 \\
\end{array}$ & 255 & 4,87 & 255 & 4,46 & 255 & 4,66 & 255 & 5,39 & 255 \\
\hline & 60 & 0,99 & 168 & 1,08 & 189 & 1,12 & 190 & 0,76 & 114 & 0,92 & 138 & 1,02 & 149 & 4,39 & 255 & 4,49 & 255 & 4,41 & 255 & 3,48 & 255 & 3,65 & 255 & 3,21 & 255 \\
\hline & 10 & 0,16 & 48 & 0,17 & 50 & 0,19 & 51 & 0,11 & 37 & 0,14 & 41 & 0,16 & 44 & 0,76 & 101 & 0,93 & 134 & 1,03 & 142 & 0,69 & 99 & 0,73 & 96 & 0,82 & 116 \\
\hline & DBV & $\mathbf{0 , 0 0}$ & 22 & 0,01 & 24 & $\mathbf{0 , 0 2}$ & 25 & 0,00 & 20 & $\mathbf{0 , 0 1}$ & 20 & $\mathbf{0 , 0 2}$ & 21 & $\mathbf{0 , 0 7}$ & 29 & 0,09 & 32 & 0,11 & 29 & $\mathbf{0 , 0 7}$ & 29 & $\mathbf{0 , 0 8}$ & 25 & 0,05 & 30 \\
\hline \multirow{5}{*}{$\mathbf{R 2}$} & 300 & 4,04 & 255 & 4,23 & 255 & 4,12 & 255 & 3,20 & 255 & 3,67 & 255 & 3,49 & 255 & 5,72 & 255 & 5,69 & 255 & 5,02 & 255 & 4,50 & 255 & 4,70 & 255 & 5,35 & 255 \\
\hline & 60 & 1,09 & 151 & 1,16 & 168 & 1,16 & 211 & 0,76 & 123 & 0,94 & 125 & 0,95 & 142 & 4,31 & 255 & 4,47 & 255 & 4,56 & 255 & 3,45 & 255 & 3,63 & 255 & 3,09 & 255 \\
\hline & 10 & 0,17 & 46 & 0,19 & 49 & 0,20 & 51 & 0,10 & 37 & 0,15 & 40 & 0,15 & 41 & 0,74 & 107 & 0,93 & 125 & 1,00 & 144 & 0,68 & 95 & 0,72 & 95 & $\mathbf{0 , 8 1}$ & 121 \\
\hline & 1 & 0,00 & 22 & 0,01 & 24 & 0,03 & 26 & $\mathbf{0 , 0 0}$ & 19 & 0,01 & 20 & 0,02 & 21 & 0,14 & 37 & 0,15 & 37 & 0,14 & 36 & 0,08 & 24 & 0,09 & 33 & $\mathbf{0 , 0 8}$ & 34 \\
\hline & DBV & 0,00 & 22 & 0,01 & 24 & 0,02 & 24 & 0,00 & 19 & 0,01 & 20 & 0,02 & 20 & $\mathbf{0 , 0 7}$ & 29 & 0,11 & 31 & 0,10 & 37 & 0,06 & 28 & 0,08 & 25 & $\mathbf{0 , 0 7}$ & 31 \\
\hline \multirow{4}{*}{$\mathbf{R 3}$} & 300 & 3,82 & 255 & 4,28 & 255 & 4,20 & 255 & 3,36 & 255 & 3,45 & 255 & 3,50 & 255 & 5,75 & 255 & 5,43 & 255 & 5,05 & 255 & 4,62 & 255 & 4,71 & 255 & 5,39 & 255 \\
\hline & 10 & 0,16 & 46 & 0,19 & 48 & 0,21 & 45 & 0,11 & 36 & 0,13 & 40 & 0,17 & 45 & 0,73 & 105 & 0,97 & 134 & 1,05 & 138 & 0,68 & 91 & 0,69 & 94 & $\mathbf{0 , 8 0}$ & 117 \\
\hline & 1 & $\mathbf{0 , 0 0}$ & 22 & $\mathbf{0 , 0 2}$ & 24 & $\mathbf{0 , 0 2}$ & 22 & 0,00 & 19 & $\mathbf{0 , 0 1}$ & 21 & $\mathbf{0 , 0 2}$ & 22 & 0,14 & 39 & 0,15 & 35 & 0,15 & 41 & $\mathbf{0 , 0 8}$ & 30 & $\mathbf{0 , 0 8}$ & 25 & $\mathbf{0 , 0 7}$ & 34 \\
\hline & DBV & 0,00 & 22 & 0,01 & 24 & $\mathbf{0 , 0 2}$ & 22 & 0,00 & 19 & 0,01 & 20 & $\mathbf{0 , 0 2}$ & 22 & $\mathbf{0 , 0 7}$ & 30 & 0,11 & 31 & 0,10 & 31 & $\mathbf{0 , 0 7}$ & 24 & $\mathbf{0 , 0 7}$ & 24 & 0,05 & 32 \\
\hline \multirow{5}{*}{ R4 } & 300 & 4,03 & 255 & 4,10 & 255 & 4,30 & 255 & 3,35 & 255 & 3,40 & 255 & 3,28 & 255 & 5,74 & 255 & 5,33 & 255 & 5,13 & 255 & 4,47 & 255 & 4,76 & 255 & 5,41 & 255 \\
\hline & 60 & 1,09 & 167 & 1,11 & 178 & 1,26 & 211 & $\mathbf{0 , 8 1}$ & 120 & 0,84 & 136 & $\mathbf{0 , 9 7}$ & 137 & 4,22 & 255 & 4,69 & 255 & 4,62 & 255 & 3,42 & 255 & 3,66 & 255 & 3,11 & 255 \\
\hline & 10 & 0,18 & 48 & 0,18 & 50 & 0,23 & 53 & 0,12 & 37 & 0,13 & 42 & 0,15 & 41 & 0,75 & 104 & 0,98 & 123 & 1,02 & 147 & 0,67 & 93 & 0,72 & 103 & $\mathbf{0 , 8 0}$ & 120 \\
\hline & 1 & 0,01 & 23 & 0,02 & 24 & 0,02 & 24 & 0,00 & 18 & 0,01 & 21 & 0,01 & 21 & 0,14 & 38 & 0,15 & 34 & 0,14 & 42 & 0,08 & 24 & 0,08 & 27 & 0,08 & 35 \\
\hline & DBV & 0,00 & 22 & 0,01 & 24 & 0,03 & 27 & 0,00 & 19 & $\mathbf{0 , 0 1}$ & 22 & 0,01 & 22 & 0,08 & 29 & 0,11 & 29 & 0,09 & 37 & 0,07 & 24 & 0,07 & 32 & 0,05 & 33 \\
\hline
\end{tabular}


ANEXO 26 - Porcentagem de prata e média final realizada nas três áreas da emulsão dos filmes radiográficos Ultra-speed e Insight, processados nas soluções Kodak e Sillib, nas três temperaturas, na faixa de 1 impulso

\begin{tabular}{|c|c|c|c|c|c|c|c|c|c|c|c|c|}
\hline Ultra-speed & \multicolumn{4}{|c|}{ Kodak $20^{\circ} \mathrm{C} / 5 \mathrm{~min}}$. & \multicolumn{4}{|c|}{ Kodak $25^{\circ} \mathrm{C} / 2,5 \mathrm{~min}}$. & \multicolumn{4}{|c|}{ Kodak $30^{\circ} \mathrm{C} / 1,25 \mathrm{~min}}$. \\
\hline Área & 1 & 2 & 3 & Média & 1 & 2 & 3 & Média & 1 & 2 & 3 & Média \\
\hline Porcentagem & 11,61 & 11,69 & 11,61 & 11,64 & 14,31 & 12,71 & 12,13 & 13,05 & 17,74 & 14,81 & 15,60 & 16,05 \\
\hline Ultra-speed & \multicolumn{4}{|c|}{ Sillib $20^{\circ} \mathrm{C} / 2 \mathrm{~min}}$. & \multicolumn{4}{|c|}{ Sillib $25^{\circ} \mathrm{C} / 1 \mathrm{~min}}$. & \multicolumn{4}{|c|}{ Sillib $30^{\circ} \mathrm{C} / 0,5 \mathrm{~min}}$. \\
\hline Área & 1 & 2 & 3 & Média & 1 & 2 & 3 & Média & 1 & 2 & 3 & Média \\
\hline Porcentagem & 6,34 & 5,61 & 5,60 & $\mathbf{5 , 8 5}$ & 7,12 & 8,59 & $\mathbf{8 , 3 5}$ & 8,02 & 9,35 & 9,46 & 8,43 & 9,08 \\
\hline Insight & \multicolumn{4}{|c|}{ Kodak $20^{\circ} \mathrm{C} / 5 \mathrm{~min}}$. & \multicolumn{4}{|c|}{ Kodak $25^{\circ} \mathrm{C} / 2,5 \mathrm{~min}}$. & \multicolumn{4}{|c|}{ Kodak $30^{\circ} \mathrm{C} / 1,25 \mathrm{~min}}$. \\
\hline Área & 1 & 2 & 3 & Média & 1 & 2 & 3 & Média & 1 & 2 & 3 & Média \\
\hline Porcentagem & 16,62 & 12,52 & 10,63 & 13,26 & 23,50 & 26,69 & 15,93 & 22,04 & 15,24 & 18,26 & 17,57 & 17,02 \\
\hline Insight & \multicolumn{4}{|c|}{ Sillib $20^{\circ} \mathrm{C} / 2 \mathrm{~min}$. } & \multicolumn{4}{|c|}{ Sillib $25^{\circ} \mathrm{C} / 1 \mathrm{~min}$. } & \multicolumn{4}{|c|}{ "Sillib $30^{\circ} \mathrm{C} / 0,5 \mathrm{~min}}$. \\
\hline Área & 1 & 2 & 3 & Média & 1 & 2 & 3 & Média & 1 & 2 & 3 & Média \\
\hline Porcentagem & 10,84 & 9,38 & 10,26 & 10,16 & 12,32 & 13,46 & 9,43 & 11,74 & 8,78 & 9,52 & 13,17 & 10,49 \\
\hline
\end{tabular}

